Submitted to the School of Architecture, Victoria University of Wellington in July, 2012 in partial fulfilment of the requirements for the degree of Master of Architecture (Professional) (MArch (Prof)) 


\section{understanding human scale and the importance of its relationship with enclosure}

Austin H. Mackesy-Buckley 


\section{Acknowledgements}

I would like to thank my parents, brother and partner for their support and encouragement throughout the past twelve months, and my supervisor Chris McDonald for his continuous patience and guidance. 


\section{Abstract}

The main objective of the research is to better understand the concept of human scale and the role that it has to play in the design of our urban environments. The need for a clearer, less ambiguous understanding of human scale is identified as a result of its poor definition and numerous manifestations across a multitude of literature. Human scale is an important part of design that flourished particularly in the middle ages, but has largely been neglected in the industrial and technological ages. Its remergence comes with the return of consideration for the comfort of people. Yet we cannot successfully apply a concept we do not wholly understand. Human scale is therefore redefined as a collective concept that embodies the multitude of existing definitions and treats them as aspects of a larger theory. As a broader but more comprehensive definition it better facilitates the identification and exploration of relationships with what are currently treated as separate urban design objectives, such as enclosure, in an endeavour to better understand the influence of human scale.

The design case study proposes a design that tests the relationship between enclosure and human scale. A large site is chosen to display how human scale operates at urban, as well as architectural and detailed levels. Through aspiring to achieve a thorough human scale design, without any exclusive emphasis on enclosure, the process and the outcome still reveal that the theoretical relationship identified in the research (that aspects of human scale foster the formation of enclosure) is unavoidable in design practice. Enclosure simply results as a consequence of thorough human scale design. The research suggests that many urban design objectives may fall under human scale's sphere of influence meaning it is not a singular concept, but an ethic of design that has many desireable consequences. While the idealistic nature of the design may be unrealistic to achieve at present, it highlights the incompatibilities with contemporary approaches and succeeds in generating discussion. 


\section{Table of Contents}

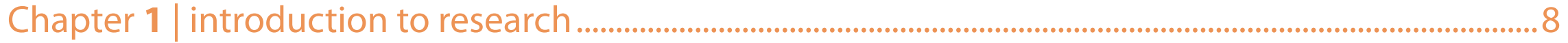

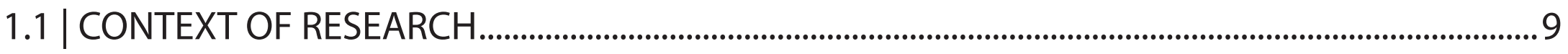

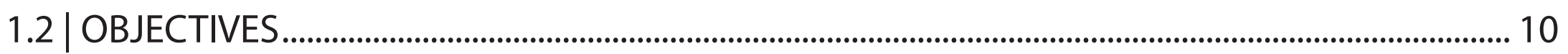

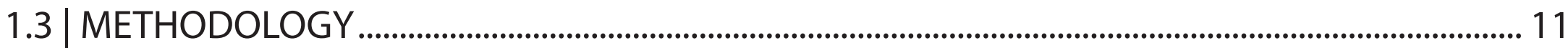

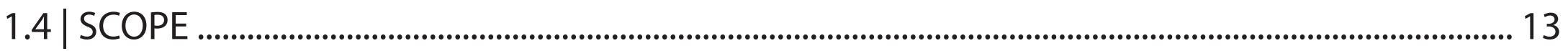

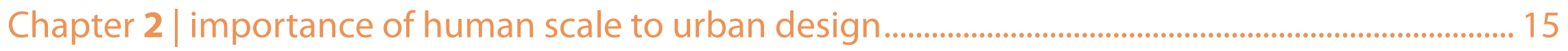

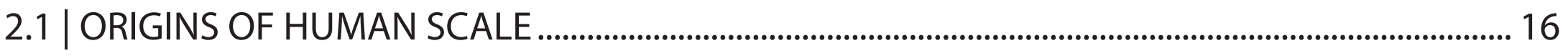

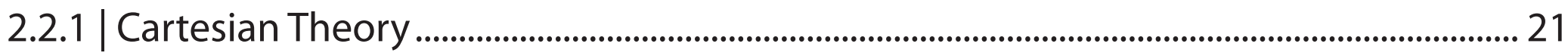

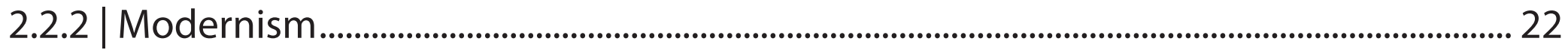

2.2.3 | Destructive Forces of Building for Money ................................................................................. 24

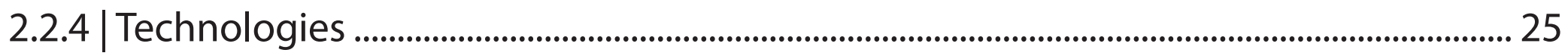

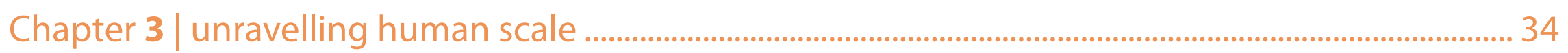

3.1 THE INTERPRETATIVE POSITION ON THE CONTENTS OF HUMAN SCALE .................................... 35

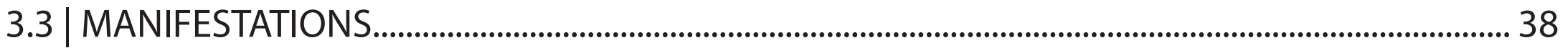

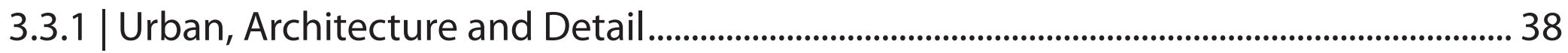

3.3.2 The Dimensional and The Extra-Dimensional .................................................................. 39

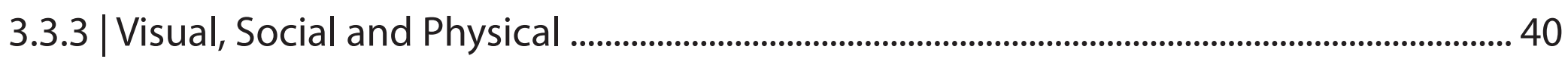

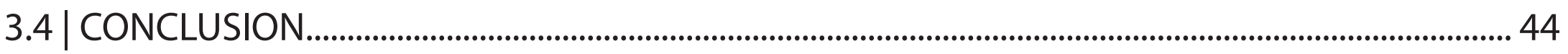




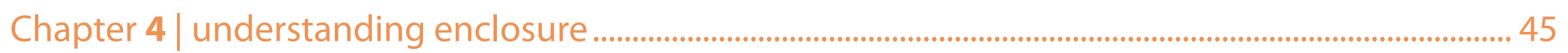

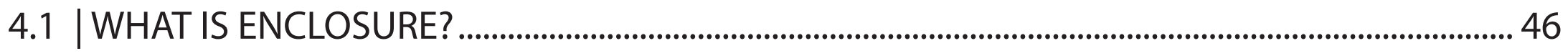

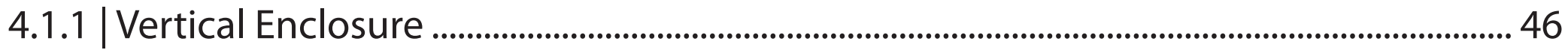

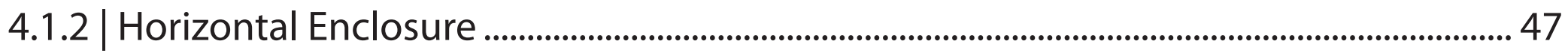

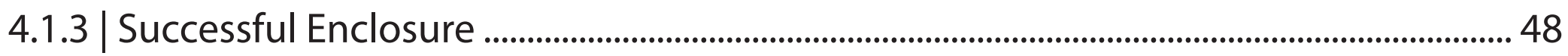

Chapter $5 \mid$ the relationship between human scale and enclosure ................................................. 52

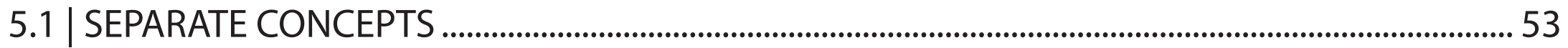

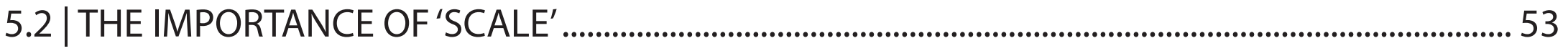

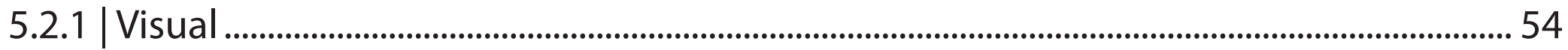

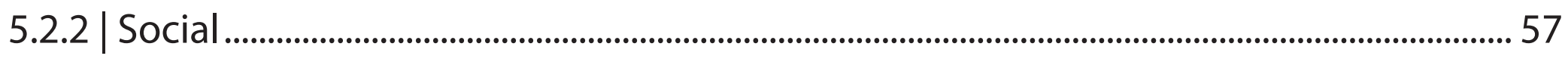

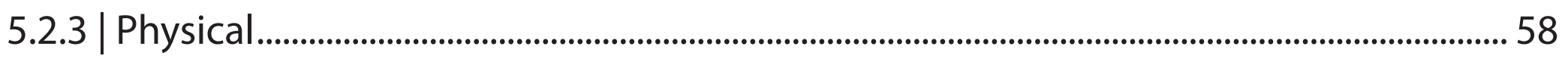

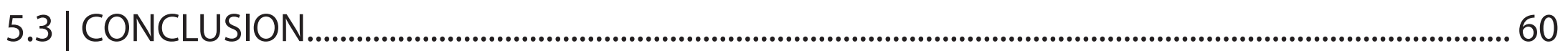

Chapter 6 | Design Case Study: Te Aro, Wellington, New Zealand...................................................... 62

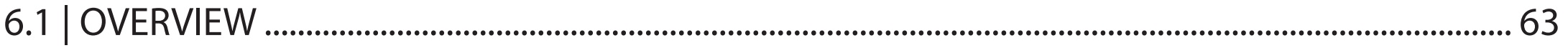

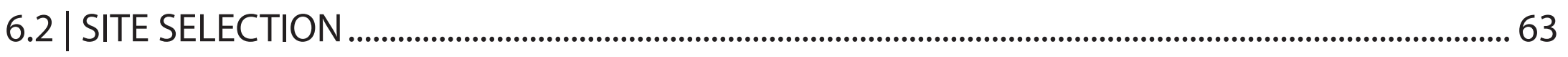

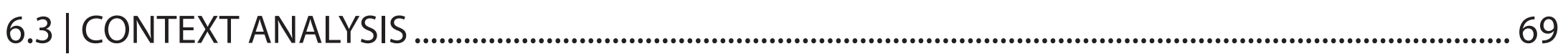

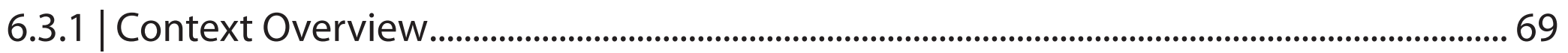

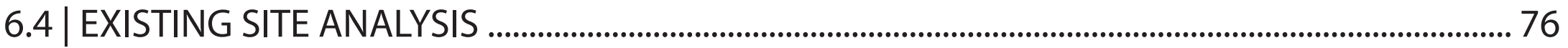

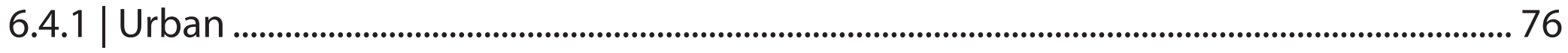

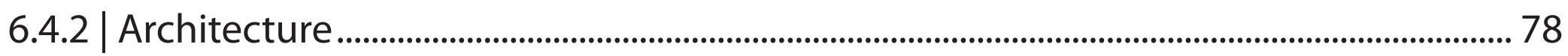




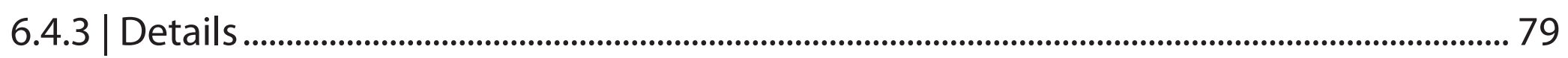

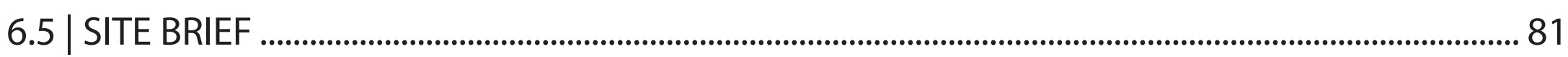

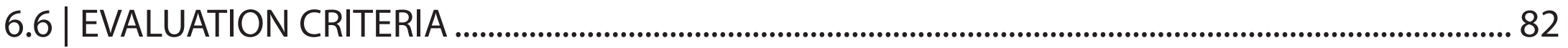

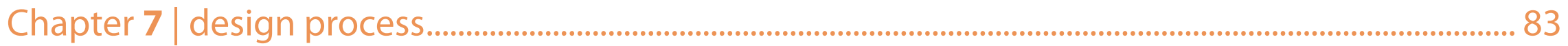

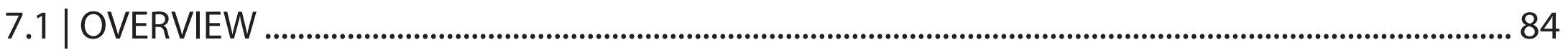

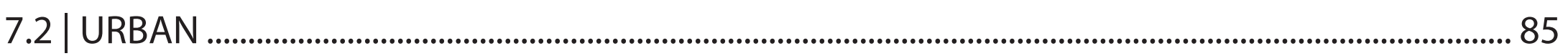

7.3 | ARCHITECTURE ......................................................................................................................................... 87

7.5 | DESIGN REFLECTION ............................................................................................................................... 97

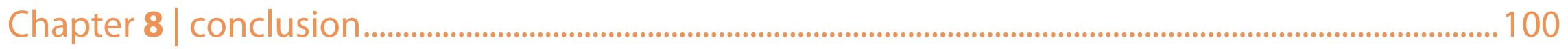

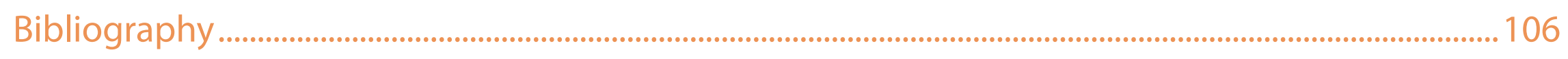

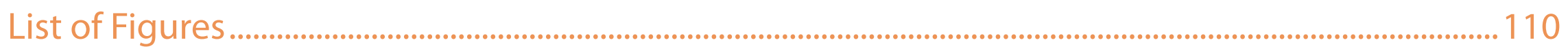

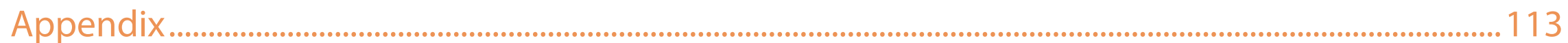

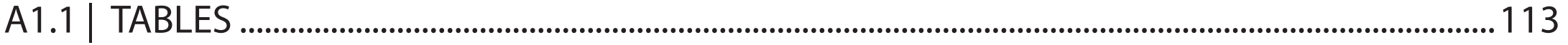

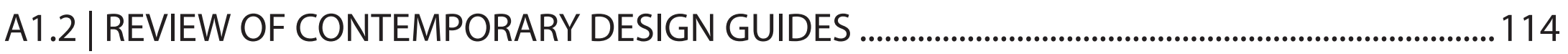

A 1.2.1 | The Edinburgh Standards for Urban Design ................................................................... 116

A 1.2.2 | Los Angeles Downtown Design Guide ............................................................................ 116

A1.2.3 | Wellington City Central Design Guide ..........................................................................117

A1.2.4 | British Urban Design Compendium ........................................................................................ 119

A1 2.5 | Conclusion .......................................................................................................................................... 120 


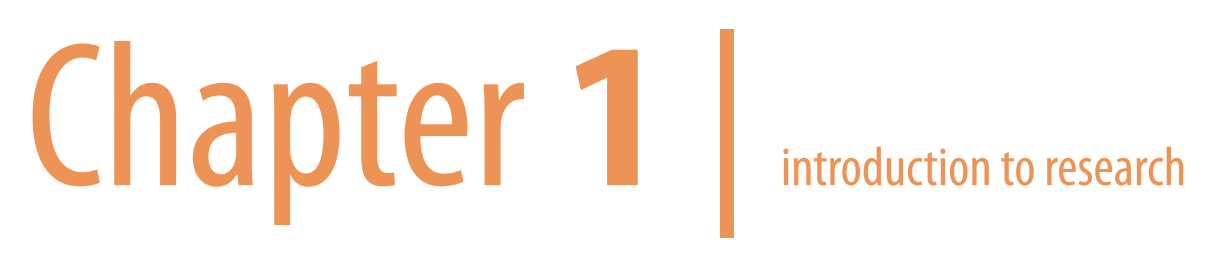




\subsection{CONTEXT OF RESEARCH}

Human scale was once intrinsic to urban environments during a time when city form and function were dictated by the restrictive nature of societal ideology and man's limited physical and technical ability. However as technological and ideological advancements were made, these limits were challenged and became less influential towards the urban environment. Over time new economic and technological forces greatly apathetic to human and pedestrian experience decided the function and form of cities, resulting in their loss of appeal and relevance to man. More specifically, certain aspects which are thought to be intrinsically connected to the human scale city, such as enclosure, began to disintegrate. Although the negative effects of inhuman mechanisms of design have been recognised since at least the late $19^{\text {th }}$ century, it is today that attempts at reviving human scale and its associated design aspects are being more commonly promoted in literature and in planning documents as objective. However there is still a reluctance to place human limits on our designs and as such these objectives are not always successful.

Coincidentally cities like Venice and Sienna, remnants of a centripetally human era, are perceived with a type of romantic envy and considered good examples of quality urban environment produced by their human scale but paradoxically current ideology holds the mentality that tradition binds us to irrelevant restrictions. Both human scale and enclosure are traditional precedents but also contemporary urban design objectives. However what has been poorly established is their intrinsic relationship to each other. Further yet it could be that we do not really understand human scale as a concept which would therefore impair our ability to establish this relationship and design enclosure, or for that matter any other characteristic of human scale environments, successfully. 
Despite being increasingly important to urban design, human scale is not welldefined. Part of the problem is that it is not specific to one thing as is often the impression. Instead it is a collective term used when referring to relationships between humans and the urban environment and is not necessarily exclusive to sizes as 'scale' normally implies. The concept of human scale is also an interdisciplinary one requiring acute knowledge in the social sciences with an understanding of the process of perception. Nonetheless the lack of sources which attempt to clearly define it, numerous manifestations of the concept in literature, and the misleading nature of the term human'scale' are but some of the more predominant issues which sustain its uncertainty today and leave it open to manipulation, and interpretation or result in its neglect. Subsequently its complexity and ambiguity raise the question of how well such a concept can be implemented.

If, as it is believed, there exists relationships between important urban design objectives, such as enclosure, and human scale, then there is a risk that they will be improperly executed, if at all, during the implementation of human scale design. It is therefore paramount to understand human scale so that if these relationships exist they can be identified and the role of human scale better understood.

\subsection{OBJECTIVES}

The main aim of this thesis is to develop a better understanding of the role that human scale has to play in our urban environments by exploring the relationship between enclosure and human scale. Through a more sophisticated and in depth understanding of human scale, it is argued that inextricable connections could be 
revealed with other important design objectives which would have a profound impact on the way we perceive and apply human scale.

Secondary objectives include demonstrating that we can look to the past to better understand modern issues by establishing that human scale derives largely from limits; that we can achieve modern exemplar human scale environments; and open up challenge to modern practice and ideology.

\subsection{METHODOLOGY}

Chapter 2 establishes why human scale is important to urban environments particularly contemporary ones. Firstly it explains the human scale nature of traditional cities, and reveals that human scale is created by limits. The movement away from traditional cities is then addressed identifying some of the events that encouraged this transition from the old to the contemporary, and their tendency to break the limits that once kept urban environments at human scale. Finally, it is noted that by breaking these limits and neglecting human scale it has been widely recognised that certain aspects found in human scale cities, such as enclosure, have deteriorated or are rarely present in their contemporary counterparts.

Chapter 3 seeks to show that human scale is not a well defined or understood concept despite its importance. Through interpretive definitions over a wide range of literature it is sought to clarify human scale and reveal its ambiguities and complexities. It

is proposed that the current confusing and confined nature of human scale could threaten to jeopardise any command or proper implementation of the concept and 
could ultimately mean that potential characteristics of human scale environments, such as enclosure, could also suffer.

Chapter 4 clearly identifies urban enclosure as defined space in three dimensions. Although enclosure is a sought after urban design quality there are varying degrees of enclosure, not all of which are desirable, that are brought about by the treatment of both vertical and horizontal configuration. Place, progression and security, are established as three main qualities believed to exist when the appropriate degree of enclosure is achieved, creating successful or well-designed space.

Chapter 5 explains why there is an intrinsic relationship that exists between enclosure and human scale. It is argued that many aspects of a more sophisticated understanding of human scale have an effect on the form of space both vertically and horizontally in a way that is conducive to enclosure. Each aspect of human scale that is related to enclosure is identified and its relationship briefly explained. The chapter also argues that because human scale focuses on human experience it is believed that the spaces that are formed are enclosed in a way that supports place, security, and progression.

Chapter 6 identifies and analyses a site and outlines the brief and evaluation criteria. A site already targeted for redevelopment by the city council is chosen which, more specifically, lacks human scale and enclosure. General contextual analysis is undertaken as well as more specific site analysis that establishes its weaknesses and strengths in terms of human scale. This analysis, reinforced by City Council objectives forms the basis for the design brief. It is followed by an outline of the criteria that will be used to evaluate the design outcome. 
Chapter 7 aims to test the relationship between human scale and enclosure whilst simultaneously improving the area in line with the Wellington 2040 Framework through means of design. Using the knowledge gained, the design will explore how a more comprehensive understanding of human scale produces enclosure and space that portrays qualities of place, security and progression.

Chapter 8 concludes by discussing the design process and whether the outcome contributes to a better understanding of human scale and the role that it has to play in our urban environments. It also seeks to reflect on any incompatibilities or congruities between the research and current practical objectives.

\section{$1.4 \mid$ SCOPE}

In exploring human scale the research broaches many theories, although some more briefly than others. Focusing on all aspects of human scale in an in-depth manner is impossible for the scope of this thesis, but an attempt is made at negotiating carefully, and selectively between the most relevant areas while still providing the conceptual framework.

The design focuses on a specific area in Wellington, although the principles explored can be applied globally. A large site is chosen to demonstrate specifically how human scale exists at an urban level and how it affects enclosure. Due to time and resource constraints and the amount of detail that is required in the streetscape to achieve a human scale environment, the architectural and detailed design is limited to a smaller 
portion along Taranaki Street. However, a large enough section is detailed to achieve a comprehensive exploration of the topic.

The design however is purely a theoretical and suggestive design meaning material choice, architectural styles and overall design are simply one of many possible avenues one could take in addressing human scale issues. 


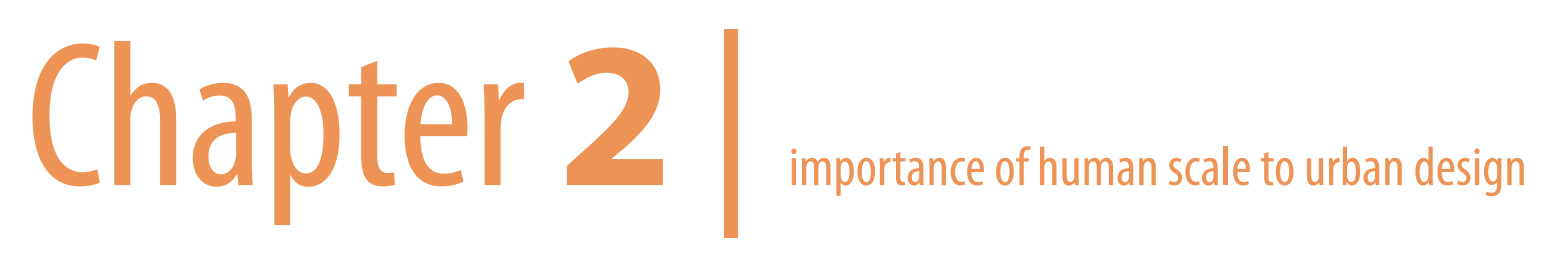




\subsection{ORIGINS OF HUMAN SCALE}

Often traditional cities such as Venice, Sienna and Bruges are noted for being beautiful examples of human scale environments, yet in our contemporary world we have struggled to achieve the same intimacy. This is because there were a number of factors keeping traditional settlements at human scale, such as the level of technology, the way of life, and collective societal values and ideologies, which are no longer applicable today.

The level of technology was often responsible for much of the human scale nature of traditional cities. Low building heights were the result of construction techniques and available materials, as well as rigorous regulations that sought to achieve harmony and propriety and maintain the prominence of those civic buildings permitted to break cohesive design ordinances.

The human scale and intimate nature of town planning was another aspect partly caused by limited technology. In many cases the simple grid was not an option due to the topography of the chosen site. Mountains could not be moved or lakes or rivers filled in without great expense and effort. This commonly lead to narrow, twisting, intimate streets often following the contours and on a plan map could appear"...to be like a maze with no logical form (because it lacks pure geometry)..." but was actually very functional and based on the inhabitants daily routes. (Spreiregen \& American Institute of Architects., 1981, p. 11) In many cases such sites were chosen specifically because these landscapes provided natural barriers and were suitable for defensive reasons. Even if they could, removing them would jeopardise the settlement.
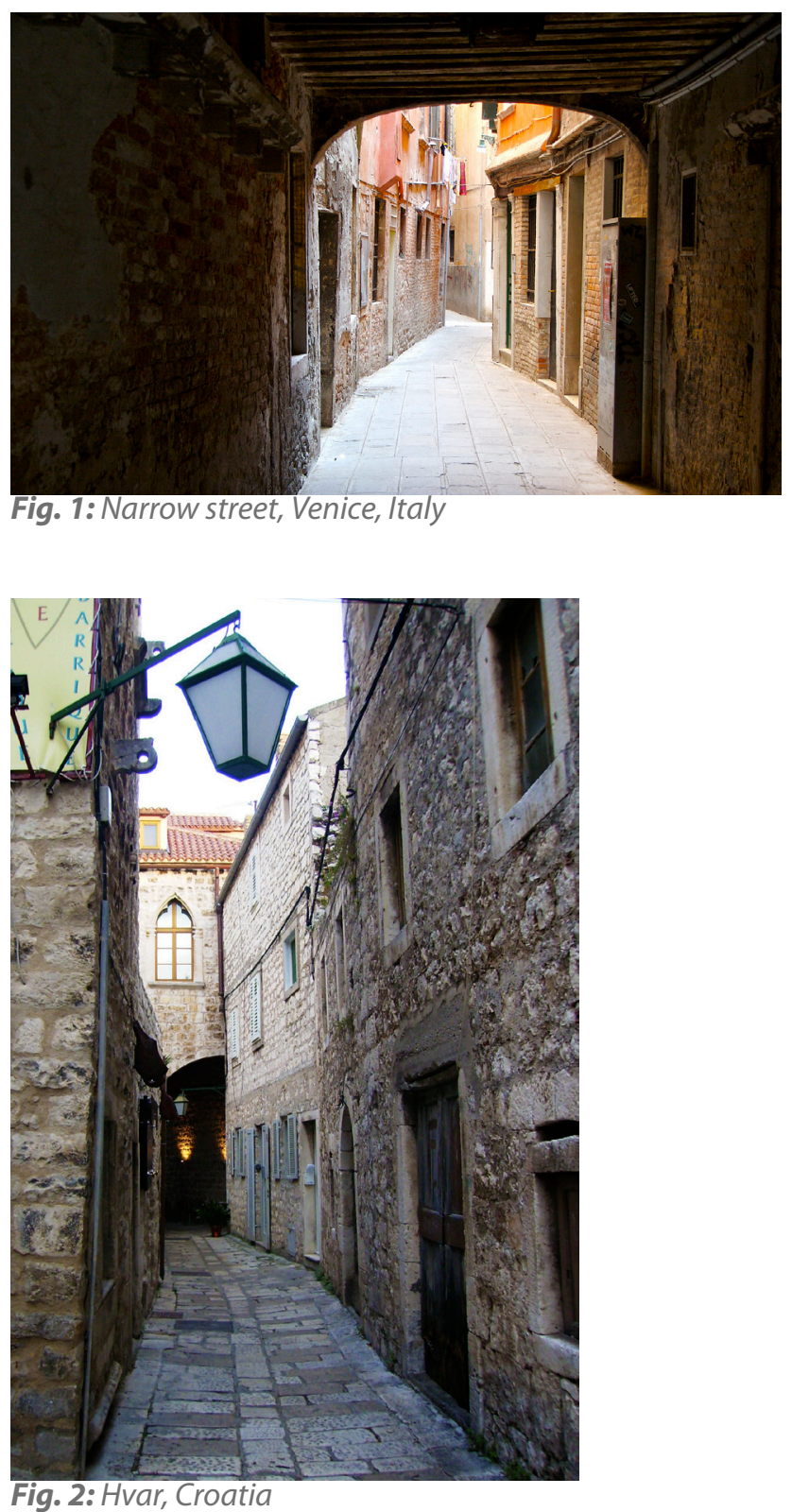
The ever-present threat of war which encouraged settlements to frequently establish themselves in easily defendable positions (Spreiregen \& American Institute of Architects., 1981, p. 10) or to surround themselves with defensive walls was merely part of life, but also provided a basis for dense, small, human scale settlements. In the event of expansion, such limited technology meant removing or altering natural barriers was costly and time consuming, and even expanding city walls suffered similar dilemmas. As a result the settlements were confined to small spaces and were forced to use the space they had wisely. "'...the medieval burgher's need for reassuring surroundings resulted in a similar sense of human scale in his towns and buildings." (Spreiregen \& American Institute of Architects., 1981, p. 9)

One of the biggest factors that contributed to human scale in traditional cities was simply the collective way in which people saw the world.

"The characteristic that distinguishes a traditional society is order, the sense of coherence in every aspect of life. This order or coherence derives from a shared knowledge of origins and gives validity to every event." (khambatta 1989:257)" (Pearson \& Richards, 2004, p. 10)

This shared knowledge and communal understanding of the world often stimulated sets of common values, or ethics, accumulated within cultures that determined the form of our cities. This idea is reinforced by Jane Collier who notes that as far as design was concerned, "...aesthetics were modulated and evaluated in the light of relevant ethical criteria" (Collier, 2006, p. 309) . 'Relevant ethical criteria' can also be identified as codes that were often put in place. In many cases they represented the desire for order as a collective social value. These codes were normally regulatory rather than advisory (Talen, 2009, p. 146) and as such were largely responsible for the harmonious
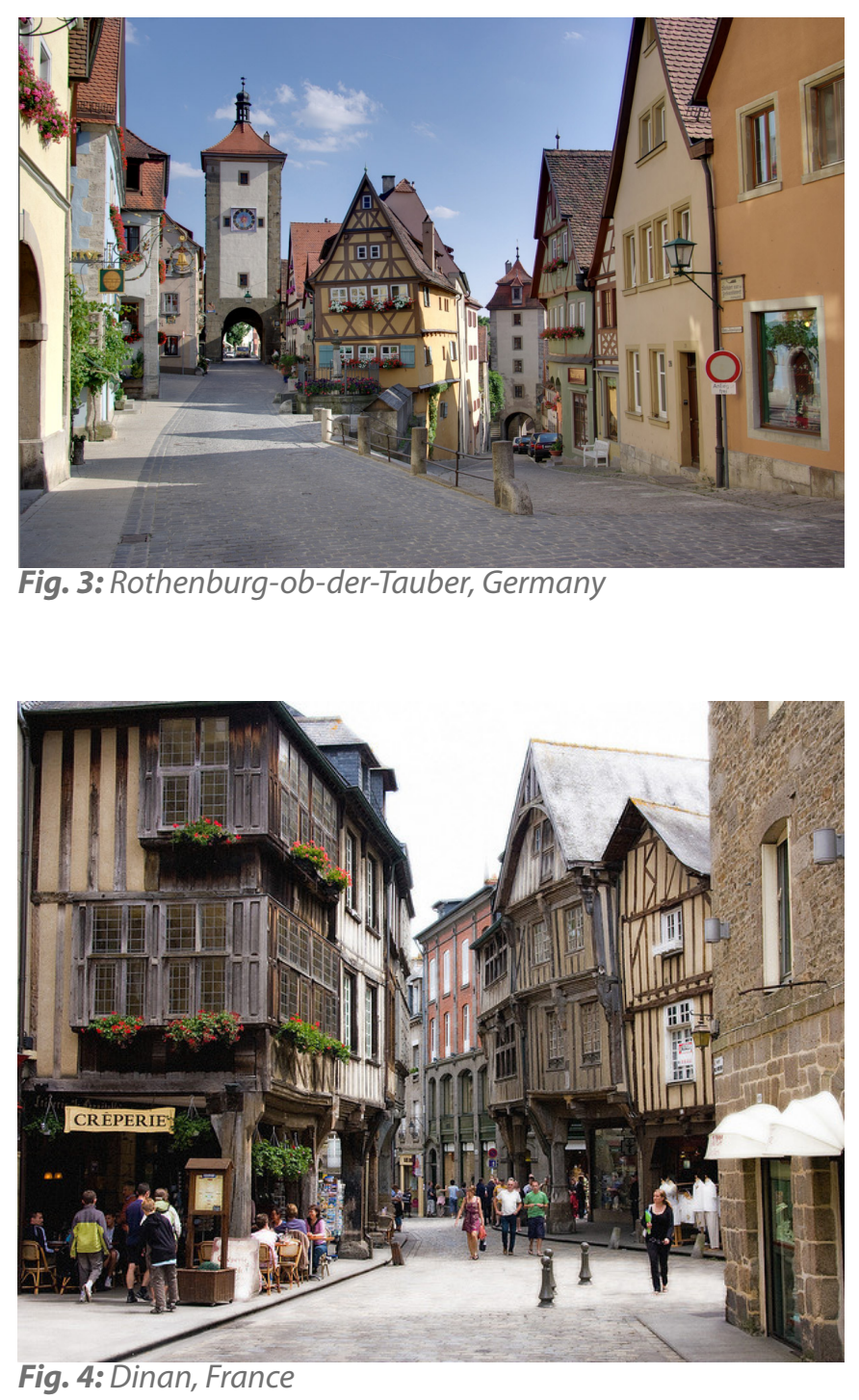
form of traditional cities.(Davis, 2006, p. 202) For example, "Islamic codes yield finegrained urbanism and many courtyards. They are driven primarily by concern for privacy, prevention of damage, and decorum." (Talen, 2009, p. 153) This collective mentality helped to keep the city responsive to humans, their values and lifestyle and thus in human scale.

The order of traditional societies was as Erik Maaløe says, "...not orderliness, but a sense of unity that gives the whole its character." (Maaløe, 1976, p. 73) This unity unlike orderliness, allowed for variation, and in many ways was a by-product of regulations stemming from cultural and social norms. The aesthetic value of harmony, however, was acknowledged and often deliberately incorporated into regulation. Codes promoting order for the sake of aesthetics was not uncommon. Sienna was an example in 1346 when it created an ordinance concerned with the continuity of the building line for aesthetic reasons (Kostof, 1999a, p. 70) In terms of aesthetics of scale, it was understood that that which is'in'scale, means the object in question is achieving harmony with its context, in this case humans. As Moughtin points out, harmony in architecture and urban design is partly born from "...the employment of a constant, particularly human scale." (Moughtin, 2003, p. 63) in which man's perception of the world is understood and acted on. (Davis, 2006, pp. 206-207) Thus such conditions and codes required architects to "...design the visible exteriors of their buildings to best suit the total viewing conditions of small spaces." (Spreiregen \& American Institute of Architects., 1981, p. 10) In fact, despite the small spaces and seemingly laissez-faire street network, the careful treatment of the urban environment ensured that "...one never feels lost, for the town is small and gives constant assurance of its human scale in visible construction and human activity. The Italian hill town of Sienna is a good example of these characteristics." (Spreiregen \& American Institute of Architects., 1981, p. 10)

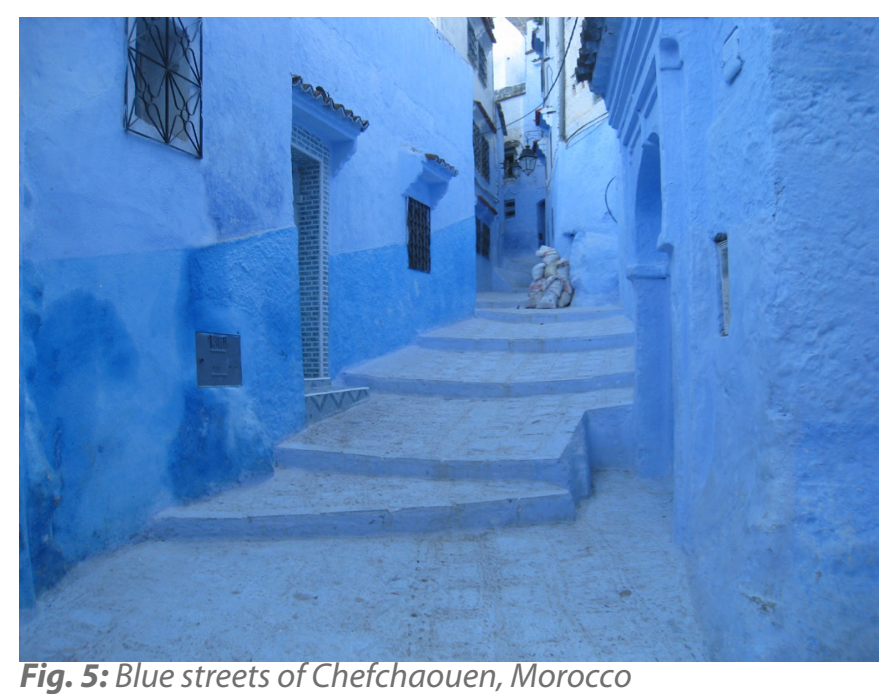

Fig. 5: Blue streets of Chefchaouen, Morocco

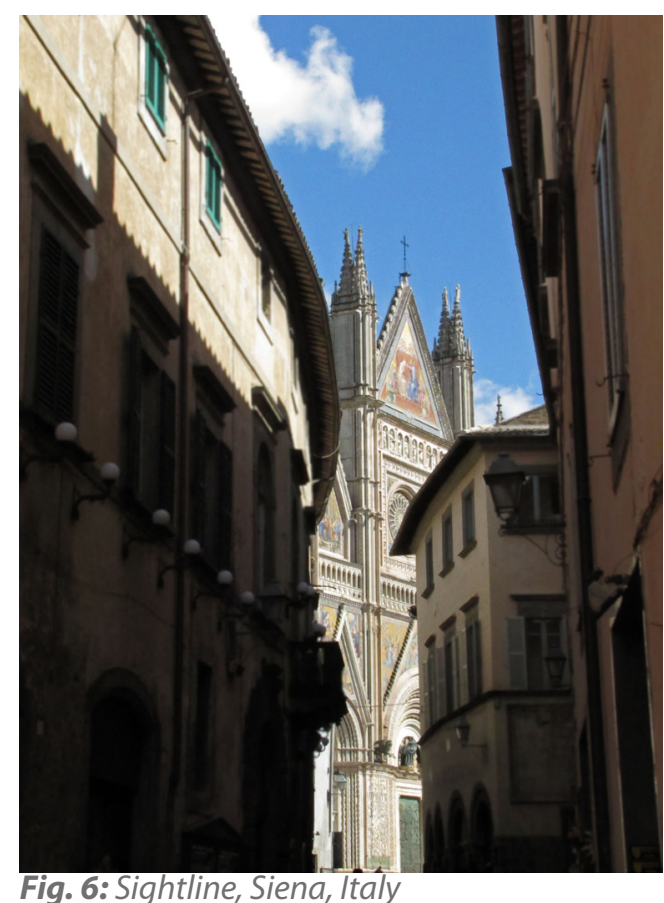


Such contextual design was common occurrence, as typical protocol involved the design to evolve with construction in direct response to context and issues as they arose on-site (Davis, 2006, pp. 47, 52-53) This design process helped to ensure a propriety among traditional towns, which as Gordon Cullen says, "...stems from the mutual respect which a true society should maintain amongst its members, which is not quite the same thing as manners." (Cullen, 1995, p. 65) This propriety could be seen as a type of discipline, controlling and limiting the design potential for the sake of order and coherence. As Moughtin clearly puts it, "Without discipline [prohibitions maintained by ethic] there is only chaos." (Moughtin, 2003, p. 32)

One could say that in the past human scale was created by the limits of traditional society, of which in today's society limits are few and far between. This idea is echoed by the contemporary Colombian Architect, Símon Vélez, who in an interview reveals his belief that human scale is "...architecture that acknowledges limits." (Gorus, 2010) It must be noted that many of these 'exemplar' cities are remnants of the middle ages. This is understood to be for two reasons; the first is because the era covered an enormous time period, around one-thousand years from the $5^{\text {th }}$ to $15^{\text {th }}$ centuries, in which settlements began to take the shape we can recognise today. Due to this enormous expanse of time very little coherent urban fabric remains from ages prior to the middle ages. The second reason is that the urban environment drastically began to change with the onset of the renaissance. Human scale was gradually left behind as the limits of a previous age began dissolving due to rapid and significant advancements in society.

In summary, the coherent and limited nature of traditional society consequentially endowed their urban environments with human scale. This is why existing traditional cities such as Venice, Sienna, Bruges etc are frequently referred to as good examples 
of human scale urban environments. Almost everything was compared against both the physical and perceptual ability of the human, naturally creating a human scale fabric; sometimes as the product of intentional act, but also commonly a result of the limited technologies and ideologies of the time. This however is not to say they are thus rendered irrelevant to our age, for they still embody human scale, and are valuable precedents from which we can learn despite significant changes in society, technologies and ideologies. They are timeless in the sense that we continue to enjoy them and appreciate them as observed in their manifesting as romantic and idyllic destinations. As this thesis later explores, enclosure is one such aspect of traditional cities created by their human scale nature which we now pursue as objective in today's urban environments.

\section{$2.2 \mid$ THE STATE OF CONTEMPORARY CITIES}

Large changes in ideologies and technology had significant impact on the physical form of cities in a way that left them largely devoid of human characteristics. Subsequently, some aspects of the built environment that were once integral to traditional human scale cities, such as enclosure, have deteriorated considerably.

"Western historians cite three major events to mark the moment of transition: the dawn of science; the fall of Constantinople; and the discovery of the New World." (Spreiregen \& American Institute of Architects., 1981, p. 11) Much of the world as we know it today began to form around the end of the $15^{\text {th }}$ century. Change came much faster than previously experienced and many were reluctant to accept it. Spreiregen continues to say that "The new era was to pit for centuries the forces of one group

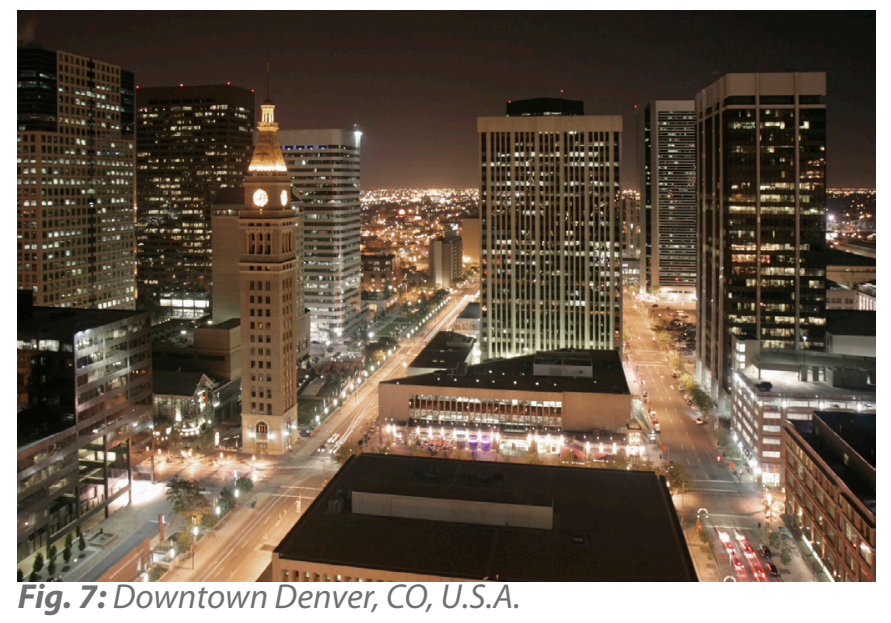

20 
against another... In this conflict the design of cities was to become an instrument of political administration and many of the gains of medieval urban design were to be discarded, particularly the sense of scale..." (1981, p. 11) The notion of human scale, or man as the measure of all things, was displaced gradually as city and society alike needed to accommodate new emerging dominant ideologies such as Cartesian theory, modernism and capitalism and technology such as the vehicle.

\subsubsection{Cartesian Theory}

Accelerated progress in ideology brought about swift change that began to dissolve aspects of traditional society, more particularly, the parts of traditional society that supported human scale. This changed the way cities were built and what they looked like, and it did so by reducing trust and common understanding between people as new ideas and knowledge circulated. One theory in particular that destabilised collective society occurred in the seventeenth century and signalled a pivotal change in ideology, technology and subsequently society and city building. Renée Descartes successfully critiqued current ideas of explanation, proposing a new theory widely come to be known as mechanical explanation (Clarke, 2005, p. 15). It is a method in which content can be understood and proven by analysing it separately from context and is largely concerned with classifying and quantifying. This was to affect the world in a way that would aid the dissolution of human scale in our towns and cities.

This ideology meant that roles became more defined with explicit protocol creating a division between specifically educated professionals and uneducated laymen (Davis, 2006, pp. 100-101). The field of architecture was no different and this eventually led to design being severed from construction, sewing the seeds for fragmentation not only among industries but in the social and built environments. As the architectural 
profession became more exclusive and separate from society and indeed other building professions, explicit knowledge meant that architecture was no longer understood by society and as such lost connection with it. "The professions acted in ways that were consistent with these mentalities and that eventually led to a built environment reflecting their own discrete and explicit nature." (Davis, 2006, p. 106) The city form was soon dictated by these professionals, rather than the people, whom having different ideals in many cases used the city as their canvas. Architects were keen to break free of the traditional limits and codes formed by outdated collective values that kept harmony within the city, not only between the built components of the urban environment but between the built environment and man.

\subsection{2| Modernism}

One such movement driven by professional architects was Modernism. Those immersed in the modern movement were influenced by machines and new technology, the work of engineers. Le Corbusier, an architect noted for his dislike of cathedrals and admiration of American grain towers once said that,

"The Engineer's Aesthetic and Architecture are two things that march together and follow one from the other: the one being now at its full height, the other in an unhappy state of retrogression ... The Engineer, inspired by the law of Economy and governed by mathematical calculation, puts us in accord with universal law. He achieves harmony." (Corbusier, 1986, p. 11) 
Le Corbusier's attitude, like others in the modern movement such as Adolf Loos and Walter Gropius, was that architecture should "express the spirit of the age" or zeitgeist (Krier, 1998, p. 71; Maaløe, 1976) a concept which helped to hasten the dispatch of traditional ideologies and technologies. The zeitgeist of modernism, however, was one not particularly conditioned to human scale, and more concerned with precision, simplicity and efficiency of new ideas and technology. It was a movement which treated the Cartesian theory as if it "...really were the nature of things, as if everything really were a machine." (Alexander, 2002, p. 16) The desire for such meticulous, functional order, not only applied to architecture but to urban design as well. Le Corbusier's plan for Paris, Plan Voisin, is an example of this as well as his criticism of organic street forms labelling them "the pack-donkey's way" throughout his 1924 book'The city of to-morrow and its planning'. The movement was so devoid of human consideration its theories have been audaciously but frequently compared with the ideologies of Hitler and Nazi Germany. This is because the order of Modernism, unlike the order of traditional society, was concerned with orderliness which produced a rational and socially controlling and disconnected environment quite similar to those in which "The meticulously planned despatching of millions took place..." (Pearson \& Richards, 2004, p. 23)

This type of ideology later helped influence and elevate the importance of the city plan as a mechanism for design. However despite Le Corbusier's acknowledgment that "... a birds'-eye view such as given by a plan on a drawing-board is not how axes are seen" stating that "...they are seen from the ground, the beholder standing up and looking in front of him." (Corbusier, 1986, p. 187) the Brasilia syndrome as Jan Gehl calls it is "...rooted in modernism, which focuses on buildings rather than holism and city space." (Gehl, 2010, p. 196) This birds'-eye view planning overlooks the more intimate smaller scales experienced at ground level which are crucial for establishing
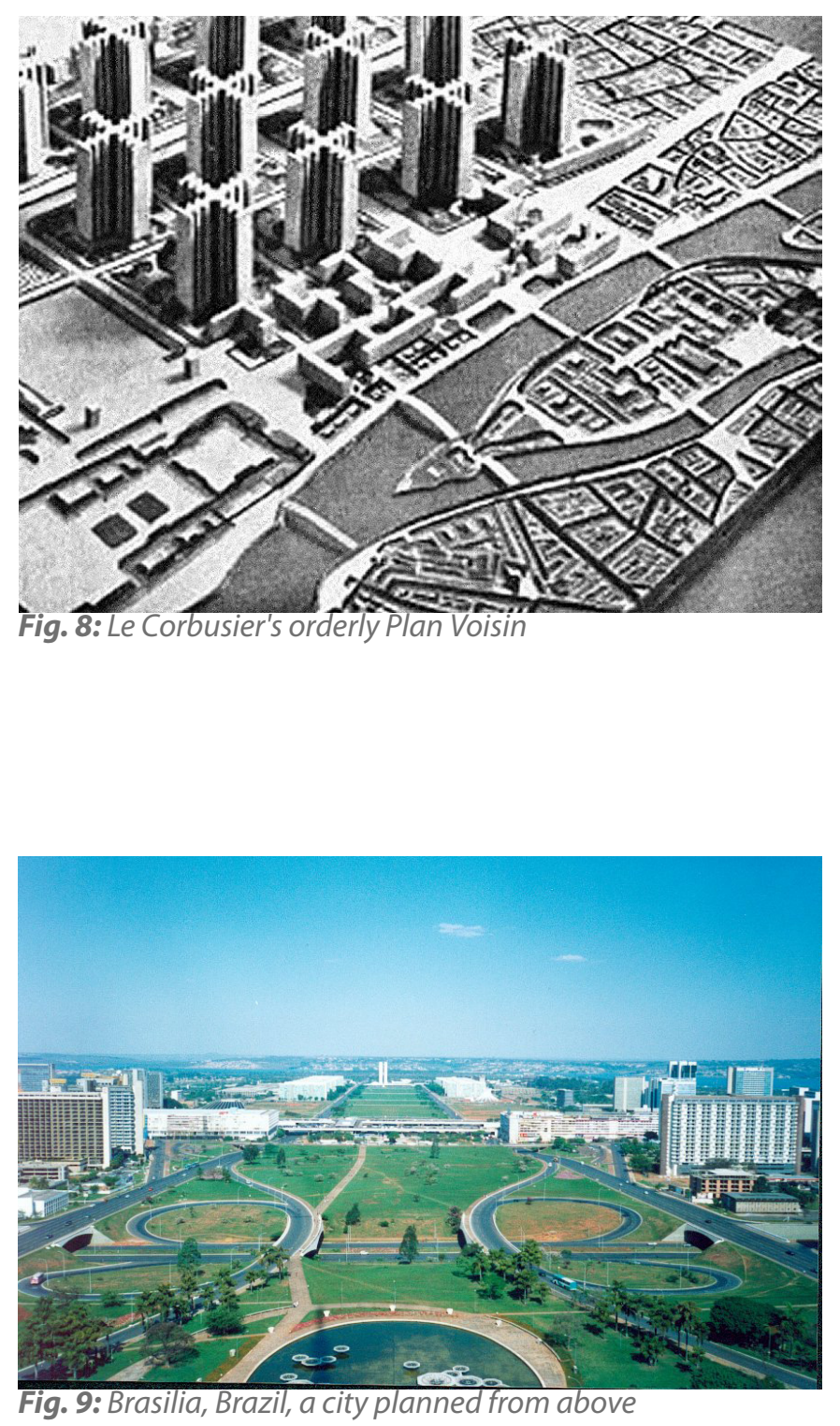
numerous aspects of human scale. Salingaros goes so far as to say we should avoid scale models for this purpose believing that, "Any philosophy that eliminates the individual human being from consideration merits an automatic commonality with destructive events such as the holocaust." (Salingaros \& Mehaffy, 2006, p. 19) . It was an era in which the increasingly divorced nature of the architectural profession from the public and human value could only culminate in its ultimate rejection. However, despite its collapse, it has impacted heavily on later generations.

\subsubsection{Destructive Forces of Building for Money}

Along the lines of the traditional mentality, Richard Rogers believes rightly that "..in a democratic age, contemporary architecture and planning might be expected to express our common philosophical and social values." (Rogers, 1997, p. 17) however he and others recognise that this is a challenging process with the mentality that exists today. Unfortunately "The construction of our habitat continues to be dominated by market forces and short term financial imperatives." (1997, p. 17) and as Howard Davis expresses, sole focus on profit and financial imperatives "... does not guarantee the production of buildings that support and enhance human life and the quality of cities." (Davis, 2006, p. 118) The exponential increase in the value of time and money has drastically effected the ability of urban environments to express and respond to humanity. High labour and material costs, mean reducing the number of craftsmen, and increasing productivity off-site and using prefabricated materials. In a commercial sense, it is often "...the cost of money and the need for the building to be profitable as soon as possible..." where time and money become of the essence (Davis, 2006, p. 72) This kind of building culture however runs the risk of putting quantity before quality, in which shortcuts are taken to the detriment of the public and the quality of life that

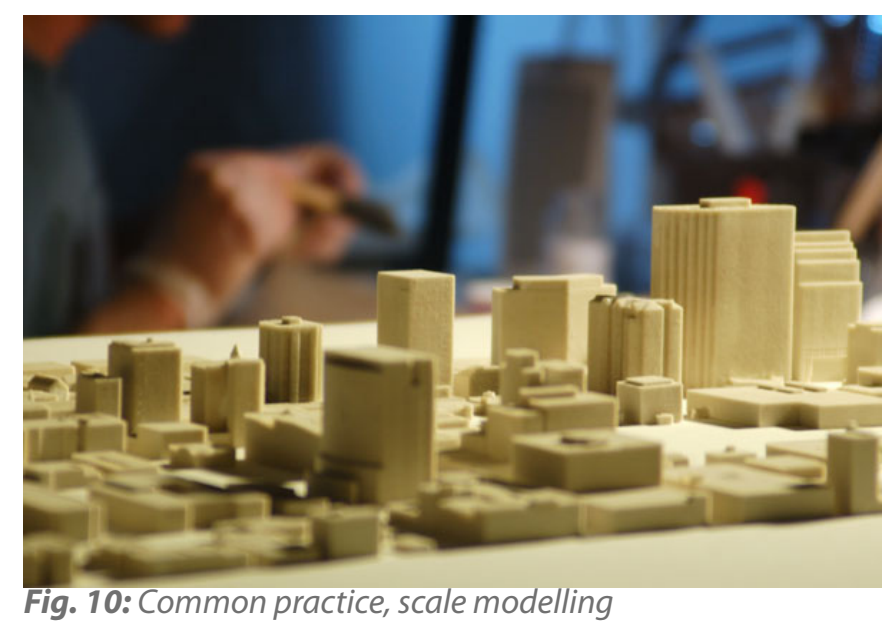

Fig. 10: Common practice, scale modelling 
our built environment as the human habitat should be giving us. In other words many aspects of human scale design are put at risk. Spreiregen warns that "When these principles [of human scale] are violated the results are cities without human form, cities without sympathy, cities without pride. Worse still are the effects on the spirit and human sensitivities of its people. At that point the city is a failure." (Spreiregen \& American Institute of Architects., 1981, p. 69)

\subsection{4| Technologies}

New technologies have provided us with almost limitless capabilities. Large buildings are now common place, made possible by new materials and construction techniques and the invention of the automobile has caused cities to adapt to a new means of transport, one that requires more space and travels much faster than humans. Man as the measure of all things has been replaced by the limits of his technological knowhow and such is now the driving force for city form.

According to Lord Rogers, "Breaking with preconceptions about architecture frees the architect to exploit new technologies and manufacturing techniques." (Rogers, 1997, p. 82) However, new building technologies often have very little to do with people. Materials are frequently sized according to shipping standards (Spreiregen \& American Institute of Architects., 1981, p. 70) (what can fit on a truck, train or ship) and their size is no longer proportional to man because man no longer has to work and lift these materials by himself. Instead his strength has been replaced by forklifts and cranes. By sizing materials according to the ability of machines, it is easy to understand how many contemporary materials quickly surpass any relationship 
with humans. Some such as Nikos Salingaros advocate the use of natural materials as he believes humans have an evolutionary connection with them (Salingaros \& Mehaffy, 2006, p. 56). Modern materials such as glass, concrete and steel do not have the natural structure and texture we subconsciously seek. "As a result of thirty years of experimenting with revolutionary materials and novel ideas, burning all the rule books and purveying the theory that man is a machine, we have ended up with frankenstein monsters, devoid of character, alien and largely unloved, except by the professors who have been concocting these horrors in their laboratories..." ((Prince of Wales), 1989, pp. 7-9)

In terms of construction technologies, advancements in engineering urged forward by the invention of steeland reinforced concrete, break any limits that may have previously validated small construction. Although of course, there are still technological limits, they are now far beyond human scale and it is in fact the adverse effects of such large buildings that are proving to be restrictive. Despite living "...in a world of mechanical wonders which, every day, are offered as solutions to all sorts of urban ills." (Spreiregen \& American Institute of Architects., 1981, p. 69) they also produce urban ills. Wind, earthquakes, fire, cost, and psychological disorders are just some of the factors that are now affecting the sustainability of continued enlargement.

Vehicles on the other hand have left a similar impression on the built environment. They too induced a larger city helping to change it from one that is walkable to one in which it is unpleasant or impossible to walk. There have been many studies on the impact of vehicles on the quality of life of a city. Wider, straighter roads, extensive surface parking, sprawling suburbs and a change in architecture to adapt to vehicles 
are all ways in which the city has tried to accommodate such a strong presence and in the process has failed to consider the impact on human scale. As Norman Crowe succinctly points out,

"The invention of the motor vehicle, which has the capacity to travel effortlessly at high speeds across distances, has introduced a scale of reference that bears little relationship to human perception of urban space, detail, order and scale. Twentieth century solutions to problems of urban order have sometimes accommodated the automobile to the almost complete exclusion of our experiencing the city in a traditional way." (Crowe, 1995, p. 226)

Yet he also says that "As the city has changed, our concept of the city has changed with it." $(1995$, p. 211) and in this sense the city is no longer a place reserved for pedestrians, and nor do we see a city as such. "No one denies the place of swiftly moving traffic in the life of a town." as Gordon Cullen reinforces, but "...It is the universal spread of traffic, its arrogant seizure of all roads, that calls for protest." (Cullen, 1995, p. 122) Corbusier argues to separate functions so that people don't have to share space with vehicles. (Corbusier, 1986, pp. 58-63) but this could also have adverse effects in a modern city as Spreiregen identifies. "We must be careful, however, in concluding that all the trouble comes from the mixture of pedestrians and cars. Many city streets would be lifeless without cars. The problem comes when cars prevent the free flow of pedestrians." (Spreiregen \& American Institute of Architects., 1981, p. 62) This very point was noted over one hundred and twenty years ago by Camillo Sitte, who saw the impending threat vehicles would pose to pedestrian mobility and safety. (G. R. Collins, Collins, \& Sitte, 2006, p. 233) 
"In a town, a lived-in place, the layout of the spaces in which the public moves is a matter having direct impact on the emotions..." (Cullen, 1995, p. 46) but when this layout is dictated by vehicles, the emotional impact on pedestrians can often be negative. But now "...the city has become too large, too impersonal, and too dangerous from within. A city that no longer effectively shelters its inhabitants encourages them to seek refuge in the suburbs." (Crowe, 1995, p. 228) The social human scale has been dispersed as the car "... has played a critical role in undermining the cohesive social structure of the city." (Rogers, 1997, p. 35)

\subsection{RECOGNISING THE ABSENCE OF HUMAN SCALE}

It is inevitable that ideologies and technologies which have had such an enormous impact on society would also leave their mark on the built environment. The harmonious nature of traditional cities and the more chaotic and diverse nature of our contemporary cities is truly proof that "...the form of urban space is a representation of the ethics of a society." (Canniffe, 2006, p. 4) Much in line with Collier and Canniffe, Krier asserts that "Cities and landscapes are illustrations of our spiritual and material worth. They not only express our values but give them a tangible reality." (Krier, 1998, p. 90) leaving one almost able to read the city in a way that reveals its inhabitants values. However values change with time, and there has been a realisation of the importance of human scale now that we are aware of its absence. As Jan Gehl notes of modernism, 
"The modernist rejection of streets and the traditional city in the 1920s and 1930s and the introduction of functionalist ideals of hygienic, well-lit dwellings resulted in visions of the widespread tall city between freeways. Walking, cycling and meeting other in shared urban spaces were not part of these visions, which is subsequent decades had an immense impact on new urban development all over the world." (Gehl, 2010, p. 56)

Part of the recognition of past failures is the reaffirmation by many that the architectural profession is one that is responsible for creating environments focused on facilitating human perceptual and physical behaviour and that much of the contemporary city has failed to do this. If we accept that architecture is concerned with anthropology, then it must include a firm understanding of the social sciences, (Moughtin, 2003, p. 6) to better design for humans. As Nikos Salingaros reinforces, "An architect's mind has the power to either create designs that adapt to human needs and emotions, or to impose arbitrary forms on the environment." (Salingaros \& Mehaffy, 2006, p. 195) To design for human scale not only means to understand how humans behave but also how they process information and in return respond to their environment.

However there are clashing ideologies on how to progress. Some believe the past holds the key to the future, but others believe the past is irrelevant and restrictive. It can be clearly observed through the contrasting words of many authors. For example Lord Richard Rogers believes that "'Traditional aesthetics based on buildings conforming with their neighbours need to be challenged." (Rogers, 1997, p. 80) noting a merit of the modernist era was that it sought to break free of the limits imposed by tradition. This is a common stance among contemporary architects who believe in 
the zeitgeist, a continuation of a modernist ideology. However there are those who believe that successful buildings simply embody spirit, in which age is transcended. That architecture cannot escape the era in which it is built, but the era does not have to effect the architecture. (Krier, 1998, p. 71) Howard Davis neatly sums up this dilemma between the contemporary and the traditional camps - those forces 'pitted' against each other since the renaissance.

"Shared traditions allow people to maintain connections to a common past, and therefore to each other. But the concept has a charged meaning, particularly today, when the world is changing so fast. After all, modernism, as it has been defined through the twentieth century, is inherently antitraditional. The idea of "traditional architecture" - particularly traditional vernacular architecture - is sometimes seen as static, locked in the past, and inappropriate to today's society; those who promulgate it are regarded as hopelessly reactionary and conservative. Indeed, if we look at tradition purely this way, as buildings from the past, such criticisms may be valid. But if tradition is seen not as a blind handing down of habits and objects but as part of a process in which what has come before has the ability to teach, then the concept takes on a more dynamic meaning." (Davis, 2006, p. 17)

Also, it is still widely debated which emotions are innate, and which are learned (Hinton, 1999, p. 1; Lock \& Peters, 1999, p. 206) It could be that "...what makes us... respond to an event is culturally determined." (Lock \& Peters, 1999, p. 206) Even so, as Cliff Moughtin states, "Culture is never entirely static, it is in a constant state of change." (Moughtin, 2003, p. 13) He also notes that as "The world is getting smaller... there is increasing contact between peoples. As a result, cultures are changing. What is more, they appear to be changing at an increasing rate." (2003, p. 13) This would suggest 
subjectivity in whether what we perceive is perceived by all. Hence one would think the phrase, "beauty is in the eye of the beholder" has some meaning, and explains current differences in opinion of what is visually pleasing in our contemporary built environments. There is no reason why this doesn't extend to people opinions of what human scale is. Yet as Leon Krier brings to light, there are rarely any objections towards traditional urban environments (Léon Krier, 1998, p. 21) therefore one must assume that there is an innate preference in how man perceives his environment which transcends time (Salingaros \& Mehaffy, 2006, p. 28). This could however simply be because traditional urban environments respond well to humans and are thus perceived as more intimate and connected to us than, generally speaking, its contemporary counterpart.

For as Spreiregen notes, "Inspite of its constant lack of ease and assurance, the medieval world had produced a system of town design that was truly liveable. That human element of urban design was bound to be lost, for the main purpose of town design ceased to be the comfort of its inhabitants." (Spreiregen \& American Institute of Architects., 1981, p. 12) In recognising this, one can establish that the neglect of human scale caused certain aspects that contributed to this 'liveable' traditional city to disappear. It is has been noted that one of these aspects frequently found in human scale urban environments, and is today an uncommon feature, is enclosure. Although not a direct property of human scale, successful enclosure is largely the result of a human scale approach to design. Without constantly responding to human needs, city space can quickly lose definition, or can'over' enclose. Although traditional enclosure is also a likely product of other circumstances, such as lack of space and limited technologies, it created desired human qualities as has been expressed by numerous authors. However although the consequences of neglecting human scale 
have been repeatedly identified Jan Gehl reminds us that, "Unfortunately, new cities are still being built according to principles that shatter the scale. There are too many spaces, they are too large, and the human landscape is therefore cold and dismissive or even completely unusable." (Gehl, 2010, p. 167)

It is likely that the very notion of human scale as a principle of architecture and urban design would seem ironic to an ancient, as man was inherently considered the measure of all things in cities for thousands of years. The very fact that we talk about human scale application suggests that we no longer have human environments. When our surrounds facilitate human perception and use, as traditional cities did, in some cases inadvertently, this notion of human scale merely becomes an unnoticed by-product. Like many good things, it only becomes noticeable when absent. In other words, because we have lost over time the art and knowledge of city-building for humans, we have created this notion of human scale, and the difficulties of understanding it. Fortunately, this has occurred because we have now realised that we have been neglecting our own well-being. In fact the profession of urban design as we know it today is in someway a reaction to the degradation of city spaces due to adverse influences.

However one of the more severe side effects of neglecting human scale, is precisely the environment it creates, or for that matter doesn't create. As the city responded less and less to the human, the restrictions and limits imposed by him were thus broken. The result could be seen as a type of chaos, an experiment where new ideas were tested, some were successful but some were failures, and many did not consider the human. Aspects of the traditional city which we see as desirable, such as enclosure, were aspects created from a focus on human scale. When human scale was neglected, these desirable aspects began to disappear. 
However bucking the current trend and mentality, where vehicles, ever-advancing technologies, and the desire to earn a profit at any cost are fundamental aspects of life, is difficult. The solution however may not lie in the abandonment of our current mentality, but merely the acceptance of traditional achievements in a way in which we can learn from them and adapt them. In any case, it is clear that the neglect of human scale in our contemporary cities has lead to the deterioration of certain desirable design objectives such as enclosure. As a result, in some aspects, the importance of human scale has been elevated beyond what attention it would have received in a time when human scale cities were abundant. The problem is now despite its importance to our urban environments, do we really know what human scale is in order to successfully restore and execute urban design objectives such as enclosure. 


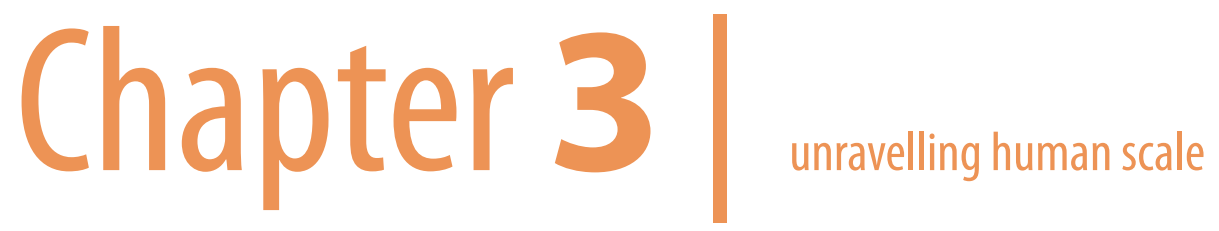




\subsection{THE INTERPRETATIVE POSITION ON THE CONTENTS OF HUMAN SCALE}

One of the issues with identifying what creates human scale is that very few authors actually give a definition for human scale, necessitating a need to extend analysis to more implicit and inexplicit literature. In such literature the discourse is referent to principles of the concept but the words 'human scale' won't necessarily appear. More often than not readers can be unaware that they are reading about human scale, unless they were already very adept in its complexity and constitution.

Many books indirectly address human scale by discussing or observing certain human scale principles without ever actually making a connection with the term. For example, Jane Jacobs is known for her support of human scale urban design, however in her seminal piece 'The Death and Life of Great American Cities', she hardly mentions the actual phrase. Leon Krier is another example, in his book "Architecture: Choice or Fate", he discusses several ideas which are pertinent to the concept of human scale but never uses the phrase himself. Camillo Sitte, again, is another who is recognised for his support of human scale in our cities, yet never mentions the term in his famous book'Planning according to Artistic Principles'. Although these authors are labelled as discussing human scale, and is most likely an agreement among most, the fact that the term human scale is never mentioned is potentially problematic.

Being unlikely that such books are simply cover-to-cover definitions of the term, raises the question of how then, is it possible to know which parts of these books address human scale if the term itself is never mentioned. Such a situation infers assumption that the reader has prior knowledge of what constitutes human scale, whether learned or innate, which enables them to recognise examples of human scale. How though can we be so sure that everyone is able to recognise an element of human scale 
when they read it? Man is no longer the measure of everything, so is it really sensible to believe that in today's individualistic and industrialised world everyone shares the same thoughts on human scale? It is entirely possible that psychological conditioning (Salingaros \& Mehaffy, 2006, p. 85) could play havoc with what might have otherwise been considered age-old knowledge.

Assuming that everyone has the same idea of human scale, or that everyone knows or understands what human scale is, is not only inconvenient and confusing for those who don't understand the topic but could also be inadvertently irresponsible to the future of urban design and architecture. The seminal nature of many of these texts and their association with human scale, make them logical starting points for those seeking an understanding of the subject, and are often responsible for providing knowledge to future generations of designers who will shape our world. It is important that such an important message is not 'lost in translation'.

However understanding human scale is no easy feat. It cannot be quickly and easily defined, nor is it convenient to do so every time it is mentioned. However it is possible that we need a source of information which helps eradicate the ambiguity and condenses the multitude of texts which broach the subject into a coherent and easily comprehensible concept.

For this reason the methodology for understanding human scale has been to locate texts which clearly link the words 'human scale' to a definition of some sort, removing all doubt that the content could be referring to anything else. From here it is then possible to recognise when human scale is being discussed in other texts when the words 'human scale' are absent. As such much of the definition of human scale has be born from my own interpretations, in which I have read certain texts and understood them to be addressing human scale when the words themselves are not present. It 
is therefore acknowledged that there could be other investigations with different outcomes - proving the need for clarity around the subject.

To begin with, however, one must obtain an understanding of the conceptual origins of the term before embarking on its subsequent definitions.

\subsection{THEORETICAL DERIVATION}

In addressing the theoretical derivation of scale, it can be considered as only one of many different types of order, and order is a product of our perception (Moughtin, 1999, p. 12). To understand scale is to understand a part of how we understand our environment.

"The arrangement of the physical, and thus perceived, form of the city is the objective of urban design... Above all, the visual and perceived results of any of these efforts must be human in scale." (Spreiregen \& American Institute of Architects., 1981, p. 69)

The ability to perceive, is a natural human function (Gehl, 2010, p. 33) . It allows us, using our senses, to decipher order in our surroundings. If we can detect order in our environments we will feel more secure and comfortable than if we perceive chaos. Scale is a type of order for which we search, that involves normally but not always, as discussed later, the comparison of sizes to determine whether something is in scale or not, which 'fits in' or not. Most commonly and traditionally the basis for this comparison has been ourselves. The human. When we can no longer compare and 
find relationships between ourselves and the environment, the environment can be said to be 'out' of human scale.

\subsection{MANIFESTATIONS}

In order to understand what relationships are considered as providing human scale, or in other words to define what it is that makes something human scale, it is logical to approach existing literature on the subject.

Scale as defined in most dictionaries, and as most people define it, is concerned with size. The literature, however, divulges that human scale is also defined in several other ways. This indicates that there are two possibilities: 1.) the concept of human scale is so large that it is constituted of many smaller parts which are scattered among different texts. As authors address their own interests and concerns, they tend only to explain that part of human scale which is relevant to their discourse. Sometimes multiple examples of human scale can be given within the same text. Or 2.) there are simply just many different interpretations of the concept which allow it to be twisted to suit anyone's purpose. A third possibility could be that these two ways of interpreting existing human scale literature are really just one and the same, and that the shear number of definitions marks the commonality between them and provides the focus of further investigation. As such human scale as a collective term is investigated interpretively to reveal its contributing properties, and ulterior manifestations.

3.3.1 | Urban, Architecture and Detail

Firstly, one does not have to research far in order to discover that the concept is not specific to individual architecture. It has an urban context, as well as what I have called 
a 'detail' context. The notion of human scale exists at all levels of our habitats, and as such is a concept which needs to be highly integrated to be successful. A building constructed and designed to appear human scale in size, is simply one piece of a much larger whole. If it sits amongst a cluster of high-rises or adjacent a four lane street it can be argued that it will fail to achieve any positive impact apart from certain juxtaposition, as would a human scale building built with oversized materials. Human scale environments are achieved through a sense of unity within a larger whole, not from individual and disconnected acts.

\subsubsection{The Dimensional and The Extra-Dimensional}

Human scale can also be observed as being dimensional and extra-dimensional. For this reason, not all aspects of human scale are 'measurable'. Interpretations of human scale are, more often than not, used to define sizes with which we can comprehend - not surprisingly, as it is dimensions with which scale is most naturally concerned. However relationships with humans can be deduced through both tangible and intangible qualities of our environment. Not all characteristics of human scale are concerned solely with size. Things such as visible craftsmanship, human activity or certain aspects of planning and design like balanced repetition, hierarchy or other abstract concepts of order still embodies the notion of "human presence" and responds to and facilitates our perception. However this extra-dimensional quality is merely alluded to and can therefore be considered a truly interpretative characteristic. It is interesting to note whether materials are dimensional or extra-dimensional or both. In one sense a material can be sized to be workable for the human (as it most often used to be), but this can mean it is either given its dimensions anthropometrically (dimensionally), or according to physical capability. For example, a brick's dimensions can be dictated by the size of our hands. A stone block on the other hand could be 
dimensioned according to a maximum weight which could be lifted.

This only multiplies the number of interpretations of how to achieve, or of what constitutes visual human scale and is partly responsible for the numerous differing explanations of human scale detailed across a selection of literature consequently adding to the confusion of the concept as a whole.

\subsubsection{Visual, Social and Physical}

Firstly, human scale appears that it can be expressed in different overarching manifestations. Notably Hans Blumenfeld, who takes much of his work from Hermann Maertens, admitted "The term [human scale] is used in a dual sense; referring to the social content and to the visual form." (Blumenfeld, 1953, p. 35) more than sixty years ago. Cliff Moughtin, who most likely is paraphrasing Blumenfeld, also recognises the concept's duality in visual and social terms. (Moughtin, 2003, p. 37) Most interpretations of human scale fall under these two 'categories' although Carmona, who paraphrases Cantacuzino, states that besides its visual sense"The term 'human scale' is also used in a more general sense to refer to a sense of 'human presence.' (Carmona, 2003, p. 156) Therefore revealing a dual meaning which is somewhat dissimilar to Blumenfeld or Moughtin's notion. There is no further explanation of this sense of 'human presence' but one can only assume it means either the literal presence of human beings or anything that is indicative of facilitating or being relative to human beings - a very broad concept and without further elaboration is considerably ambiguous.

The physical capabilities of humans could also possibly be another category, however nowhere is this explicitly stated. Through my own interpretation, there is evidence to show that comfortable walking distances (Krier, 1998, p. 128; Spreiregen \& American Institute of Architects., 1981, p. 72) , the flights of stairs one can climb comfortably (Moughtin, 2003, p. 50), the speed at which we walk (Gehl, 2010, p. 42), and the 
weight of materials are all responsible for limiting sizes to a more human capacity, and are significantly different to social and visual aspects of human scale.

From the literature, the following have been interpretively identified as human scale properties:

\begin{tabular}{|c|c|c|}
\hline SOCIAL & Description & Author \\
\hline Social Distances & $\begin{array}{l}\text { Social distances are distances of intimacy and } \\
\text { communication. Such as limited distances in which } \\
\text { we can recognise and communicate with people. }\end{array}$ & $\begin{array}{l}\text { Gehl } \\
\text { Blumenfeld } \\
\text { Spreiregen }\end{array}$ \\
\hline Group Sizes & $\begin{array}{l}\text { Group sizes address the appropriate sizes of social } \\
\text { groups, from families to neighbourhoods. The idea } \\
\text { is that when one reaches beyond a certain limit then } \\
\text { another unit should be created. }\end{array}$ & $\begin{array}{l}\text { Krier } \\
\text { Spreiregen } \\
\text { Blumenfeld }\end{array}$ \\
\hline Social Activity & $\begin{array}{l}\text { The mere fact of humans interacting with one another } \\
\text { in positive ways, shopping, biking, talking etc is an idea } \\
\text { which has been eluded to as something which lends a } \\
\text { human quality to the environment, as opposed to the } \\
\text { lack-there-of. }\end{array}$ & Gehl \\
\hline PHYSICAL & Description & Author \\
\hline Walking distances & $\begin{array}{l}\text { These are comfortable walking distances of the } \\
\text { average, fit, human being which should set out the } \\
\text { average size of towns and neighbourhoods as a } \\
\text { maximum limit. Building height, has in the past, been } \\
\text { determined by the comfortable number of floors one } \\
\text { can climb, which has supposedly been around five } \\
\text { stories. }\end{array}$ & $\begin{array}{l}\text { Krier } \\
\text { Spreiregen } \\
\text { Moughtin }\end{array}$ \\
\hline
\end{tabular}




\begin{tabular}{|l|l|l|}
\hline Materialsize & $\begin{array}{l}\text { Our ability to carry something can determine a limit } \\
\text { to the size of a material such as stone, or even timber } \\
\text { before we require technology to help. }\end{array}$ & Alexander \\
\hline Movement & $\begin{array}{l}\text { The linear movement of humans and the speed at } \\
\text { which they travel are also limits which require a certain } \\
\text { human scale response from the environment in order } \\
\text { to facilitate these needs. }\end{array}$ & Jacobs \\
\hline
\end{tabular}

\begin{tabular}{|l|l|l|}
\hline VISUAL & Description & Author \\
\hline Craftsmanship & $\begin{array}{l}\text { Craftsmanship, particularly of the hand, has been } \\
\text { referred to as self-expression of the human, and in this } \\
\text { sense immediately develops a connection between } \\
\text { us and the craft, which we do not necessarily find in } \\
\text { industrially manufactured ornament. }\end{array}$ & Krier \\
\hline Order & $\begin{array}{l}\text { The very notion of scale in any sense, whether it be } \\
\text { size or not, is a reflection on the order we seek in our } \\
\text { environments. It is not limited to the comparison of } \\
\text { size and in this sense could even extend to the types } \\
\text { of order we commonly see in human environments } \\
\text { such as hierarchy, definition, or other methods of } \\
\text { arrangement. }\end{array}$ & \\
\hline
\end{tabular}




\begin{tabular}{|c|c|c|}
\hline Anthropometry & $\begin{array}{l}\text { This is perhaps the most commonly known principle, } \\
\text { simply because it is arguably the most frequently } \\
\text { found in literature as a human scale-giving attribute. } \\
\text { It is the direct translation of human dimensions to } \\
\text { our built surroundings and is commonly associated } \\
\text { with buildings, but has also been used in determining } \\
\text { dimensions of streets and public spaces also. Naturally, } \\
\text { these dimensions originally stemmed from our } \\
\text { bodies providing convenient measuring tools which } \\
\text { automatically created an environment suitable to us } \\
\text { as humans. }\end{array}$ & $\begin{array}{l}\text { Corbusier } \\
\text { Spreiregen } \\
\text { Carmona } \\
\text { Moughtin } \\
\text { Ewing et al } \\
\text { Ching }\end{array}$ \\
\hline Visual Limits & $\begin{array}{l}\text { Visual limits is the limitations of our ability to see; our } \\
\text { field of view, both in distance and periphery and the } \\
\text { perception from these limits. This effectively places } \\
\text { natural restrictions on the size of streets and buildings } \\
\text { for comprehensible reasons. }\end{array}$ & $\begin{array}{l}\text { Gehl } \\
\text { Spreiregen } \\
\text { Blumenfeld } \\
\text { Maertens }\end{array}$ \\
\hline Texture & $\begin{array}{l}\text { It is thought that texture is important in providing } \\
\text { the smallest most scales in the hierarchy of scales we } \\
\text { expect to see in our environments. Texture also adds } \\
\text { to the visual information we seek. }\end{array}$ & $\begin{array}{l}\text { Salingaros } \\
\text { Gehl } \\
\text { Cullen }\end{array}$ \\
\hline
\end{tabular}

It must be understood however that these are not completely separate concepts and are largely interdependent. For example, the speed of a pedestrian will effect the visual articulation of a building, just as the visual distance used to determine building height is related to the distance of social recognition. 


\section{$3.4 \mid$ CONCLUSION}

Despite its importance to urban design and architecture, the current notion of human scale, at its best, is both complex and ambiguous. The literature as a whole, unintentionally nurtures these qualities and infers a trust in an understanding and in a consensus of its meaning, which may be a bullish supposition in today's social climate. The term also appears to be so broadly used that its numerous manifestations across the literature consequently give the impression of completely different meanings. This isn't to say that any of these different definitions are incorrect, but simply that human scale is a collective term, and not particular to any one thing. Ultimately this means it is an extremely broad subject and as a result its contents are often not well understood nor well communicated.

The term 'human scale' therefore creates a situation where this collective notion is overlooked. The word 'scale' is, with good reason, easily misinterpreted as referring solely to the comparison between sizes (dimensions), which also happens to be the most prevalently discussed human scale property, when in truth the term is also concerned with the comparison between things without measure.

If there is such importance placed on this concept in urban design and architecture but contemporary cities are still suffering from a lack of it, then there is a great need for its ambiguity to be addressed, the term more comprehensively and commonly understood and plainly defined. 


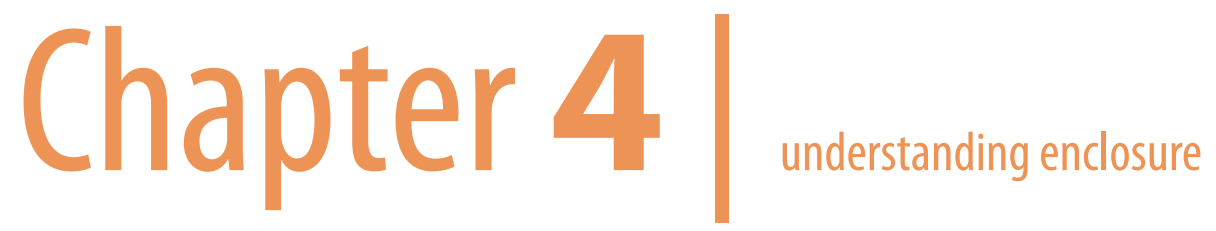




\section{1 |WHAT IS ENCLOSURE?}

As Spreiregen suggests, enclosure is a fundamental requirement of urban space (Spreiregen \& American Institute of Architects., 1981, p. 75) and something which many traditional cities have but modern ones more frequently lack. As Prince Charles wrote in his book 'A vision of Britain', "One of the greatest pleasures of architecture is the feeling of well-designed enclosure." ((Prince of Wales), 1989, p. 87) By this he means that enclosure is not always a good thing. This is because there are varying degrees of enclosure, and depending on this degree, not all enclosed spaces comfort the pedestrian and are therefore not successful.

Spatial enclosure can be seen as the three-dimensional definition of space. In creating enclosure, it is usually "... buildings that are the defining elements, sometimes walls, sometimes trees, sometimes trees and walls together, always the floor." (Jacobs, 1995, p. 277) These elements provide the spatial definition crucial to creating great streets (1995, p. 277), through both vertical and horizontal configuration (Thadani, Krier, \& Duany, 2010, p. 239). It is from this configuration that our normal frontal field of view can determine the degree of enclosure (Spreiregen \& American Institute of Architects., 1981, p. 75) and therefore the success of the enclosed space. Besides vertical and horizontal definition Jacobs believes, "There is, as well, definition that may occur at the ends of a street, which is both vertical and horizontal." (Jacobs, 1995, p. 277)

\subsection{1| Vertical Enclosure}

The vertical nature of enclosure is often addressed by comparing the height of the buildings with the width of the street (or perpendicular dimension of adjacent space). 
The use of correct proportioning between these two dimensions is a way to avoid creating spaces that are overwhelmed by tall buildings or too exposed by short buildings. However vertical enclosure must be horizontally continuous to have any profound effect and is therefore somewhat interdependent with horizontal enclosure. Even drastic changes in cornice line can diminish the degree of collective vertical enclosure (Spreiregen \& American Institute of Architects., 1981, p. 75) . It is generally accepted that the taller a building is in relation to its adjacent street or square, the more vertical enclosure the space will have, and vice versa. It is common in today's Central Business Districts and central areas for buildings to well exceed the adjacent street width, resulting in a very strong degree of vertical enclosure. Although the arguments for constructing such large buildings can be convincingly negated, "...the power and greed of major developers, and our tolerance of vertical reach, have yet to subside appreciably." (Kostof, 1999a, p. 312)

\subsubsection{Horizontal Enclosure}

The horizontal nature of enclosure is defined by the spacing between the enclosing elements. It is lessened when spaces between the enclosing elements are too large or too frequent ((Prince of Wales), 1989, p. 87; Bentley, 1985, p. 54; Spreiregen \& American Institute of Architects., 1981, p. 75). This dissolves spatial definition and allows the eye to wander unsure of spatial order. Frontage, or the building line in relation to the street line is therefore at the crux of horizontal enclosure because it is responsible for defining the public realm (Talen, 2009, p. 151). "When the two are congruent, the structure of the public space is unequivocal. As abutting buildings arbitrarily push back from the street line or protrude beyond it, an ambivalent spatial zone is created along the street channel which blurs its structure." (Kostof, 1999b, p. 
always distinguishing between public and private responsibilities for the public and private realms." (Talen, 2009, p. 151) For this distinction to occur, "streets and squares must be considered in three dimensions, as volumes." (Kostof, 1999a, p. 84) . However the shaping of positive space in this fashion has for long and frequently been illconsidered in contemporary cities because it is not conducive to vehicular travel (Gehl, 2010, pp. 43,44), and the design of stand-alone building has become common practice (Canniffe, 2006, p. 147) . For this reason horizontal enclosure is largely absent in today's urban environments.

\subsubsection{Successful Enclosure}

Now that the main properties of enclosed space have been identified, it is appropriate to address what makes, as Prince Charles calls it, well-designed enclosure. This successfully designed enclosure can be said to provide three main qualities important to a positive experience of the urban environment; a sense of security, place and progression.

\section{i) Security}

Enclosure provides a primal sense of security. As Gehls says, '...edges offer a feeling of organization, comfort and security (Gehl, 2010, p. 75) . This is largely because "Our backs are protected when we sit along the edge and good views of the space is in offer." $(2010$, pp. 75,76$)$ not only from potential dangers that we cannot see, but also from wind and other unpleasant natural elements. Having a defined edge, creates comfort within the space and around the space, and for this very reason, "If the edge fails, then the space never becomes lively." (Alexander, Ishikawa, \& Silverstein, 1977, p. 600) Despite the knowledge that it is generally accepted that "... people feel comfortable in a space that is at least partly enclosed, Alexander et al. (1977, pp. 520-1) 
noted this is not always true: for example people feel comfortable on an open beach. Nevertheless, in smaller outdoor spaces - gardens, parks, walks, plazas - enclosure seems to create a feeling of security." (Carmona, 2003, p. 139)

ii| Place

The idea of enclosure is linked to urban design as creating a sense of place, and position. As Gordon Cullen says, "Man-made enclosure, if only the simplest kind, divides the environments into HERE and THERE." (Cullen, 1995, p. 183) At the most basic level, the 'here and there' that Cullen talks about is the ability to distinguish your location from another, it is the definition of a space, but can involve a more intimate connection, the association with possession (1995, p. 21) and community ((Prince of Wales), 1989, p. 87) are concepts also closely linked with comfort and a sense of security. The importance of enclosure as a place-making principle is reinforced by Dhiru Thadani who states that "Enclosure is a physical attribute of thoroughfares and spaces that contributes to the establishment of a public realm and creates a sense of place." (Thadani et al., 2010, p. 239) He continues to explain that,

"A sense of place is a highly desirable attribute that is found in traditional urban fabric. The successful creation of a sense of place is supported by the judicious assemblage of interdependent elements, including the public streetscape, building type and use, and building frontage. The underlying goal of urban design is to conceive a sense of place for a given site." (2010, p. 239)

\section{iii | Progression}

Perhaps one of the most important qualities of enclosure is its ability to signal progression. Gordon Cullen distinguishes this quality as 'closure'. He describes it as "... the creation of a break in the street which, whilst containing the eye, does not block 
out the sense of progression beyond..." (Cullen, 1995, p. 47) Often found in traditional urban environments where spatial enclosure is common, "... the winding character of the ancient streets kept sealing off perspective views in them while offering the eye a new aspect at each succeeding turn." (G. R. Collins et al., 2006, p. 199) . Carmona refers to this quality as "integrated continuity" (Carmona, 2003, p. 141). This notion is frequently influenced by 'end-enclosure' and sight-lines. Cullen explains in more detail that,

"Closure is effected by some irregularity or asymmetry of layout whereby the path from source to goal is not automatically and inevitably revealed to the eye as in the gridiron plan. This irregularity divides the route into a series of recognizable visual statements, each one effectively and sometimes surprisingly linked to the other, so that progress on foot is rendered interesting.." $(1995$, p. 106)

When the enclosed space is not divided into these manageable chunks, which are often created by curved streets as noted by Leone Battista Alberti (Blumenfeld, 1953, p. 39), and instead reveals its entire length immediately, it is known as the tiring length perspective. Gehl elaborates that, "The 'tiring length perspective' describes the situation in which the pedestrian can see the whole route at a glance before even starting out. The road is straight and seemingly endless, with no promise of interesting experiences along the way. The prospect is tiring before the walk is even begun." (Gehl, 2010, p. 127) This can be particularly punishing if there is no end marker, or 'end enclosure'. This anticipation and sense of discovery is what helps motivate progression, and is inherent to successful spatial enclosure.

Although enclosure is a sought after quality in our urban environments, we must acknowledge that not all degrees of enclosure are desirable. It is believed that the 
comfort and liveability of a street provided by a sense of place, progression and security is what determines the acceptable degree of enclosure and from this, the appropriate absolute and proportional dimensions can then be derived. It can therefore be said that striking the balance, in which enclosure is not too under or overwhelming, lays with understanding human limits and the needs and restrictions required by such.

Hence, the next chapter will address the relationship between human scale and enclosure and why it is thought that human scale will not only naturally produce enclosure but perhaps more importantly a degree enclosure that fosters a sense of place, progression and security. 


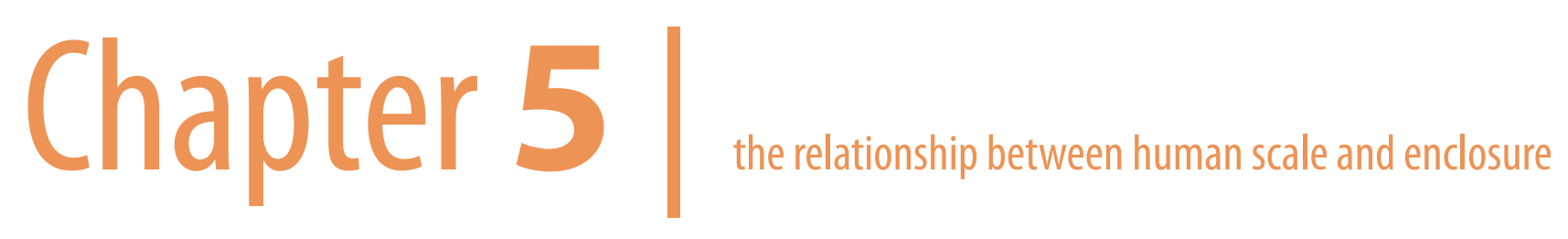




\section{1| SEPARATE CONCEPTS}

Enclosure and human scale are often considered two different urban design qualities as illustrated by Ewing et al. In their work Identifying and Measuring Urban design qualities related to walkability (Ewing, n.d.-a, p. 226). Their definitions clearly do not share any distinct relationship, stating that "Enclosure refers to the degree to which streets and other public spaces are visually defined by buildings, walls, trees, and other elements. Spaces where the height of vertical elements is proportionally related to the width of the space between them have a room-like quality." (Ewing, n.d.-a, p. 226) and "Human scale refers to a size, texture, and articulation of physical elements that match the size and proportions of humans and, equally important, correspond to the speed at which humans walk. Building details, pavement texture, street trees, and street furniture are all physical elements contributing to human scale." (Ewing, n.d.-a, p. 226) Like most definitions for human scale, its narrowness debilitates the ability to recognise potential connections to other design qualities. It is proposed here that although both human scale and enclosure can be treated as two different qualities, there is a distinct relationship between them where it is believed that a comprehensive understanding of human scale could lead to the production of enclosure.

\section{2 |THE IMPORTANCE OF'SCALE'}

The very notion of urban enclosure embodies the literal meaning of scale. Enclosure is largely concerned with comparing sizes; that of building heights with street widths. However, in terms of human scale it can be argued that the size of the human body is not particularly important to enclosing a space (because a space can be enclosed 
regardless of its comfort to a human). This is where a more comprehensive and sophisticated understanding of human scale allows us to extend the meaning of 'scale' beyond the comparison of sizes. From this revised definition we can recognise that the very formation of enclosure may not depend on human stature but it is fundamentally related to human visual limits and perception. This relationship can be clearly seen through some identified human scale characteristics which have been linked to aspects of enclosure.

It is important to note that not all aspects of human scale actively take part in the formation of enclosed space. While some are directly linked to the three-dimensional definition of space, others simply enhance the level of comfort in an enclosed space. The latter are therefore noted as having an indirect relationship to enclosure, as they are not fundamental to its creation but are still paramount in aiding the development of a degree of enclosure that nurtures place, progression and security. A broader understanding of human scale can therefore be said to naturally encourage successfully enclosed space that is comfortable and interesting for the pedestrian; an objective often sought after by contemporary urban design.

Below are the identified aspects of human scale which are thought to show either direct or indirect relationships to enclosure.

\subsection{1|Visual}

\section{Visual Limits (Direct)}

Our field of view places restrictions on the heights of buildings, which have significant value to the degree of vertical enclosure. The height of a building is limited to roughly five stories when human perception is considered. This is largely for two reasons - the 
distance we can clearly see detail, and the upper angle of our field of view. Humans can begin to clearly see detail at around 20-25m which thus determines the height of a building to the cornice line (Alexander et al., 1977, p. 118; Blumenfeld, 1953, pp. 35, 36 ; Gehl, 2010, p. 34), and also defines the maximum street width in order to keep us intimately connected with our surrounds both vertically and horizontally.

The angles of our field of view have not been agreed upon, however, taking Hermann Maerten's study in which man's field of view is said to extend $30^{\circ}$ above the horizon, it can be said that full enclosure exists when the building height to street width ratio equals $1: 1$ or when the cornice line is about $45^{\circ}$ from the viewer's normal eye level $\left(15^{\circ}\right.$ above our upper limit). Maertens states that a ratio of $1: 2$ or $27^{\circ}$ ( $3^{\circ}$ below the upper limit) is the minimum distance for perceiving the facade as a whole (Blumenfeld, 1953, p. 37) . However under this ratio if we maintain a height of $25 \mathrm{~m}$, this will make the street width $50 \mathrm{~m}$ and would put us out of intimate horizontal contact (Gehl, 2010, p. 76).

It is believed that for this reason, not all building fronts were expected to be seen as a whole (Carmona, 2003, p. 139). Only religious or civic buildings of great importance were privileged enough to be given proportionally sized adjacent space (public squares) specifically so that the facade could be seen as a whole. However this does not mean then that the height of ordinary buildings has no relevance to our experience of the building or the space, for it still has great effect our perception of enclosure. Street width and building height should never exceed this distance not only for the reason that it will visually disconnect us but with particular concern for building height, it will severely increase the degree of enclosure.

Typically, buildings far taller than the street width have an oppressive effect. This is because in smaller spaces (narrower streets) our field of vision does not permit us to see the tops of the structure or the sky unless we crane our necks, something which is not natural to us (Gehl, 2010, p. 41) . However, many great streets have higher 
building heights compared to street width (Jacobs, 1995) though that said, building heights are generally less than $30 \mathrm{~m}$ (Jacobs, 1995, p. 281). This street type is typical of traditional cities such as Venice, Rothenburg ob der Tauber or Chefchaouen, yet we perceive these spaces as quaint and intimately beautiful. It is about achieving balance, and limiting street width and building height helps bring us visually and socially closer to more of our surrounds.

\section{Order (Direct)}

The requirement for order is something which can be said to betray a human habitat; its presence is a reflection on how we perceive our environments. However it can be argued that this is not orderliness but that sense of unity which gives the whole its character as specified by Maaløe (Maaløe, 1976, p. 73), an abstraction of our original habitat; nature. As such it could be expected to be found throughout our architecture, its components and the wider urban setting. This order helps establish propriety among building heights, unless there is need to emphasise a hierarchy or importance of a particular structure, which is crucial for a street's collective vertical enclosure. This type of order also requires defined space embodying the 'here and there' that Gordon Cullen discusses in his book Townscape. It does so by promoting continuous building lines ensuring that space contains the eye and prevents it from wandering beyond its boundaries for "...one feels at ease in a space where the gaze cannot be lost in infinity." (G. R. Collins et al., 2006, p. 199) an exception to this is when the eye is purposefully guided beyond the enclosed space to another node offering bearing and progression.

\section{Anthropometry (Direct)}

Although anthropometry is not something needed to create enclosed space, it is something which is useful in creating successful enclosure. Understanding the size 
of a person, or more specifically, the general height from which they view their surroundings is important in resolving the correct degree of enclosure. It also helps one avoid designing spaces that may be too cramped for the number of people it is expected to accommodate at any given time (Gehl, 2010, p. 66).

\section{Craftsmanship and Texture (Indirect)}

Both craftsmanship and texture, like anthropometry, are aspects of human scale which do not create enclosure but offer familiar, intimate and interesting surrounds to an enclosed space. Humans are thought to naturally connect with an object forged by human hand as they are often examples of self-expression (Léon Krier, 1998, p. 201) and intricate detail. Textures are said to connect us to our primal roots, particularly those of natural materials such as stone and timber. Often when a space lacks human scale, in terms of size, such aspects are used superficially in an attempt to make the space appear more human. One important part of enclosure which is often forgotten, but which craftsmanship and texture can make an incredible difference, is the floor. Exquisite paving can help an enclosed space immensely - particularly considering it is the one part of the urban environment with which we are in closest and most frequent contact.

\section{2 .2 | Social}

\section{Social distances (Direct)}

Overlapping with visual limits, social distances are distances which we can recognise and communicate with one another. These are important in creating an intimate, human scale environment. As social creatures it only makes sense to design our urban environments in a way that facilitates and encourages this behaviour. In terms of enclosure, these distances also help determine how wide a street should be, and the 
height of buildings in order to maintain contact with people (Alexander et al., 1977, p. 116; Gehl, 2010, pp. 35, 42), which roughly coincide with that discussed in visual limits. It could be the comfort and liveability of the street which really determines the upper height limits - or the amount of place, progression and security - not necessarily "absolute or proportional height" (Jacobs, 1995, p. 281).

\section{Social Activity (Indirect)}

Providing social activity is not something design can do, however it can encourage it through the quality and intention of design. The existence of social activity is something which can turn a seemingly dangerous, unimportant, or overbearingly enclosed space into something more welcoming and safe.

\subsection{3| Physical}

\section{Walking distances (Direct)}

Firstly walking distances is concerned with distances comfortable for humans to walk, both vertically and horizontally. Both have an effect on enclosure. It is thought the average human can comfortably walk up four to five typical floors, which had obvious implications for building heights until the invention of elevators, however still poses some relevance in terms of safety. In terms of horizontal distances, it is believed that the average human can comfortably walk up to one kilometer, which some say should be the diametrical limit for small towns or neighbourhoods.

Density is also a product of short walking distances, as a result of keeping buildings together to prevent sprawl. Not only does this make a place more vibrant, but also more visually interesting - space becomes valuable and is rarely wasted providing good foundations for both vertical and horizontal enclosure. However it is has its limits - and as some authors believe once these limits need to be exceeded, then a 
new neighbourhood or town needs to be developed in the same compact manor, a method familiar to the Ancient Greeks. It is often argued that they are justified through the need to house, and office the ever increasing population, however it has been noted that far more people lived and worked in similar amounts of space in old city areas (Gehl, 2010, p. 66) despite much lower heights, and they did so quite comfortably. The medieval period for instance, is often thought of having congested, dark narrow streets, but this was more likely an occurrence in the post-medieval era (Kostof, 1999b, p. 207). The main difference was that older cities used space far more efficiently, largely because they had to.

\section{Movement (Direct)}

Our perception has largely evolved based on our movement which is fairly slow and linear. The faster we move (such as in a vehicle) the less information in our surroundings we are able to process and the larger and the further apart building become in order to adapt to this. However at walking speed, buildings have narrower widths, and are closer together to provide pedestrians with a balanced amount of information to absorb in relation to the speed at which their leisurely stride takes them (Gehl, 2010, p. 43). Jan Gehl refers to this as the $3 \mathrm{kph}$ scale versus the $60 \mathrm{kph}$ scale.

It is also thought that pedestrian movement advocates for small, fine grain urban block networks promoting strong permeability to respond to our more agile but slower nature than vehicles. This ultimately helps in determining block lengths of around 90-100m (Ewing, 2009b, p. 4) - a size scarcely exceeded in most human scale traditional cities. It also aids in determining enclosure - too few entrances to a street increases the degree of enclosure, however one must also be aware that too many can reduce the degree of enclosure (Bentley, 1985, p. 54) and lessen the sense of security ((Prince of Wales), 1989, p. 87) and create confusion (Jacobs, 1995, p. 266) 
Again a human scale characteristic which does not create enclosure but which aids it in becoming more successful, is material size. Surfaces that are constructed with materials that can be lifted and worked by man are normally quite small. They are not always determined by the size of our hands, but by their weight, and these restrictions consequently limit the size. This small size not only infers the work of man, but adds to the detail and information that human expect to read in their environments, much to the same effect as texture and craftsmanship. Large flat surfaces, common in today's architecture are chosen for efficiency and cost, however excessive use of these oversized materials can be visually punishing for human experience of the space.

It is noticed that end enclosure is not particularly addressed unless one takes into consideration what Jan Gehl describes as the "tiring length perspective", in which when everything is presented to us at once, we can become tired of journey before it even starts.

\section{3 | CONCLUSION}

Currently, human scale and enclosure are often treated as two completely separate design objectives. However, research shows that enclosure can been linked to human scale design. The relationship that exists is both direct and indirect, with aspects of human scale that consequentially form enclosed space, and others that provide conditions which simply enhance the comfort or degree of enclosure without any impact on the definition of space. The human limits and considerations of both are believed to be partly, if not wholly, responsible for the development of the sense of 
progression, place and security found in successful enclosure. As a result one may conclude that although enclosure can be approached as an independent concept, it can also be considered a consequence of human scale design.

Through graphical analysis and design we shall test the research by applying the knowledge gained to explore whether human scale design naturally produces enclosed space and if so whether that enclosed space is of a degree which could be said to be successful. 


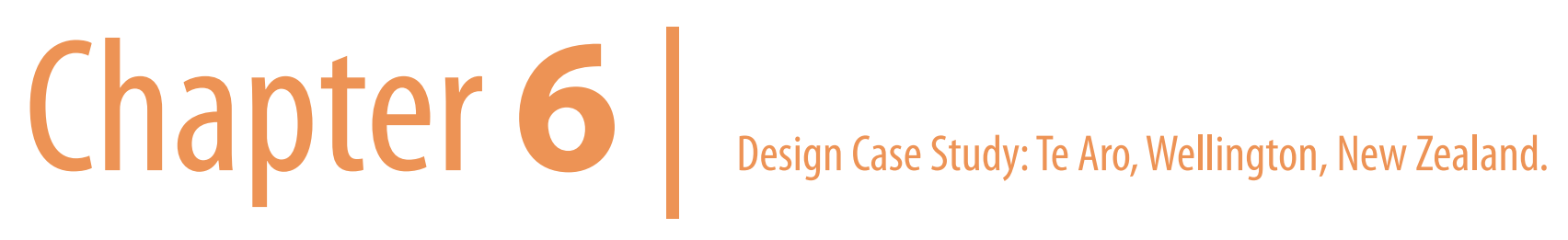




\section{$6.1 \mid$ OVERVIEW}

The pre-design stage intends on using existing analysis of Wellington City found in the Wellington 2040 Framework to identify targeted areas for development. Although analysis and design is primarily based on thesis research, it seeks to align, where possible, with the Wellington 2040 Framework and act as a possible "next phase" development whilst challenging current planning controls that may conflict with human scale design.

Once a site on Taranaki Street with poor enclosure and human scale was selected, common contextual analysis was carried about before site specific analysis more focused on human scale. The three levels of human scale, urban, architecture and detail - have been used as an analytical tool, in which firstly the site is analysed against the defined aspects of human scale, and weaknesses or strengths identified.

A brief has then been developed after considering both Wellington 2040 objectives and thesis objectives.

\subsection{SITE SELECTION}

Currently much of the Te Aro basin area lacks horizontally and vertically enclosed, defined, comfortable public space. Height limits vary considerably and there are many vacant lots, surface parking or'dead'space between buildings which frequently do not create any coherent building line. Most building heights are not proportional to street width or to each other, and nor are they necessarily concerned with human visual perception. Those streets which do have a good sense of enclosure are often bordered by historic buildings, such as Cuba Street and interestingly enough it is 
in these historic areas that maintaining the feeling of enclosure and human scale is encouraged more stringently than in newer developments. Though this does appear to be changing, particularly with the advent of the Wellington 2040 Framework.

The Wellington 2040 Framework is an important new document which focuses on the future urban development of the city. Much of it is centred on Te Aro, and clearly identifies problem areas for targeted development. One such area, is Taranaki Street. Despite being an important city street, it suffers many urban ills. Most noticeably, a lack of enclosure and appropriate scale. However although the street has been recognised as a problem area, as we have discovered, any current approach to its solution may be inadequately informed. It is also likely that many significant elements of human scale will not be employed in its redevelopment because of the nature of current design codes and guides. Although the Framework recognises design problems with Taranaki Street and suggests approaches, this thesis uses the Framework only as reference and challenges it where appropriate to the subject content.

The Framework considers Taranaki Street as perhaps “...Wellington's key urban boulevard, linking the city's southern precincts, Massey University and the War Memorial to the Waterfront, Te Papa and Courtenay Place." (Boffa Miskell, Wellington City Council, \& Randles Straatviet Architects, 2011, p. 44) and from its southern end commands large views to the north over the harbour. However the document also states that over time "...Wellington's spatial structure has become less clear. This is evident throughout many of Wellington's precincts and major streets such as Jervois Quay and Taranaki Street, where contradictions in scale, and uncertain alignments contribute to spatial ambiguity and a sense of being nowhere. (2011, p. 38) The framework identifies uneven height controls for the street as a "...challenge to its boulevard vocation." (2011, p. 69) with buildings ranging from one to fifteen stories. It 
suggests an increase in height on the north-western side to provide referential scale (2011, p. 69) however this may jeopardise the pedestrian experience of the qualities of successful enclosure and human scale. The document however continues to stress the importance of the pedestrian stating that, "To create the boulevard it should be, Taranaki Street needs to be masterplanned with better footpaths, rationalisation of traffic management, new street trees and new built form to provide street activity and mark its key intersections. (2011, p. 44) and that "Taranaki street's boulevard potential relies on pedestrian comfort, ground level uses, and more consistent good quality development." (2011, p. 69)

The issue with streets such as Taranaki is that they are vehicular focused, and this effects the scale and the design of the street in a way that does not take into consideration pedestrian experience. "In effect these streets are merely acting as corridors rather than as spaces where people can be." The Framework's Boulevard Strategy seeks to make streets such as Taranaki more inviting and pedestrian friendly, however, current codes and design guides do not always consider pedestrian experience either. The Wellington 2040 proposes the revision of building and planning controls, creating an opportunity to challenge existing guidelines and rules.

The Framework states, therefore, that the objectives concerning Taranaki Street are to:

- Implement boulevard policy with new built form guidelines and incentives for new developments

- Prioritise pedestrian comfort through comprehensive landscaping, paving and lighting projects

- Target key sites for public and private catalyst projects. (2011, p. 65) 
This thesis, however, cannot address the entire street, but as discussed by the 2040 Framework, the Boulevard Strategy under which Taranaki street falls, suggests it would be delivered incrementally and where potential developments are likely. Therefore one area with potential for further development and lacking in human scale and enclosure is more closely investigated. The site is located along a portion of Taranaki Street between the intersections of Vivian and Ghuznee Streets.

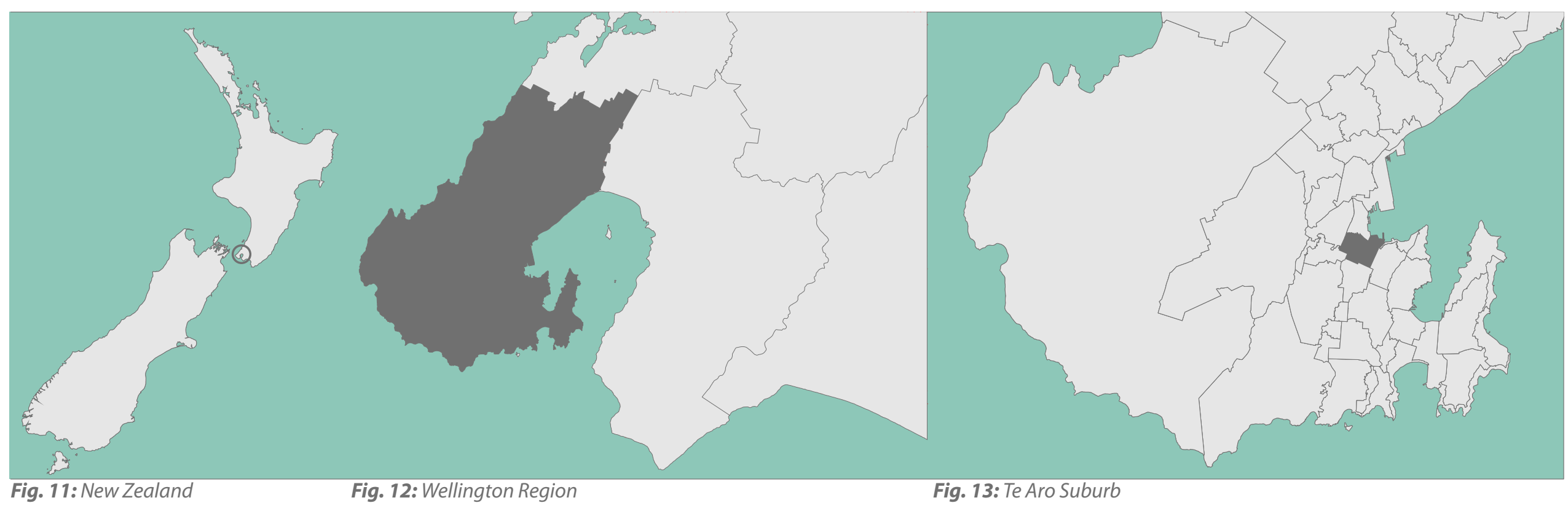



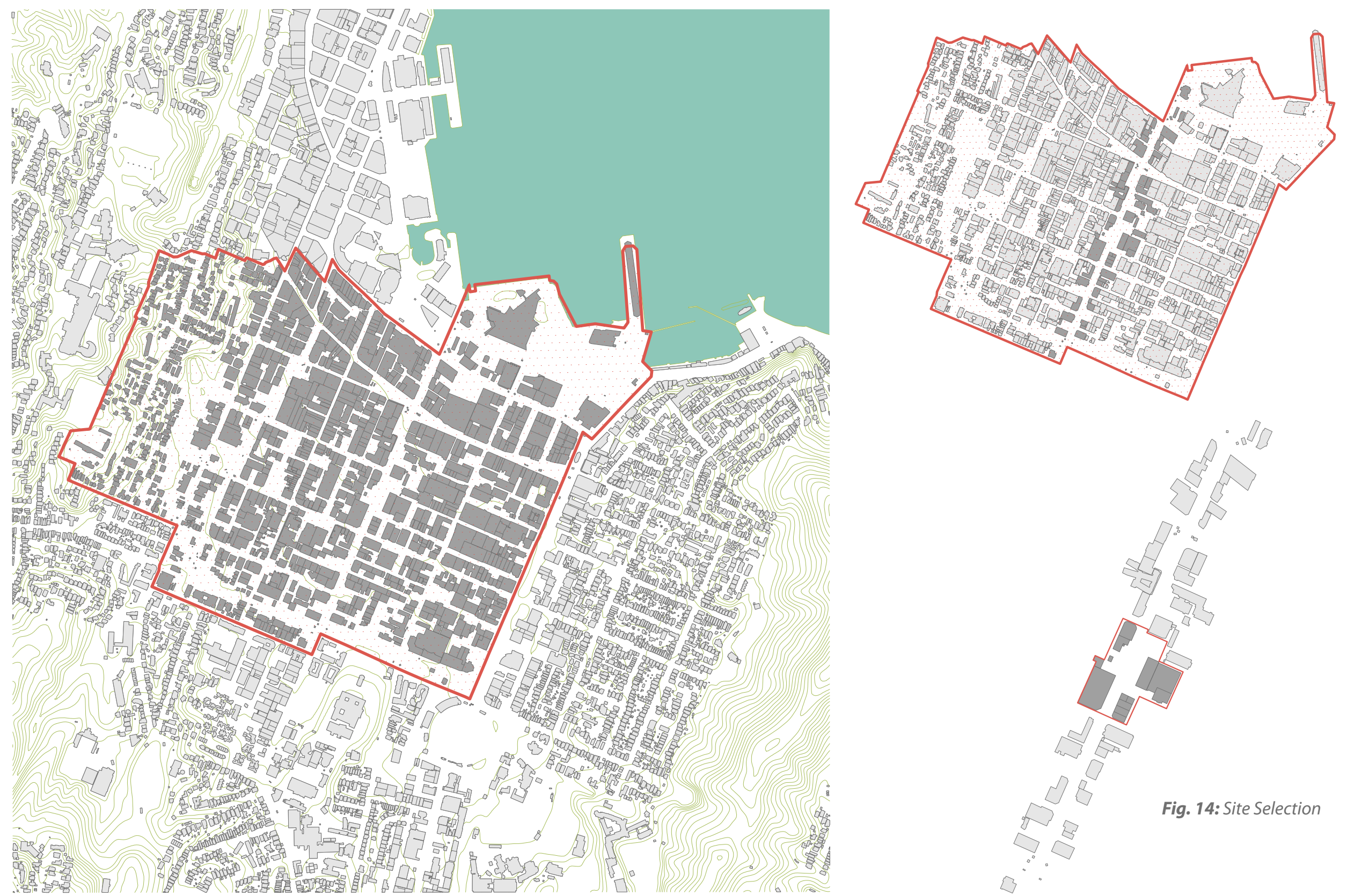


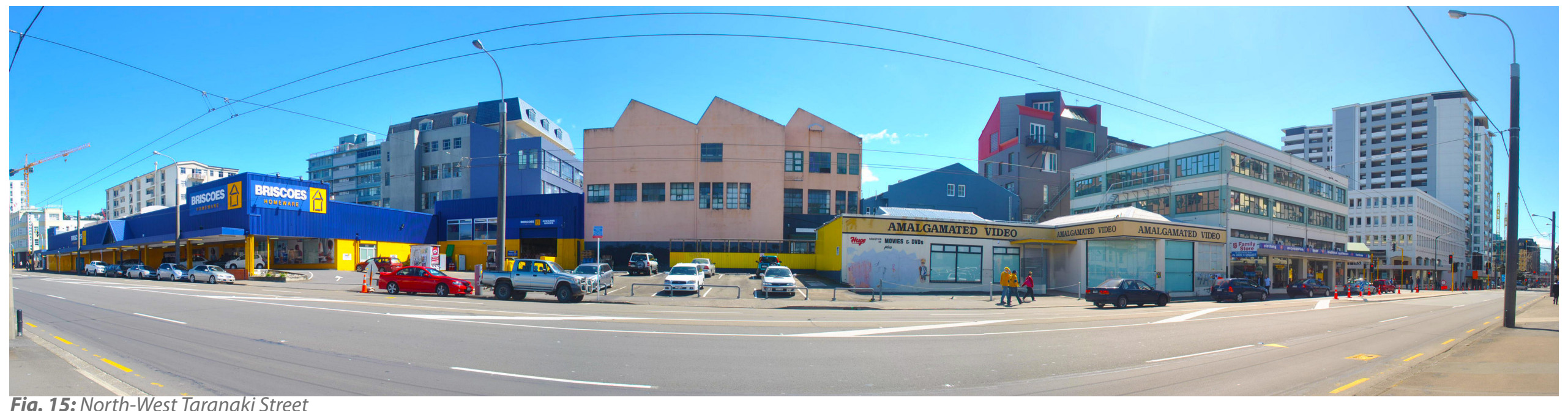

Fig. 15: North-West Taranaki Street

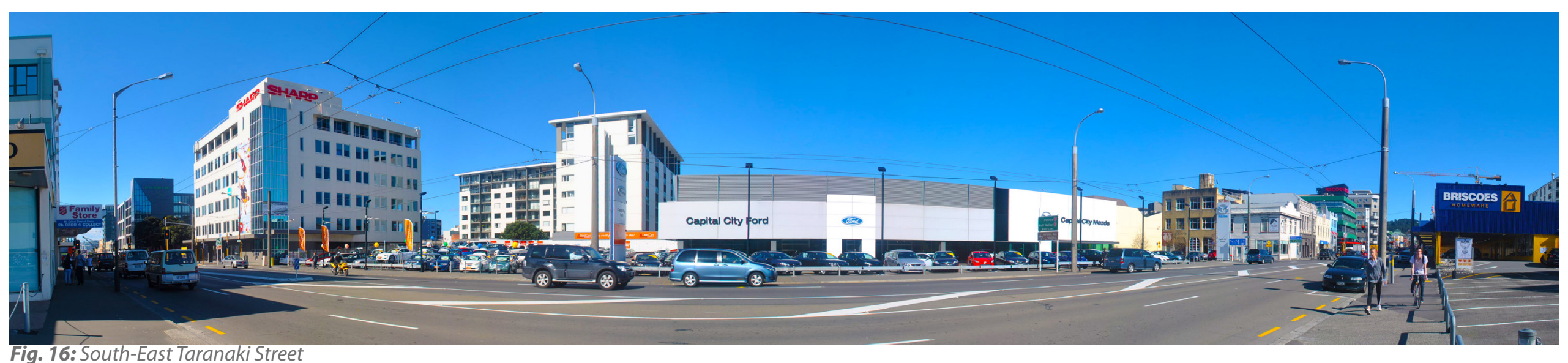




\section{3 | CONTEXT ANALYSIS}

\subsection{1| Context Overview}

The site is located in almost the very centre of Te Aro and contextual analysis concerns anything within a $500 \mathrm{~m}$ radius, the diameter being the equivalent of the maximum comfortable walking distance.

The history of Te Aro is extensive, and the colonial grid still exists almost as it did in 1840 with relatively few drastic changes over the past 170 years. Taranaki Street was widened twice, in the 1920's and 50's, and not only has served as a connection between the southern suburbs and the waterfront, but also is the divisive line between two patterns of planning in central Wellington. On the north-western side of the street blocks run long in the NE and SW direction, but are short in the NW to SE axis. On the southern side of the street, the block dimensions are reversed.

Although the grid can be seen in plan, street definition is particularly lacking throughout Te Aro. Positive space has little to no shape in many areas, and this is indicative of poor horizontal enclosure. Streets with the largest number of historic buildings are most often those that are best defined, such as Courtney Place and Cuba Street.

Most of Te Aro is zoned as mixed use, with relatively low building heights although building height controls encourage a rise towards the CBD in the north-west. Heritage areas, such as Cuba Street and Courtenay Place have specific low height restrictions to maintain the human scale character, and design guidelines are stringent for such areas.

Public transport is left solely to both diesel and trolley buses in Te Aro and their routes frequently follow the busiest streets including Taranaki. Pedestrian activity is

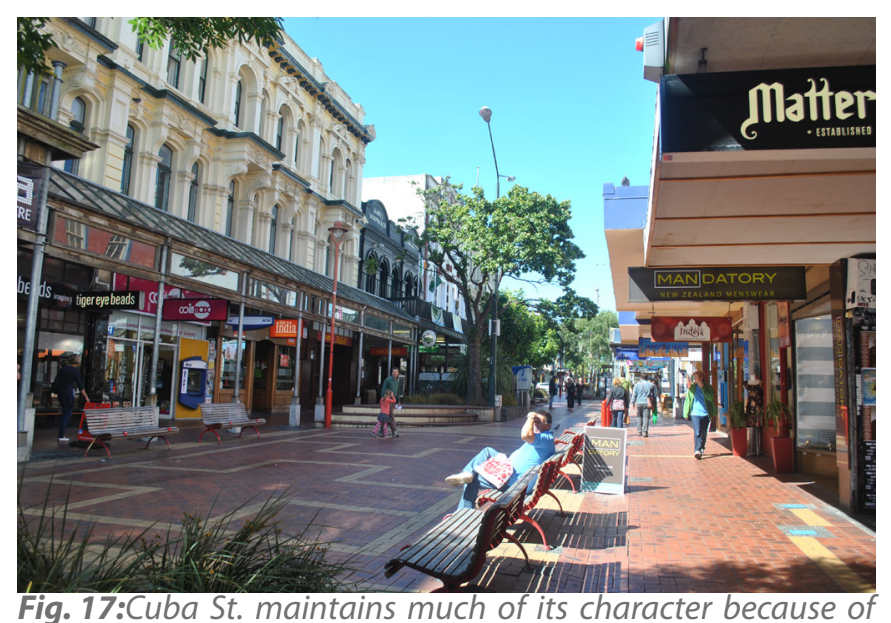
regulation 
largely focused around Cuba Street and Courtenay Place for a number of reasons, including they are more pedestrianised than other streets with limited vehicular traffic. However, most of Te Aro is accessible by vehicle, and even smaller streets can be busy during rush hour. Te Aro is largely designed for vehicles, and has numerous traffic generators, including petrol stations, vast amounts of parking, garages, and car sales yards as well as State Highway 1 which offloads and receives large quantities of vehicles everyday. Taranaki Street crosses both incoming and outgoing State Highway routes in two places, ends at the water front and acts as a collector for the southern suburbs meaning its vehicular traffic can be very intense. This is possibly one reason why there is very little pedestrian activity on the street.

Focusing more on the context of Taranaki Street itself, it is perhaps one of the most poorly defined streets in Te Aro, with no continuous building line and numerous gaps between buildings. With both building height, size and style varying radically there is little that presents the street as a unified space. It is interesting to note the morphology of the street's buildings from many small structures in 1893 to much fewer larger structures today. Building use is another reason for low pedestrian numbers for there are very few building types that generate frequent and lingering pedestrian activity.
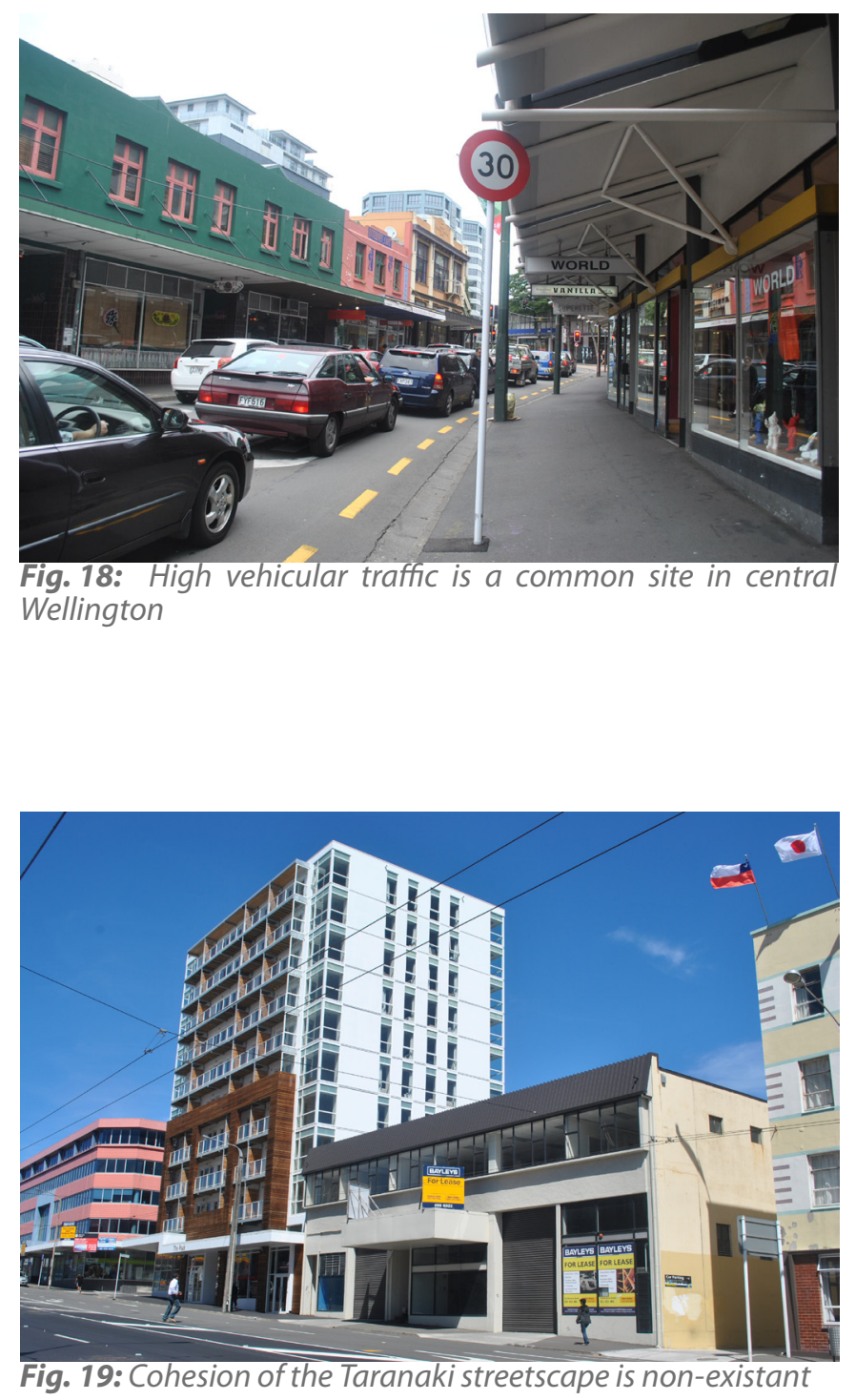
block and street history

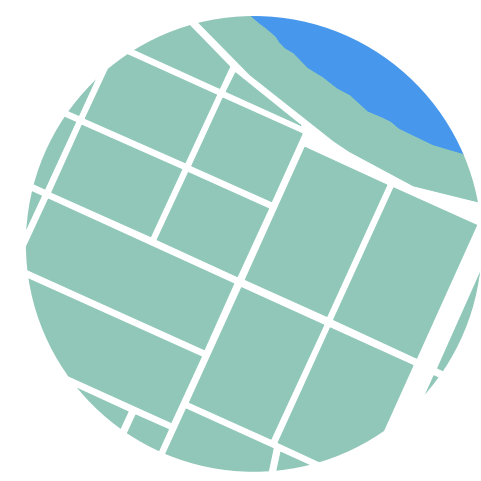

1840

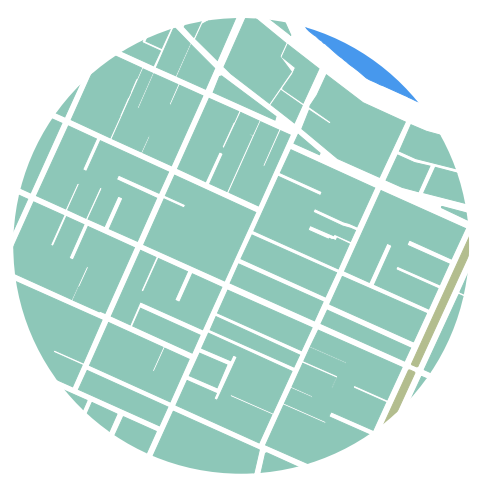

1892

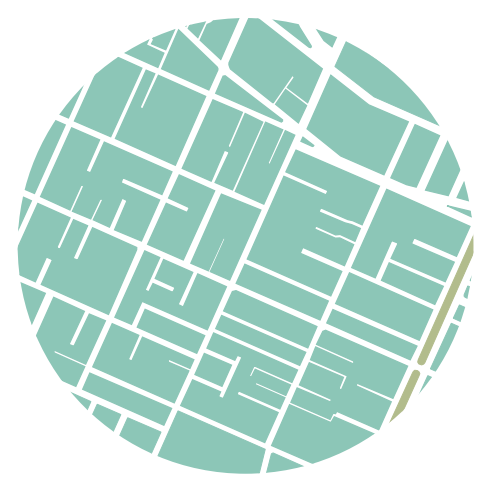

1915

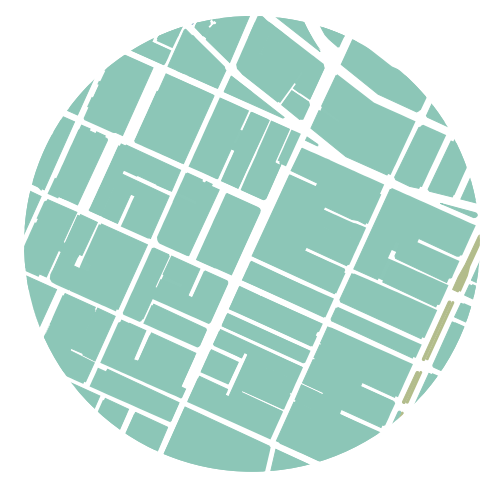

1942

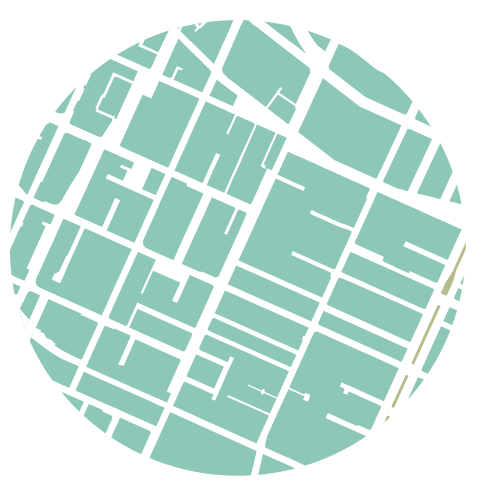

2011 


\section{spacial analysis}

Fig. 20: Figure/Ground

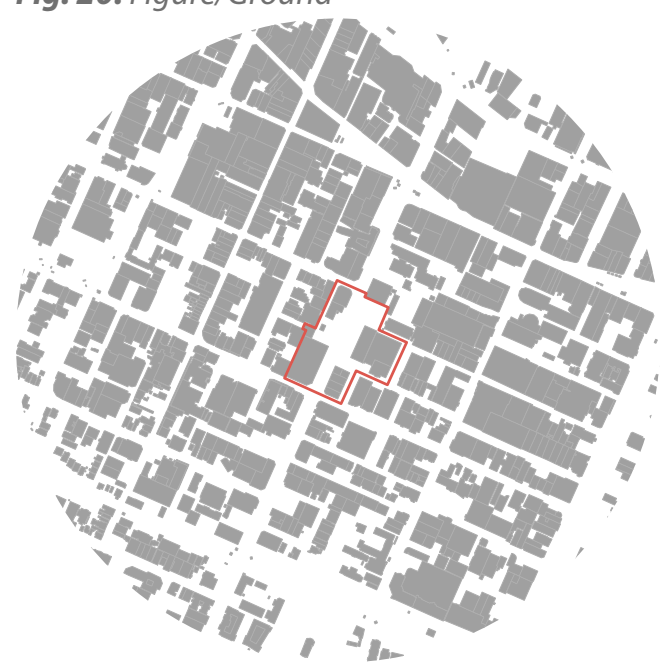

\section{zoning}

Fig. 23: Current height limits

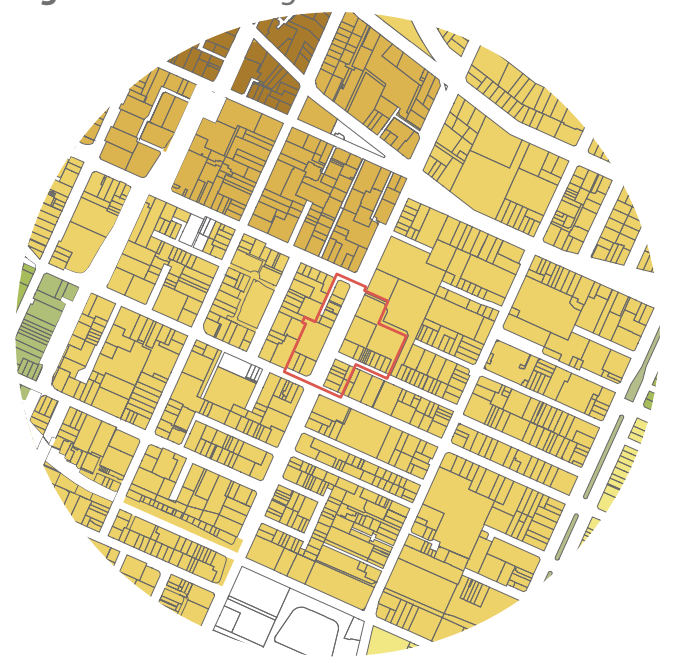

Fig. 21: Inverted Figure/Ground

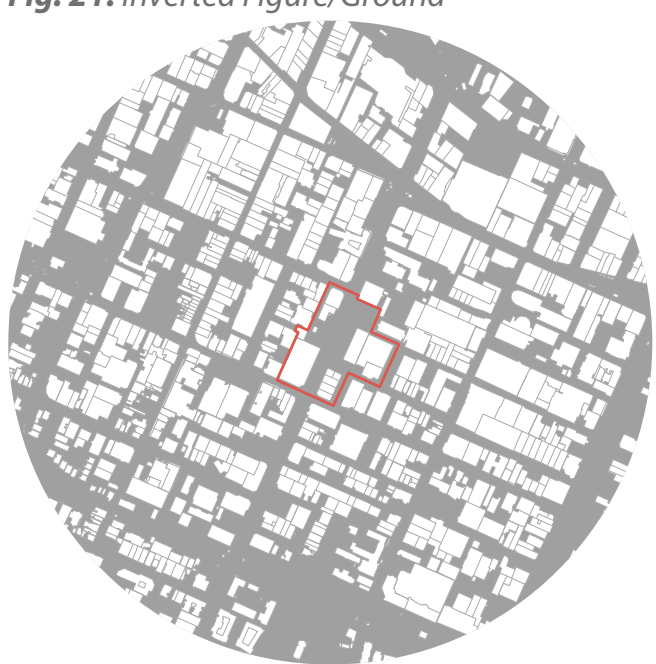

Fig. 24: Protected heritage precincts

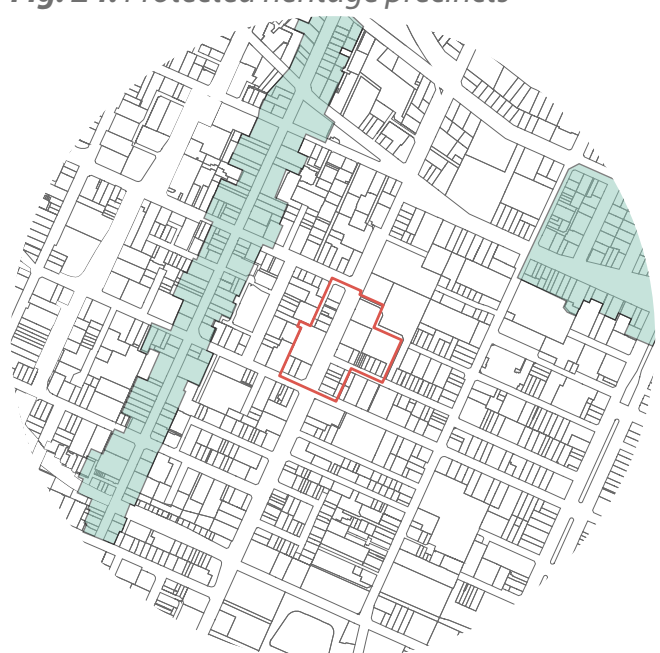

Fig. 22: Designated streets and block outlines

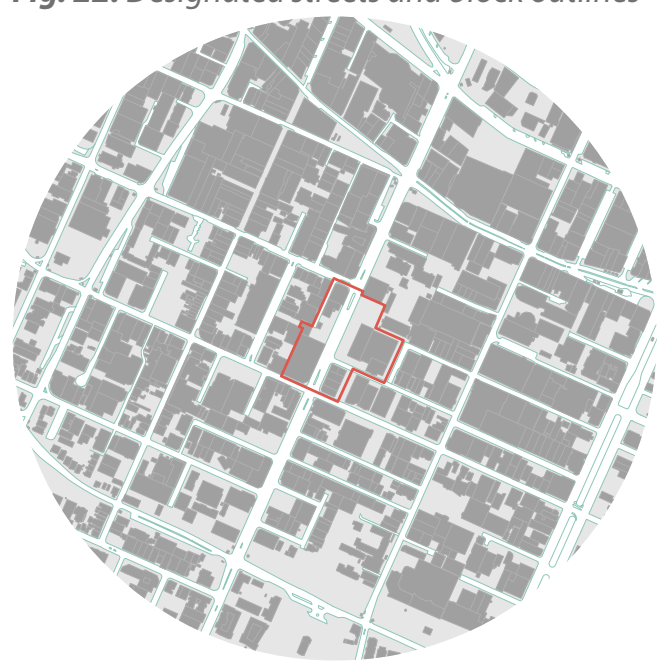

Fig. 25: Heritage Character areas

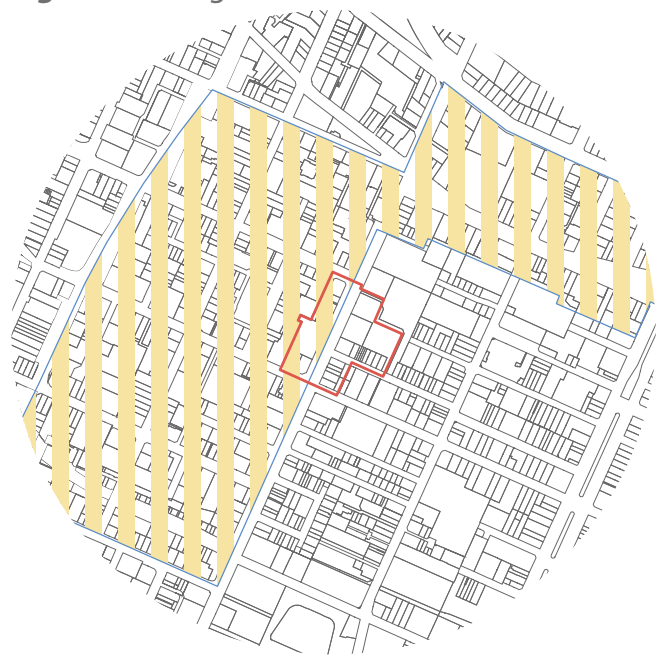




\section{public transport}

\section{Fig. 26: Bus stops}

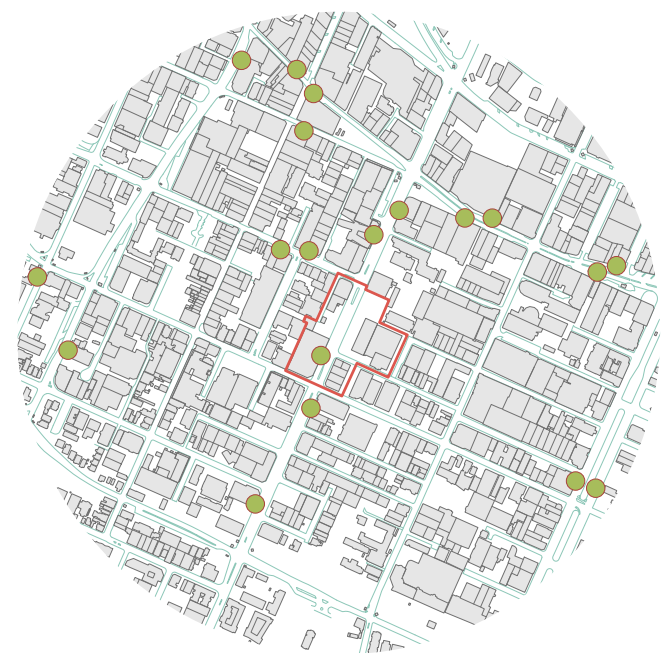

Fig. 27: Bus routes

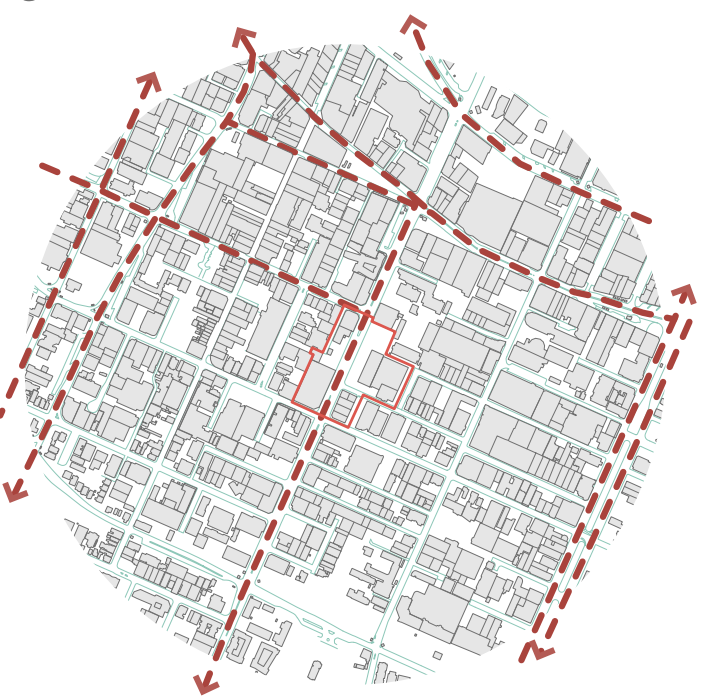

\section{pedestrian circulation}

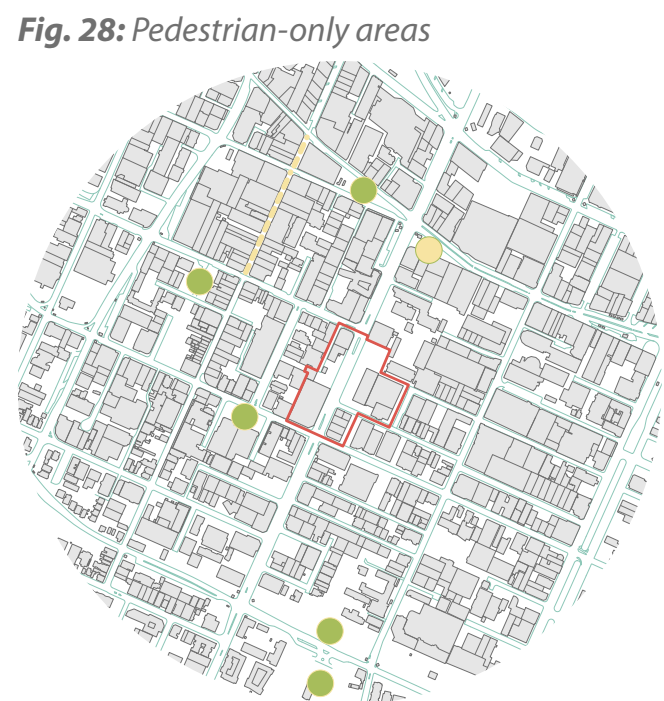

Fig. 29: Main pedestrian thorough-fares

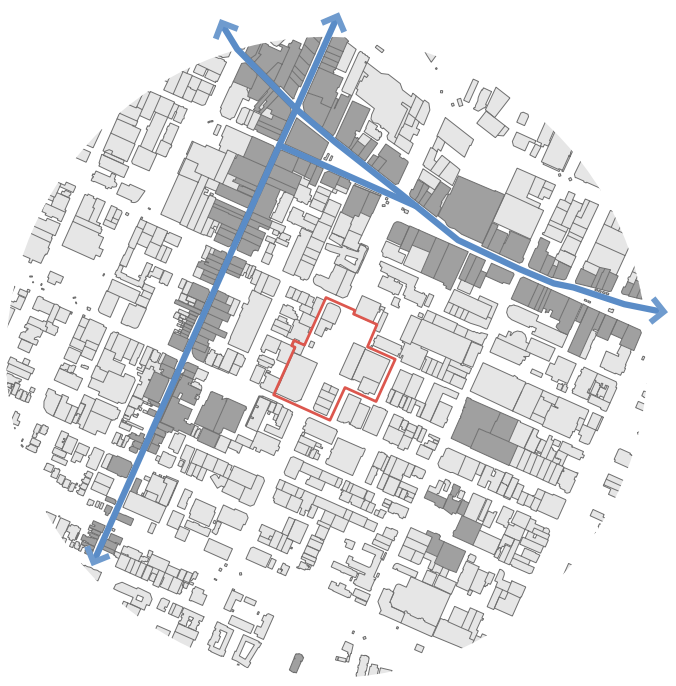

\section{vehicular circulation}

Fig. 30: Traffic generators

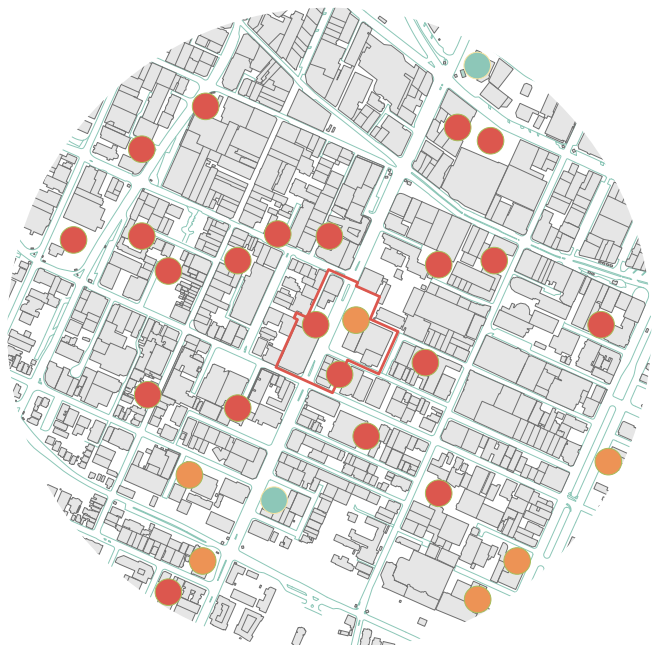

Fig. 31: Main vehicle thoroughfares

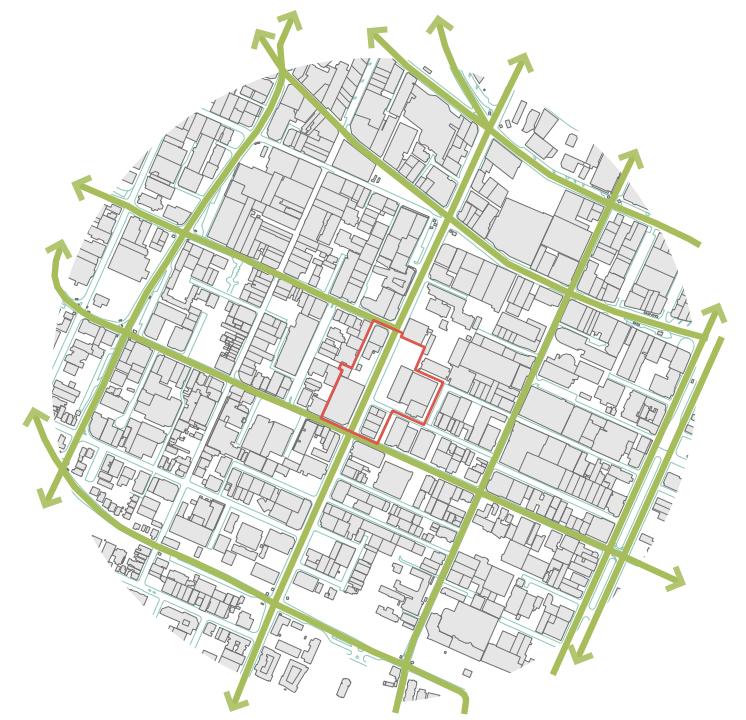


figure ground

Fig. 32: Figure/Ground

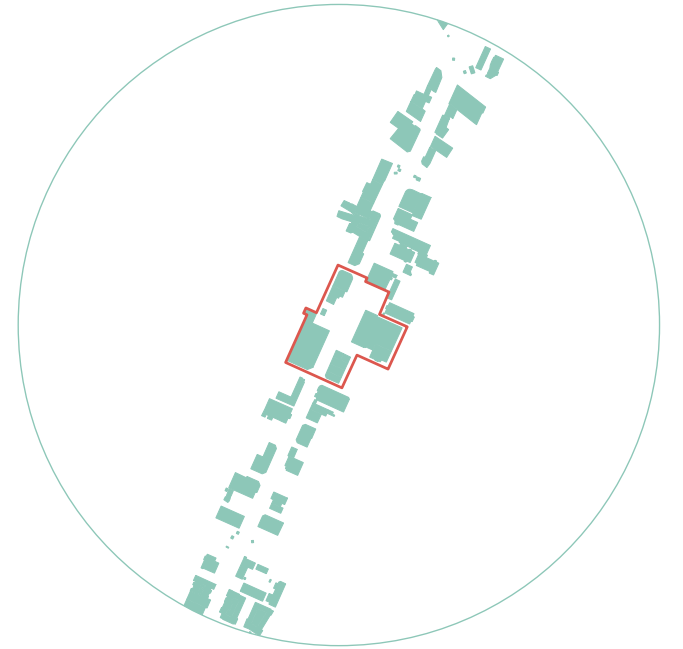

Fig. 33: Inverted figure/ground

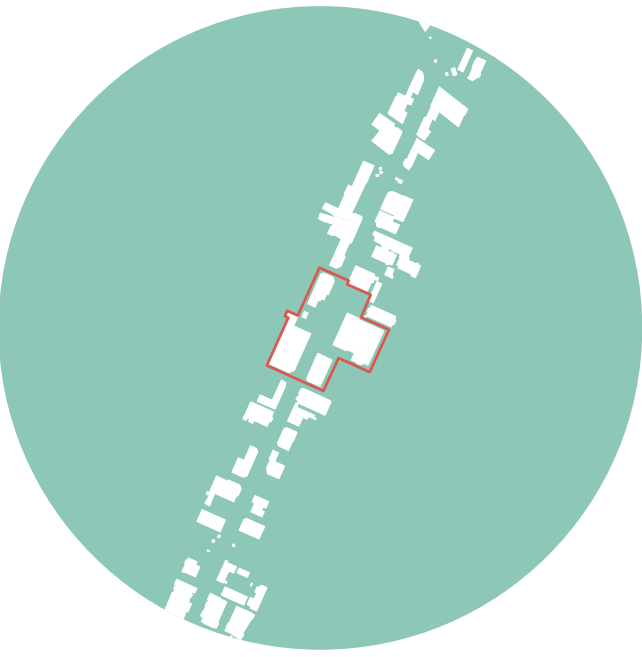

\section{street boundaries}

Fig. 34: Street definition

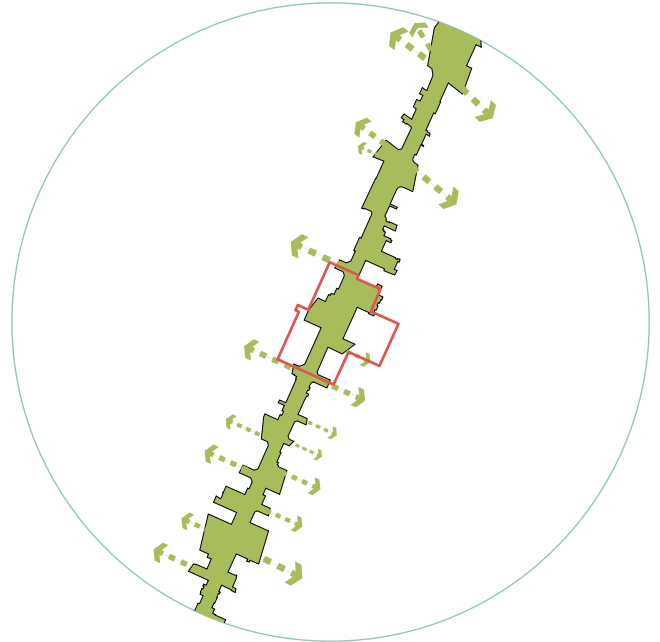

Fig. 35: Official road definition

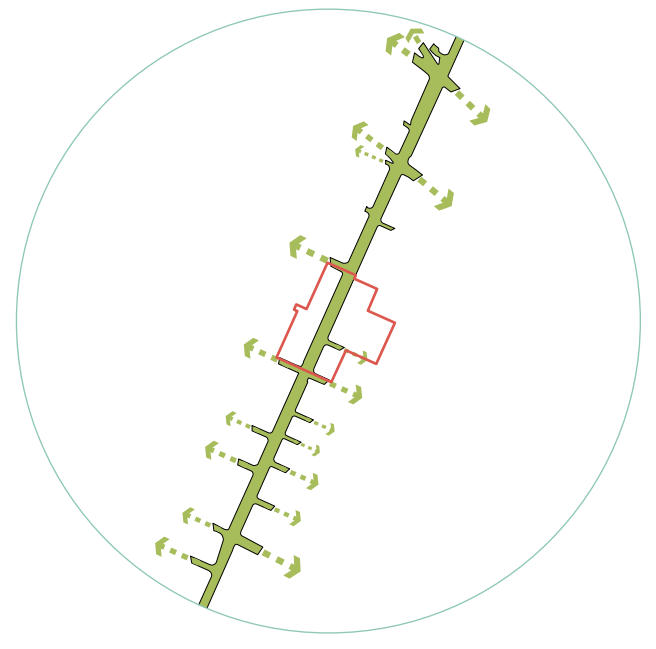

\section{building morphology}

Fig. 36: Building footprints 1893

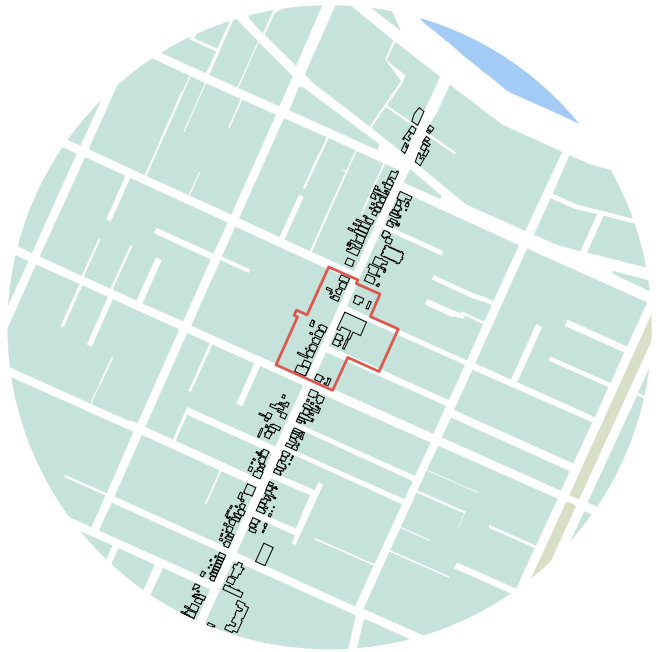

Fig. 37: Building footprints 2012

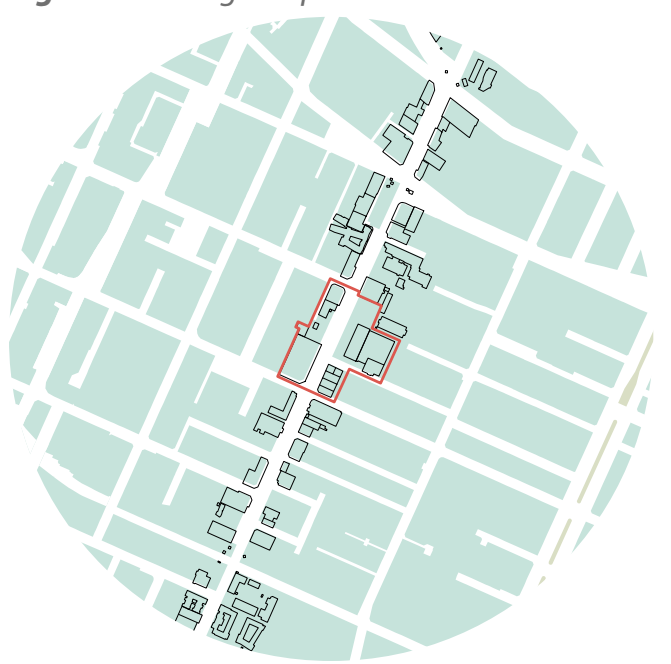




\section{building characteristics}

Fig. 38: Building heights

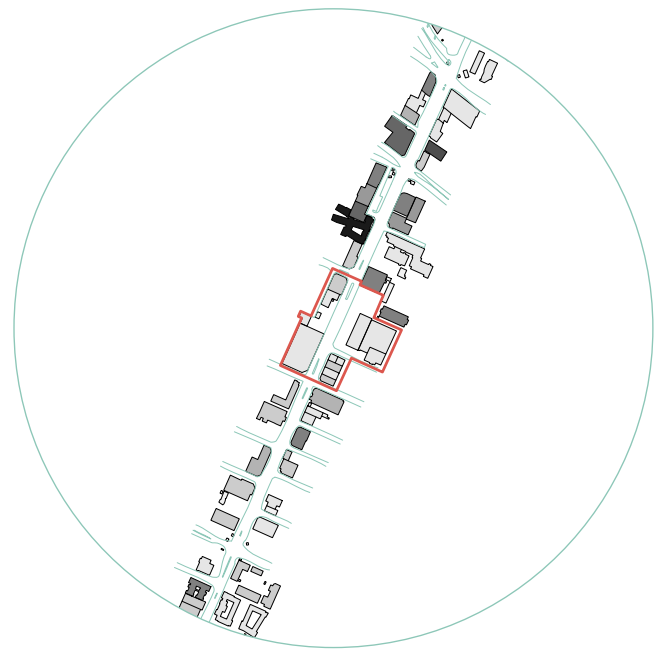

Fig. 39: Building use

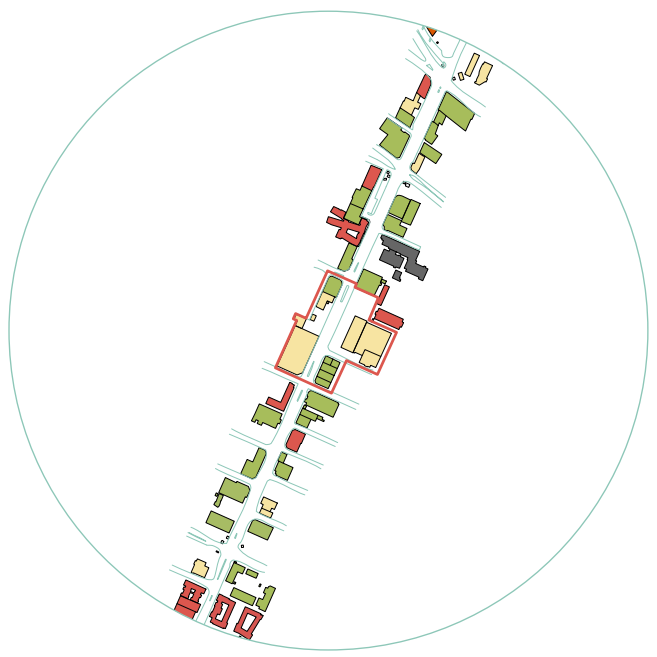

northern elevation

Fig. 40: Building height consistency

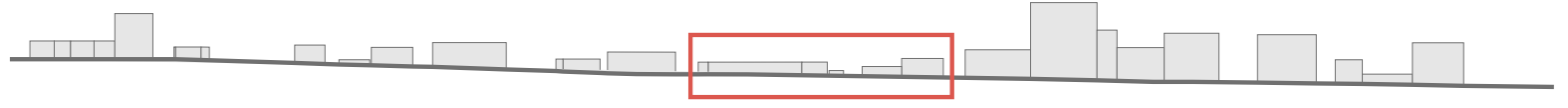

Fig. 41: Building height consistency

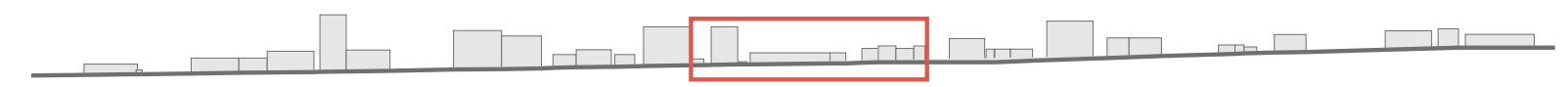




\section{4 | EXISTING SITE ANALYSIS}

\subsection{1| Urban}

\section{Block sizes and connectivity}

Because Taranaki Street is situated between two different patterns of grid planning its sides are not particularly symmetrical like that found in Cuba or Vivian Streets. This is particularly obvious within the site, as there are no four-way intersections. Current block lengths parallel to the site are roughly 50m (SE block), 170m (the NW block) and the NE block continues unbroken for another $290 \mathrm{~m}$ (190m past site boundary) excluding York street which is a dead end. Currently there are only three entrances and exits to the site via vehicle and two more unofficial pedestrian connections.

\section{Street widths and lengths}

Currently, the width of Taranaki Street within the site boundaries is roughly $20 \mathrm{~m}$, and just over $26 \mathrm{~m}$ including the sidewalks falling barely within intimate visual range. The street holds two lanes in both directions however at its widest point there are seven lanes including the median strip. If we consider the street as positive space then it just falls short of $70 \mathrm{~m}$ at its widest point. Jessie Street is just under $7 \mathrm{~m}$ wide and $12 \mathrm{~m}$ including the sidewalks.

Taranaki Street, like most of the oldest streets in Te Aro is extensively long, providing monumental views, particularly from its southern end, and better driving conditions, but is not so good at catering to human perception and physical ability. It presents a classic case of Jan Gehl's'tiring length perspective', (РНОTO of tiring length perspective from site) in which the street presents its entire span at a glance, and appears long

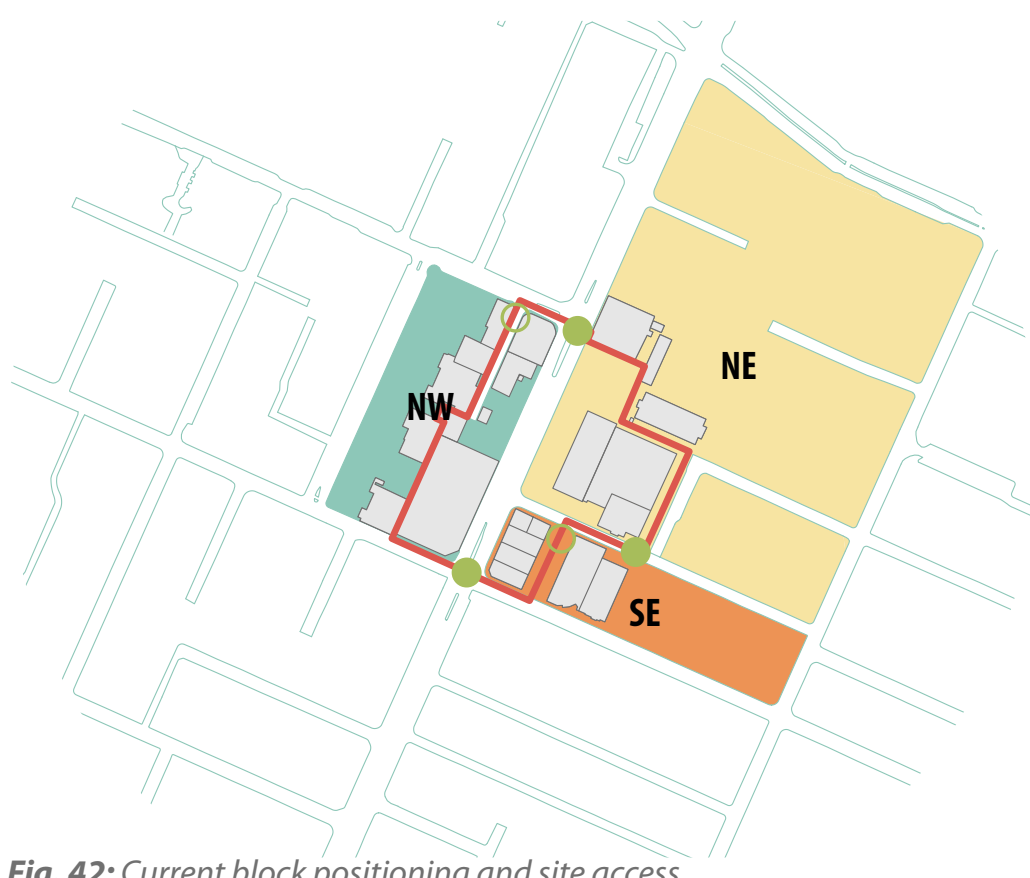

Fig. 42: Current block positioning and site access

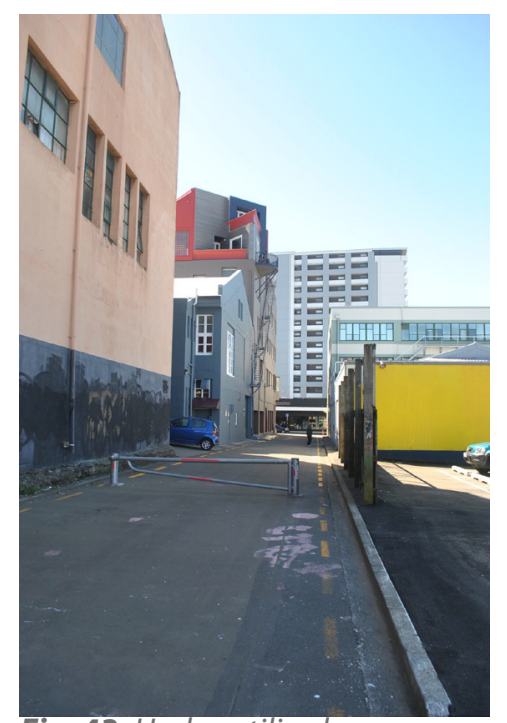

Fig. 43: Under-utilised access 

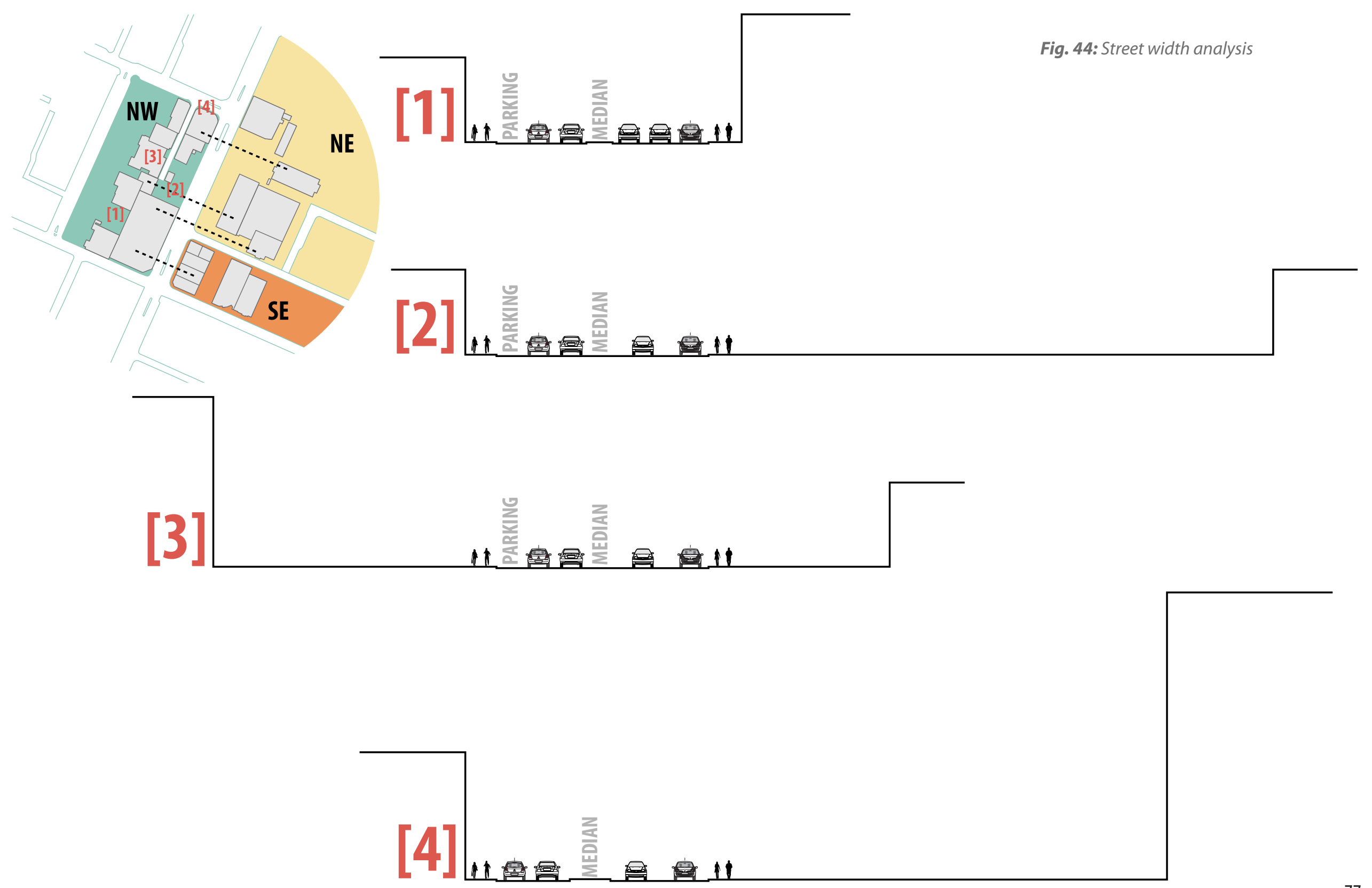
and boring. From within the site, this is the case looking both south and north along the street.

\section{Plot sizes}

Although plots are parallel with the street line some are excessive in size or have been conglomerated. There are also no incentives to build to the front of the plot meaning buildings have not formed a cohesive building line, and are some too large horizontally for pedestrian movement and perception. This being said there do exist smaller plots within the site more suitable for humans.

\section{Outdoor rooms and building use}

Currently there are no places in this site that could be considered a comfortable place to be for pedestrians or building uses that may promote human activity outside.

\subsubsection{Architecture}

\section{Building heights}

As discussed in the previous paragraph building heights are not only important in maintaining good spatial definition, but also in maintaining intimate visual and social connections with as much of the immediate environment as possible. Four to five stories is often the most common number used in outlining the maximum height of a human scale building and with ceiling heights normally between $2.7 \mathrm{~m}$ and $3 \mathrm{~m}$, a five storey building would not be expected to exceed $20 \mathrm{~m}$. This is $5 \mathrm{~m}$ less than our visual limit for detail, and a couple meters less than the maximum distance for brief conversation, providing clearer visual and social connections. Buildings however may be shorter than this, as long as drastic changes in height are avoided.

Within the site boundary, no building exceeds four stories. However although

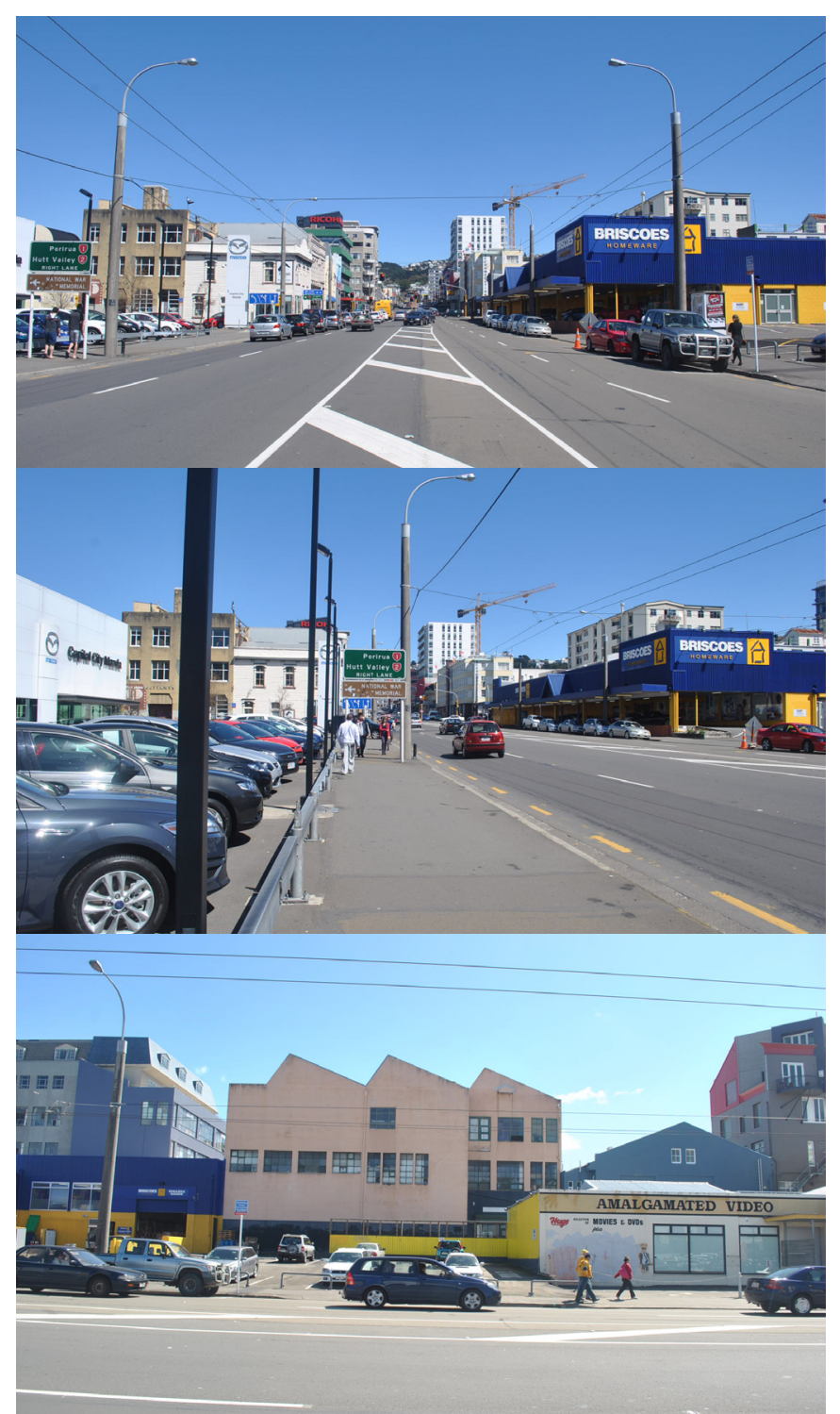

Fig. 45: Current street width is on the verge of being too large Fig. 46: Unattractive and uninviting space

Fig. 47: Drastic changes in building height and roof line 
buildings are not tall, two are very long and broad. The Briscoes building and the Ford showroom do not respond to human perception and can be labeled as typical 'big box' architecture. The official height limit is $27 \mathrm{~m}$, of which some surrounding buildings reach, but this height is believed to be well in excess of human scale. As there is no existing continuous building line, height propriety is not particularly relevant. There is also no relationship between building height and street width.

\section{Continuous Building Line}

Continuous building lines ensure that we are constantly and continuously within a certain visual range of our surroundings, but also helps define space and provide order in our surroundings. Although existing plots have been placed so that their street-side boundary coincides with the street line the buildings have not been built to this, and some plots remain empty. This lack of density along with the setbacks has deteriorated this definition and our visual connection with parts of the site.

\section{Architectural Styles}

The architecture that currently exists in the site share very few common features. A wide variety of colours, materials and styles have been used varying from a timber colonial shop to a contemporary steel and glass showroom.

\subsection{3| Details}

\section{Architectural Components and materials}

Concerning the architectural components of the existing buildings on the site, the older ones between Jessie and Vivian Streets have surfaces broken up into smaller segments which create a hierarchy of scales across the building facades. The newer buildings tend to be more monotonous with larger surfaces, and large jumps in scale

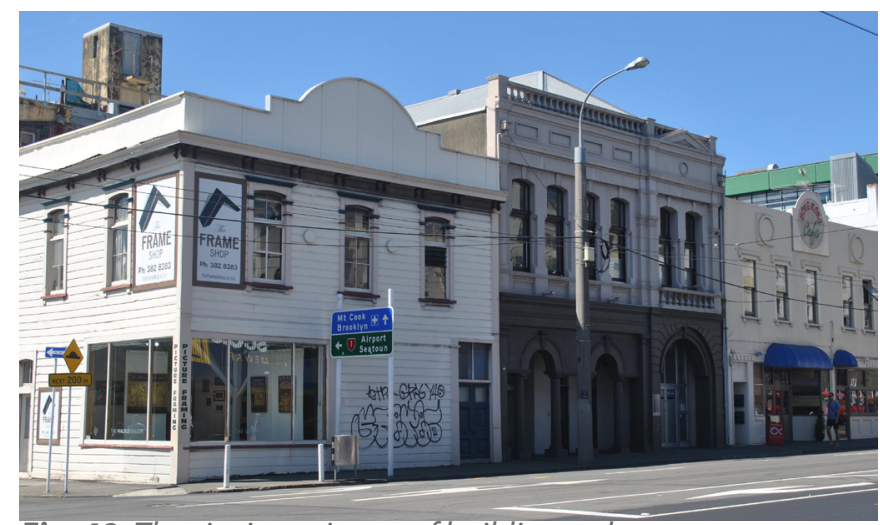

Fig. 48: The site is a mixture of building styles.

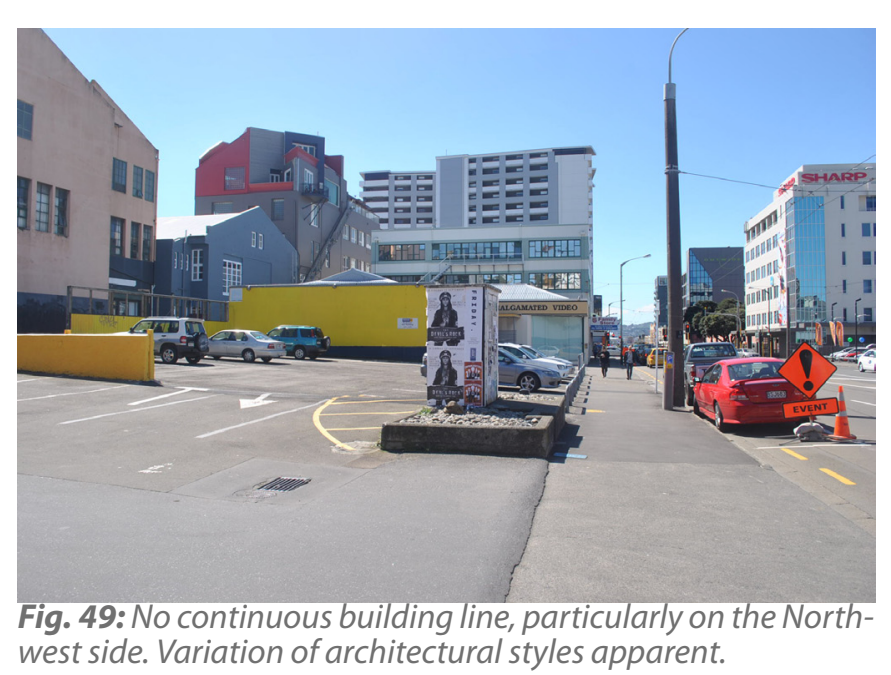

79 
making it difficult to gauge their size.

There is a general mix of material types and size, from concrete blocks to metal paneling, however the most overwhelming may be the asphalt under foot. Because the space is so vast, the asphalt is quite noticeable, more specifically it holds no visual interest.

\section{Craftsmanship}

There is little to no craftsmanship on the surfaces and this is largely due to the types of materials used which are used for their efficiency and cost. Materials such as asphalt and concrete blocks are relatively cheap and quick to install, and do not require any great skill as opposed to patterned paving or brickwork. The architecture in the site also lacks any obvious intricacies in man made ornament.

\section{Texture}

Textures within the site, where they exist, are mostly artificial and do not contribute greatly to the experience of the space. There are some small trees on the northern side of Jessie street which provide some natural relief to the otherwise concrete and asphalt surrounds.

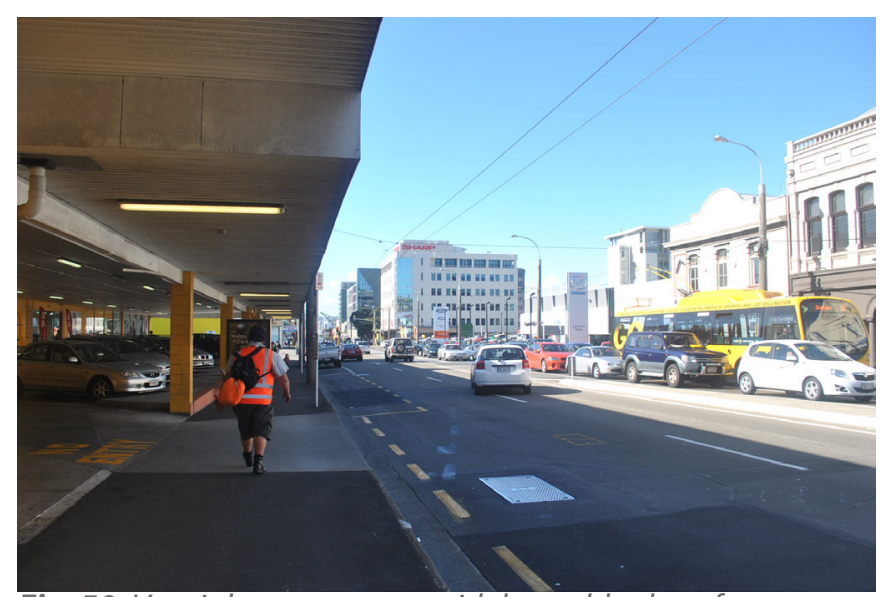

Fig. 50: Very inhuman spaces with large, blank surfaces

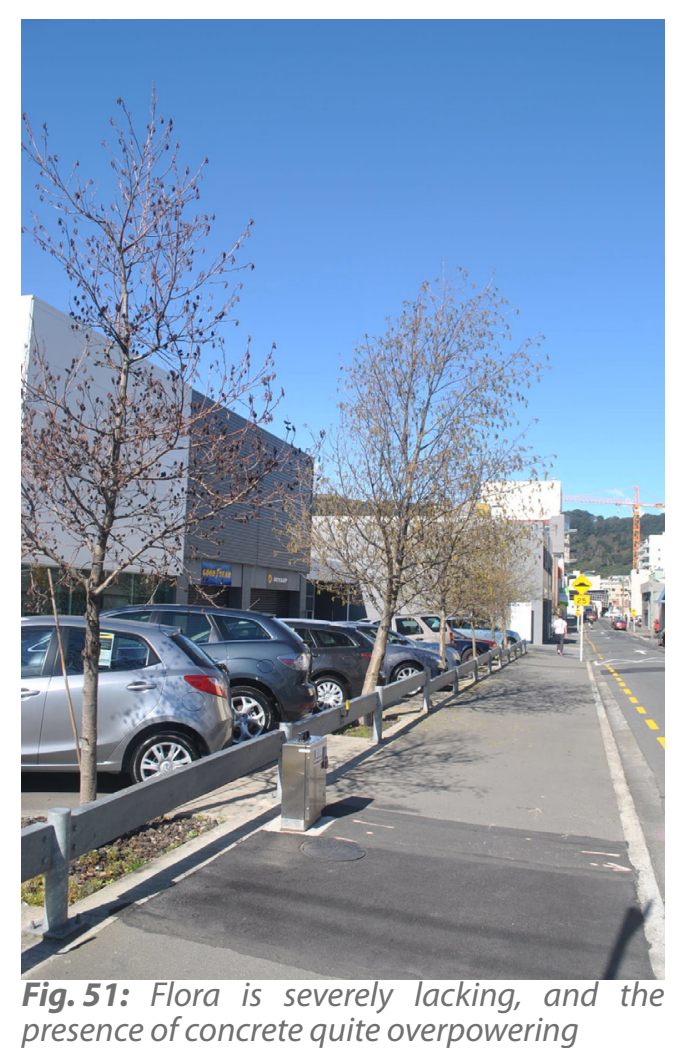




\section{5 | SITE BRIEF}

\begin{tabular}{|c|c|c|c|}
\hline \multirow[t]{2}{*}{ Design Objectives } & \multicolumn{2}{|c|}{ Aspects of Human scale which influence Enclosure } & \multirow[t]{2}{*}{ WCC Objectives } \\
\hline & $\begin{array}{l}\text { Direct Relationship to } \\
\text { enclosure }\end{array}$ & Indirect Relationship to enclosure & \\
\hline Smaller blocks and more connections & $\begin{array}{l}\text { Walking Distances (see 5.2.3) } \\
\text { Movement (see 5.2.3) }\end{array}$ & & $\begin{array}{l}\text { Lane ways to make it more efficient } \\
\text { for pedestrians to move about the } \\
\text { city, reduce size of street blocks }\end{array}$ \\
\hline $\begin{array}{l}\text { Ensure street widths and lengths are reasonable in } \\
\text { comparison to human perception and lengths utilise } \\
\text { sight lines to encourage movement and navigation } \\
\text { and break wind gusts. }\end{array}$ & $\begin{array}{l}\text { Visual Limits (see 5.2.1) } \\
\text { Walking Distances (see 5.2.3) }\end{array}$ & & $\begin{array}{l}\text { Sight lines for better navigation, } \\
\text { reduction of carriageway widths }\end{array}$ \\
\hline Smaller plots sizes & $\begin{array}{l}\text { Movement (see 5.2.3) } \\
\text { Walking Distances (see 5.2.3) }\end{array}$ & & \\
\hline $\begin{array}{l}\text { Develop outdoor space and promote building types } \\
\text { that can foster street activity }\end{array}$ & & $\begin{array}{l}\text { Craftsmanship and Texture (see 5.2.1) } \\
\text { Social Activity (see 5.2.2) }\end{array}$ & $\begin{array}{l}\text { Mixed-use, promote areas of interest, } \\
\text { reduction of vehicular dominance }\end{array}$ \\
\hline Appropriate building heights & $\begin{array}{l}\text { Social Distances (see 5.2.2) } \\
\text { Visual Limits (see 5.2.1) } \\
\text { Walking Distances (see 5.2.3) } \\
\end{array}$ & & $\begin{array}{l}\text { Greater access to natural light and } \\
\text { ventilation }\end{array}$ \\
\hline Propriety among architecture & Order (see 5.2.1) & & $\begin{array}{l}\text { Buildings designed with landscape } \\
\text { streetscape and neighbours in mind }\end{array}$ \\
\hline Continuous building line & Order (see 5.2.1) & & $\begin{array}{l}\text { Align footpaths, building lines and } \\
\text { street lines, improve density, reduce } \\
\text { surface parking }\end{array}$ \\
\hline $\begin{array}{l}\text { Hierarchical building components and materials } \\
\text { without overuse of large materials. }\end{array}$ & $\begin{array}{l}\text { Order (see 5.2.1) } \\
\text { Anthropometry (see 5.2.1) }\end{array}$ & & \\
\hline Craftsmanship & Visual Limits (see 5.2.1) & $\begin{array}{l}\text { Craftsmanship and Texture (see 5.2.1) } \\
\text { Material Size (see 5.2.3) }\end{array}$ & promote areas of interest \\
\hline $\begin{array}{l}\text { Deliberate use of textures which help add to the visual } \\
\text { interest and experience of the space. }\end{array}$ & Visual Limits (see 5.2.1) & $\begin{array}{l}\text { Craftsmanship and Texture (see 5.2.1) } \\
\text { Material Size (see 5.2.3) }\end{array}$ & promote areas of interest \\
\hline & & & $\begin{array}{l}\text { Increase amount of crossings along } \\
\text { major boulevards }\end{array}$ \\
\hline
\end{tabular}




\section{6 | EVALUATION CRITERIA}

It must be remembered that the intention is not to deliberately design enclosure, therefore the design brief does not target enclosure-specific objectives. The aim is to produce a human scale design to test whether enclosure is a by-product, validating the relationship between the two concepts. With this established, the identified human scale aspects have been used to define human scale-specific objectives, whilst at the same time noting their significance to any consequential formation of enclosure. As such in evaluating the final design, firstly it must be looked at how well the design addresses the human scale objectives, and secondly whether enclosure has occurred and if it can be deemed successful enclosure.

The three qualities found in successful enclosure as previously identified, place, progression and safety, will be used to evaluate the success of enclosure if it is formed. It is however understood that under ideal circumstances, true success would only be able to be judged through a post-occupancy evaluation perhaps six to twelve months after to gauge the inhabitants response. Although the evaluation may be considered superficial due to its theoretical rather than practical application, it still gives a reliable overview particularly in terms of where current practice may need to be re-evaluated. 
Chapter $\left.\mathbf{7}\right|_{\text {atromes }}$ 


\section{$7.1 \mid$ OVERVIEW}

This chapter outlines the redevelopment and design process of 'humanising' a segment of a central city boulevard. It explores and tests how designing with a more sophisticated understanding of human scale effectively creates successful enclosed space, which would warrant a re-evaluation of the concept's role in the design of cities. In terms of scope, only a portion of the site will be addressed in terms of architecture. As this requires much detail, it is only realistically possible to design a small segment of the site, however, a larger site has been chosen to show the impact that the urban aspects of human scale have.

The chapter is broken up into a format that corresponds with the analysis and proposes a solution to the issues outlined in the brief. Firstly it addresses how human scale can be implemented from an urban planning perspective. Secondly it looks at how architectural massing and placement can continue promoting human scale by addressing those buildings which flank Taranaki Street. Thirdly materials, craftsmanship, components and textures are all considered in order to facilitate human perception. As no one 'level' of design is completely independent there will be frequent reflection and consideration given to the overall effect. 


\section{$7.2 \mid$ URBAN}

\section{Block sizes and connectivity}

To create smaller blocks two new pedestrian streets have been proposed. An obvious continuation of Ebor Street as it once was, and a connection through to Marion Street (for the purpose of this thesis we shall call 'Briscoes Street'). This effectively halves the NW block and has the same effect of increasing walkability on the other side of the street within the proposed boundaries. It is proposed that a crossing is situated so that Ebor Street is continued across to the NW block. Not only is this intended to improve connectivity across a busy boulevard in line with the 2040 Framework but also to encourage slower speeds.

\section{Street widths and lengths}

Taranaki Street is just over $26 \mathrm{~m}$ in width and therefore more or less falls within the acceptable human scale limits. It has been identified as a 'key' boulevard and one that accommodates large numbers of vehicle therefore its narrowing is not proposed as this could cause unwanted congestion in other parts of the city. However more space will be devoted to the pedestrian by granting them $4 \mathrm{~m}$ of footpath on either side, allowing them to technically be within $22 \mathrm{~m}$ of the opposite buildings increasing intimacy. The implementation of wider footpaths also lowers the feeling of vehicular dominance and provides a more comfortable experience for pedestrians. Although there is very little on-street car parking currently, $2.5 \mathrm{~m}$ wide parallel car parks are proposed as a way of providing a buffer between a potentially busy and noisy boulevard and slower pedestrians. Four lanes of traffic are maintained with turning lanes where necessary, however their width has been reduced from $3.5+\mathrm{m}$ to $3 \mathrm{~m}$. This is to encourage reduced traffic speeds along with more crossings as proposed by
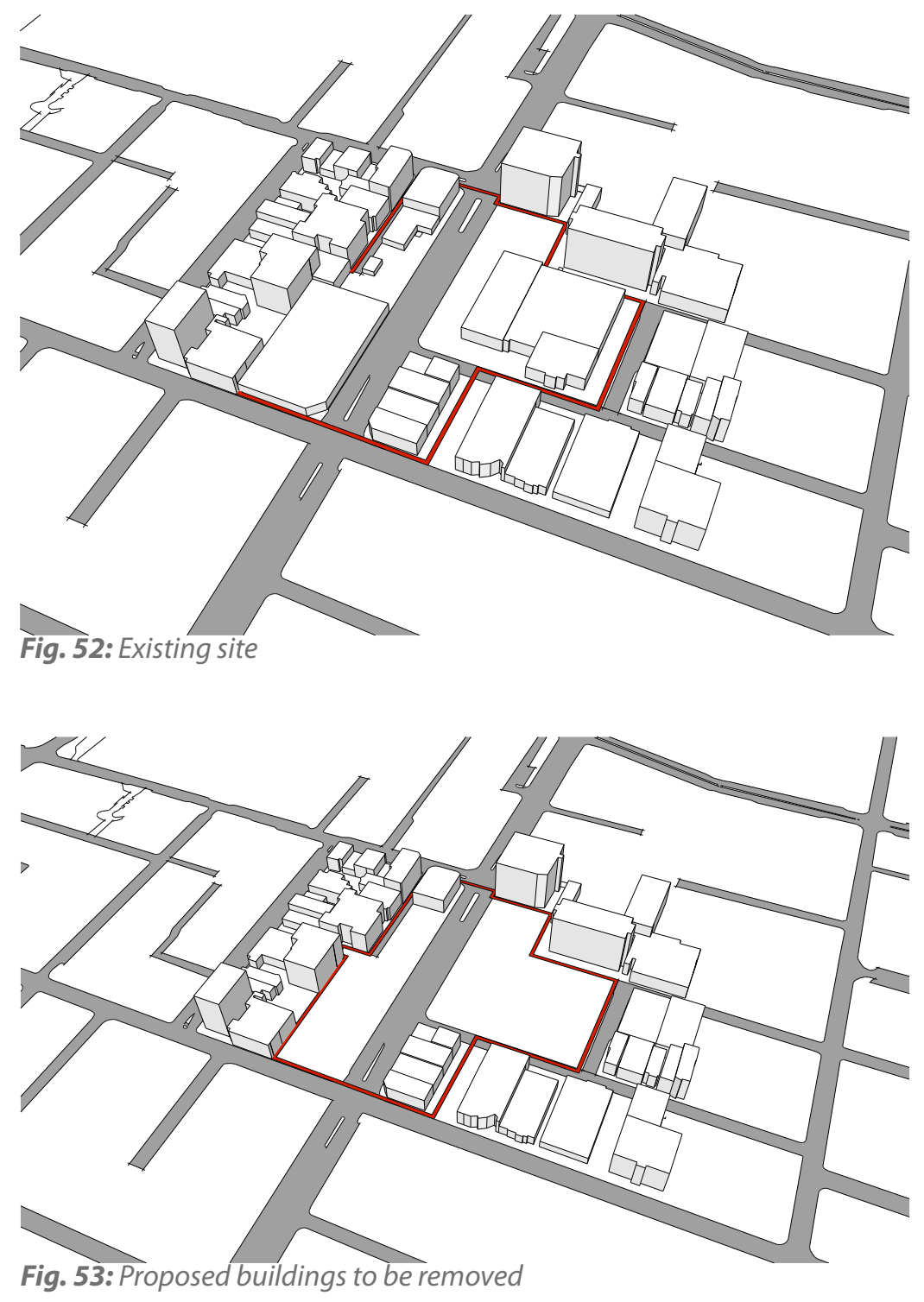
Wellington 2040. Street widths of Ebor and Briscoes Street are kept wide enough for emergency vehicles although their intended use it primarily for pedestrians.

Although the long and straight effect of Taranaki Street cannot be changed, providing ample visual interest and pleasant spaces for people by achieving human scale along the sides of the street, will help to mask its current 'tiring length perspective'.

\section{Plot sizes}

Plots are readjusted to fit within the new urban plan and are made to be narrower than they are long in order to encourage the eventual array of buildings that will provide an optimal amount of visual interest. Given their inner city location, they have been designed with the potential for the building to have $100 \%$ coverage in the hopes that these parameters will reflect onto the buildings.

Outdoor space and building use

The widening of the footpath is also to provide a comfortable amount of space for pedestrian activity be it walking, shopping, busking, or eating at tables put out by a cafe. Two other potential areas for public squares have been identified at an urban level. Building design is intended to reflect multi-use with retail on the ground floor, offices on the second and/or third floor and residential above. This is to foster maximum activity, which not only is socially desirable but also has safety benefits.
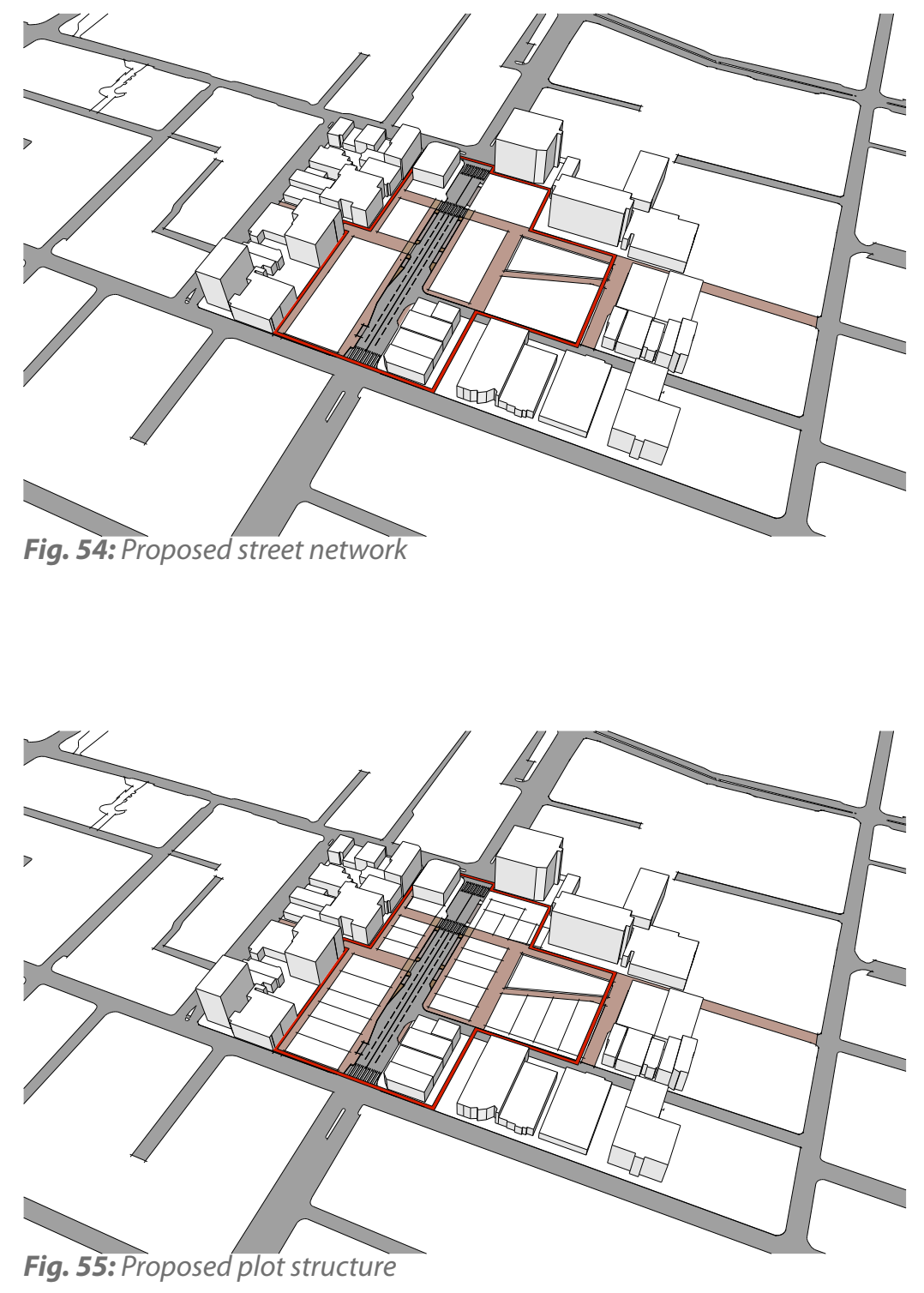


\section{$7.3 \mid$ ARCHITECTURE}

\section{Building heights}

All proposed building masses are between 16 and $25 \mathrm{~m}$. This is simply because of the emphasis on five stories as the optimal maximum threshold to maintain comfortable visual, social and physical connection with the street. However to encourage variation, there is no absolute limit. The matter should be a discretionary one involving the designer's own judgment. As such it is possible that some buildings could be six stories if designed carefully enough to maintain human scale connections with the street, however this becomes harder to do the higher the building.

This building height also opens more of the street to sunlight, has obvious seismic resisting benefits, and reduced wind speeds at their base compared to taller buildings. Despite these benefits it is still noted that current code allows buildings of up to $27 \mathrm{~m}$ in height which could accommodate up to nine floors, which is more attractive to developers and city council initiatives.

\section{Continuous Building Line}

Buildings are placed so that their plot coverage is $100 \%$. This fosters a density where building are close together and maintains ordered street definition of a continuous building line. Although $100 \%$ site coverage is not necessary to maintain a continuous building edge, the proposed buildings all have two or three bounding public streets meaning the building line must be maintained on more than one face. Such an unbroken street facade however does have a channelling effect for wind which is addressed by awnings and the introduction of Pohutukawa trees.
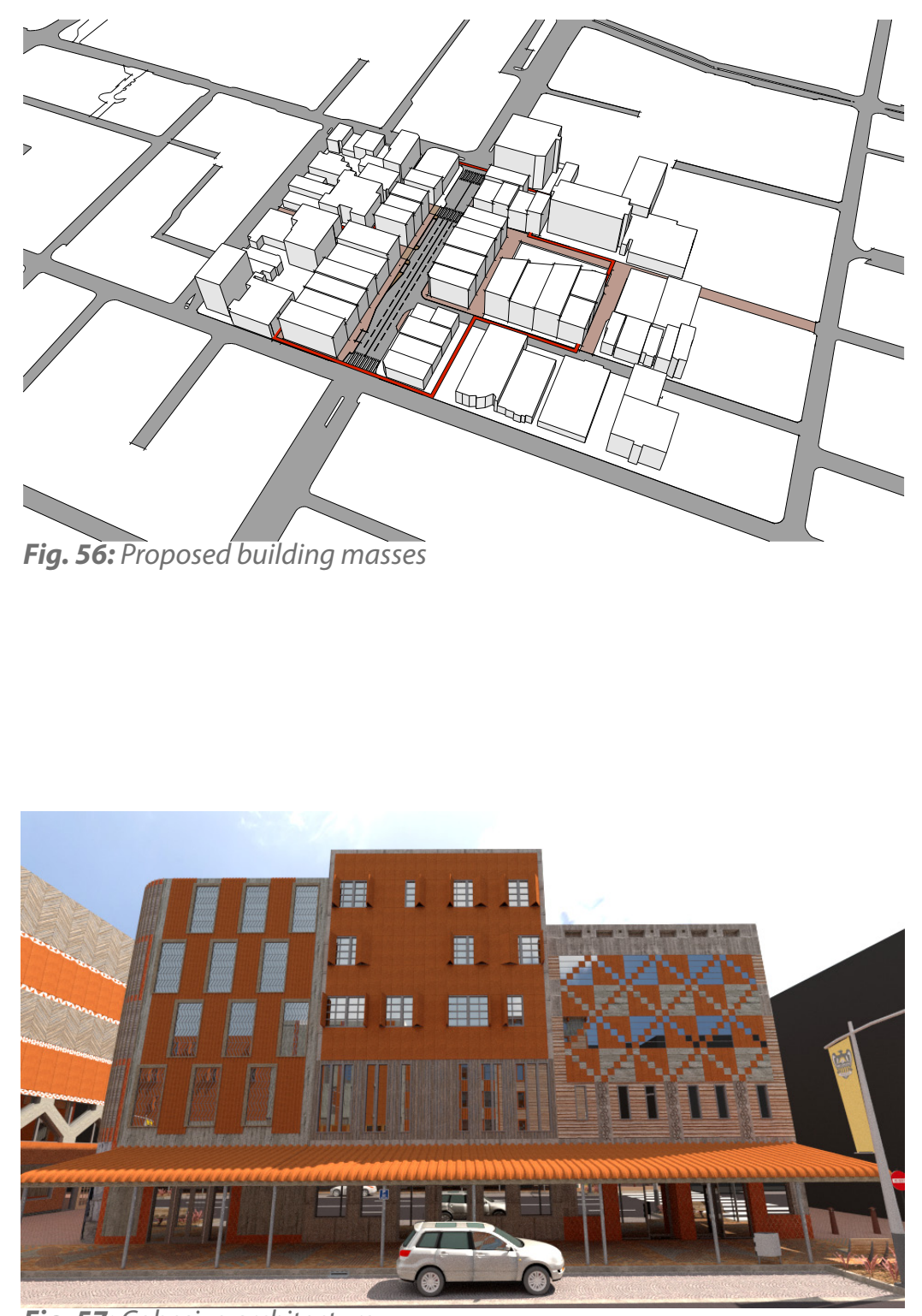

Fig. 57: Cohesive architecture 


\section{Architectural Styles}

Styles are largely the collective result of materials and component choices, design and arrangement. Complimentary styles are designed so that the street appears more unified and less chaotic. While aiming to not create identical buildings, it is important that they show'responsive cohesion'.

\section{$7.4 \mid$ DETAIL}

\section{Architectural Components and materials}

A select range of complimentary materials has been chosen to help create cohesive architectural styles and a unified streetscape.

'Inhuman' materials and components such as those far larger or heavier than a human can handle, or anthropometrically disproportionate, have not been ruled out as long as smaller human materials and components exist to provide the smaller scale necessary for our perception, to invoke the notion of human presence during the construction phase and to prevent the inhuman materials from dominating. It is understood that some massive materials can be employed in a way that promotes smaller visual components such as in-situ or patterned concrete.

\section{Craftsmanship}

Both machine-made and man-made craftsmanship have been incorporated into the buildings and the streetscape, although it is understood that man-made craftsmanship is rare due to the time and cost required. Cultural pacific patterns and fractal patterns help enrich the visual information of the facades but are used sparingly not to cause an
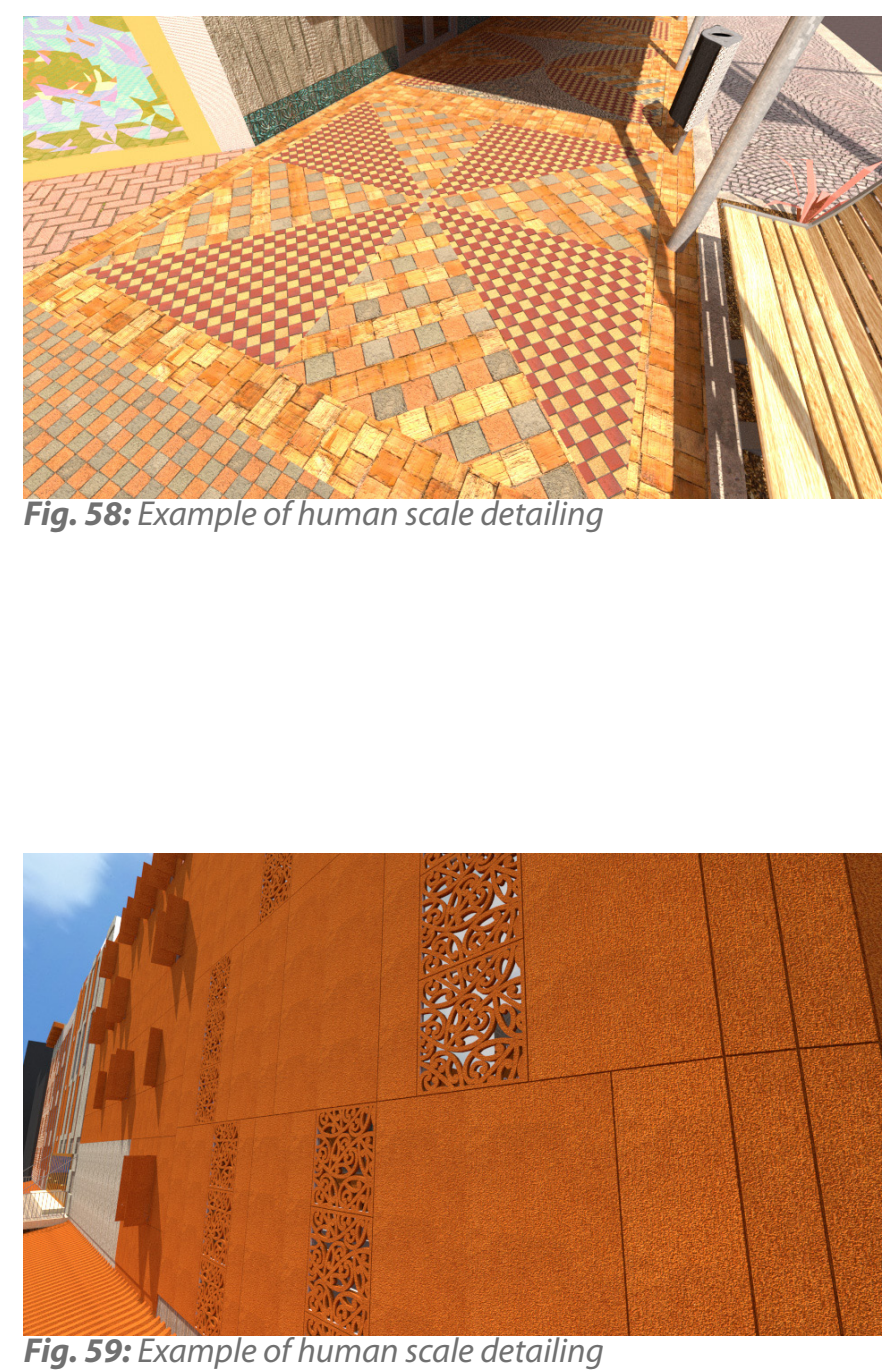

Fig. 59: Example of human scale detailing 
overload of detail and to draw attention to certain areas such as windows and doors, or to guide ones eyes in a certain direction. Paving patterns have also been proposed to ensure that the extensive ground surface is not left bare and visually boring. Although machine-made craftsmanship may not hold the same intangible qualities that objects crafted by the human hand hold, it still provides important amounts of visual information. Graffiti and public art incorporated into the streetscape can also be considered to display a human connection.

\section{Texture}

Materials have also been chosen for their textural qualities. Very few smooth and blemish free materials have been used and are not used in mass. The overall architectural composition is also considered as a larger 'texture'. Every extensive surface is adorned with a material that either has texture, creates texture or both. Where possible natural materials have been used, although it is recognised that concrete and certain metals can have desired textural effects and are often the more accessible materials. Materials that have a natural texture are often more expensive.

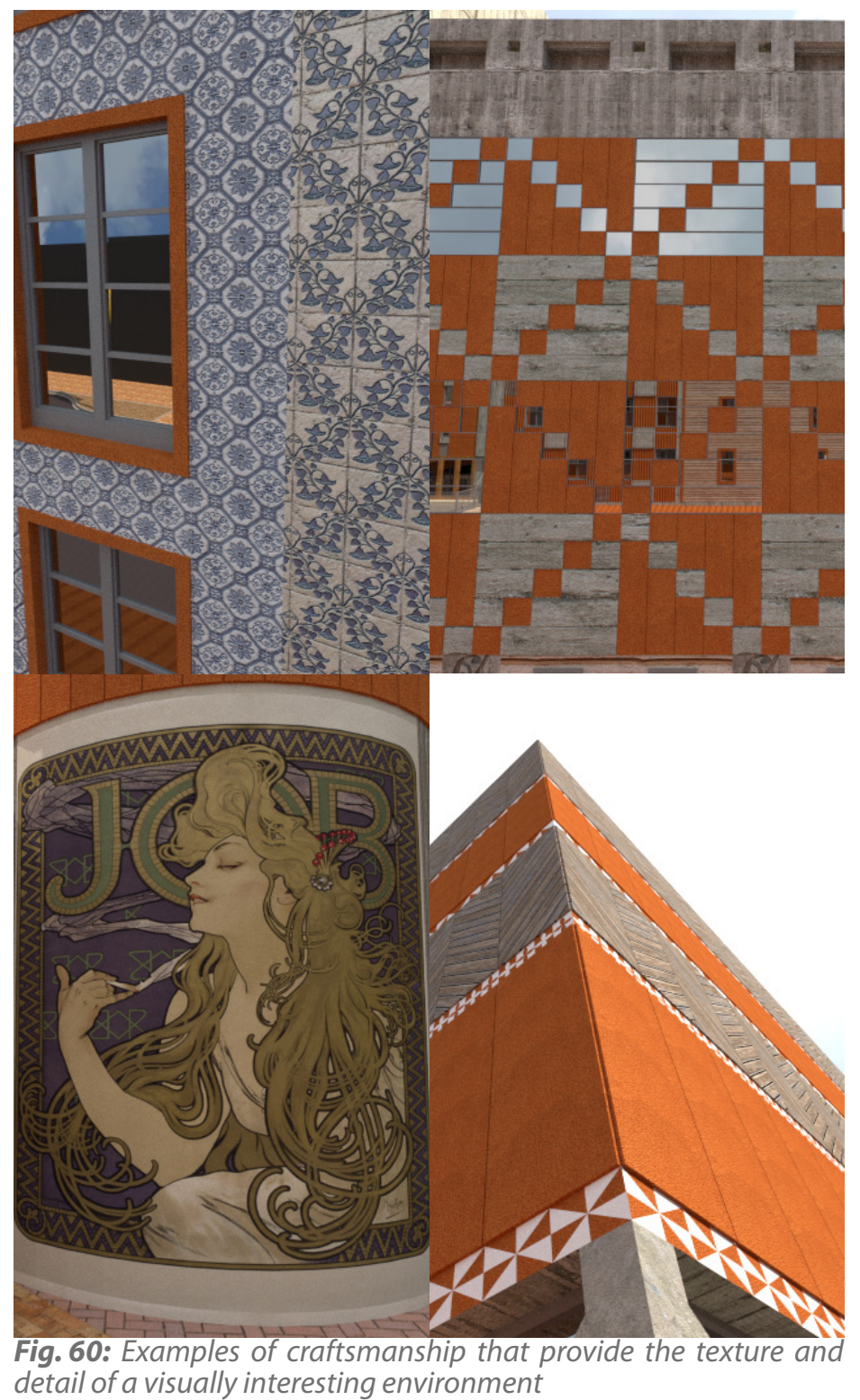




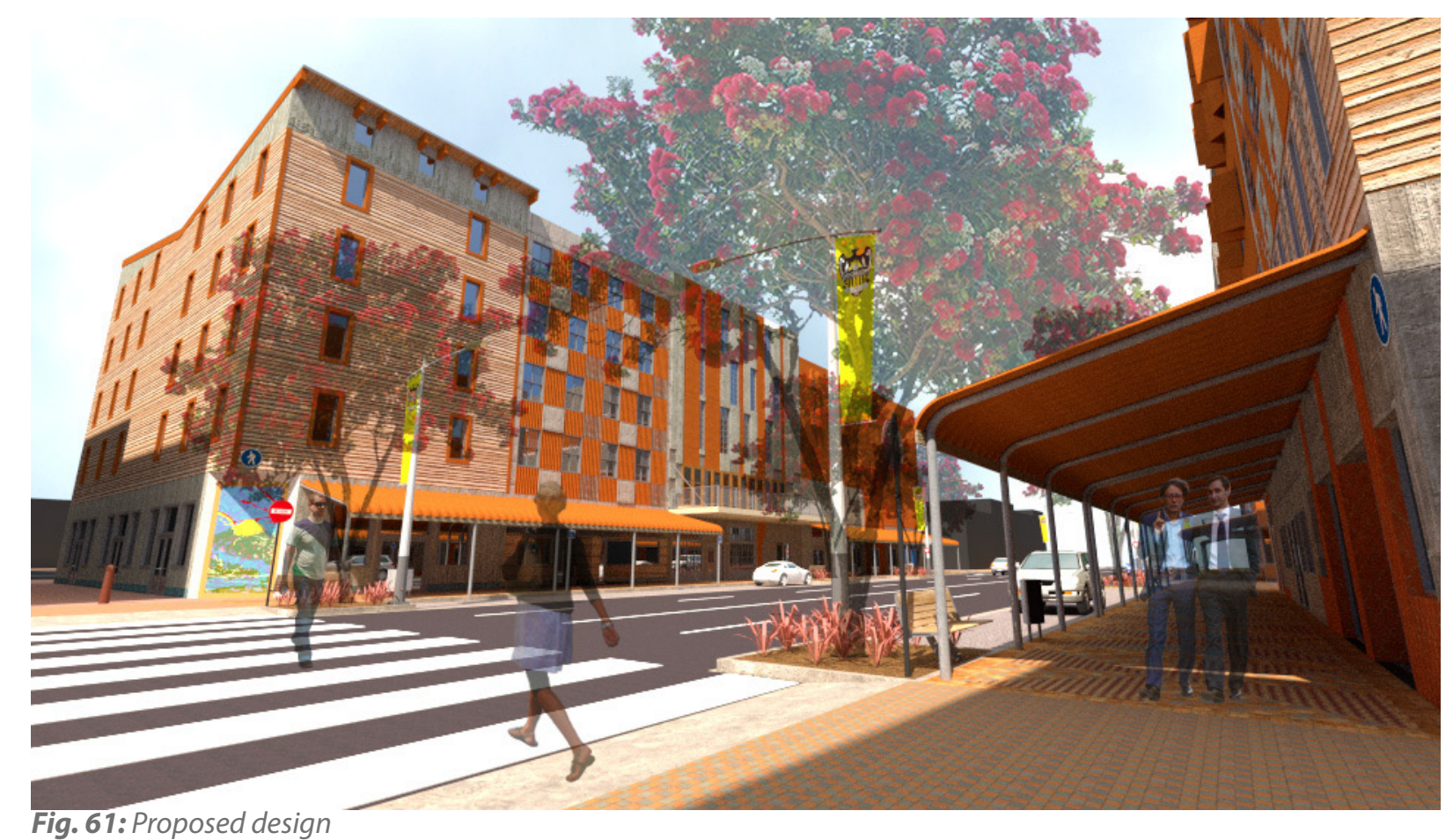




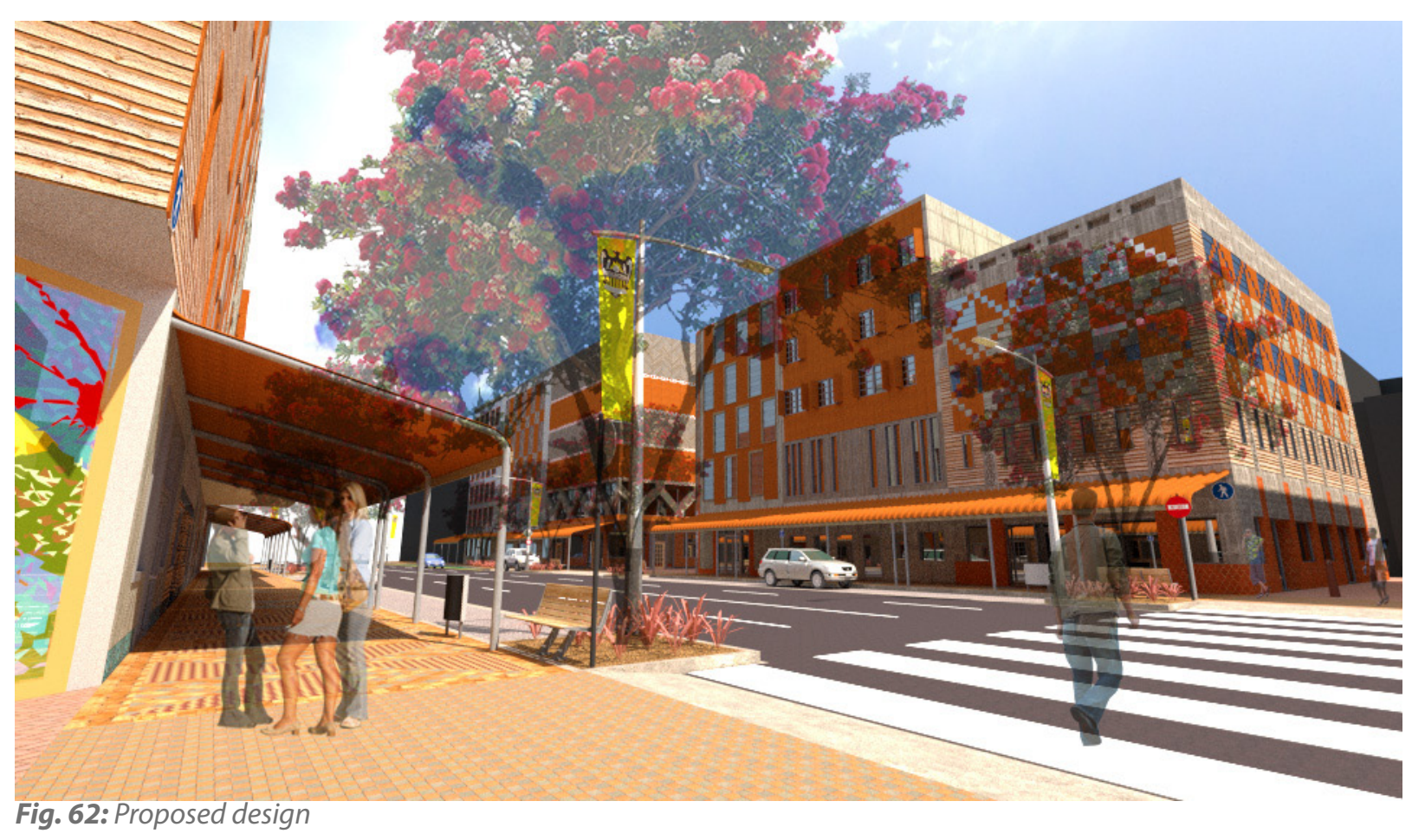




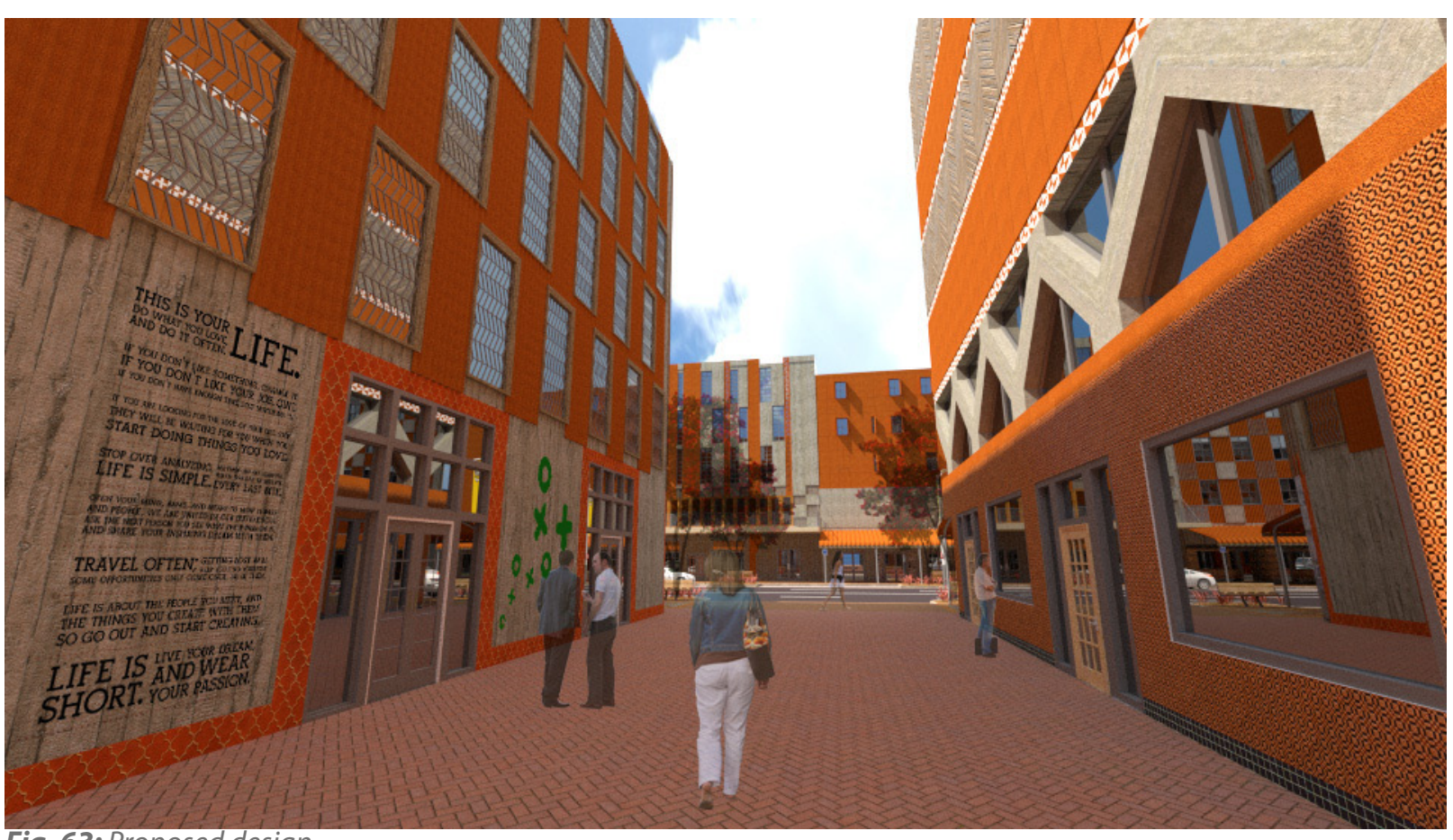

Fig. 63: Proposed design 


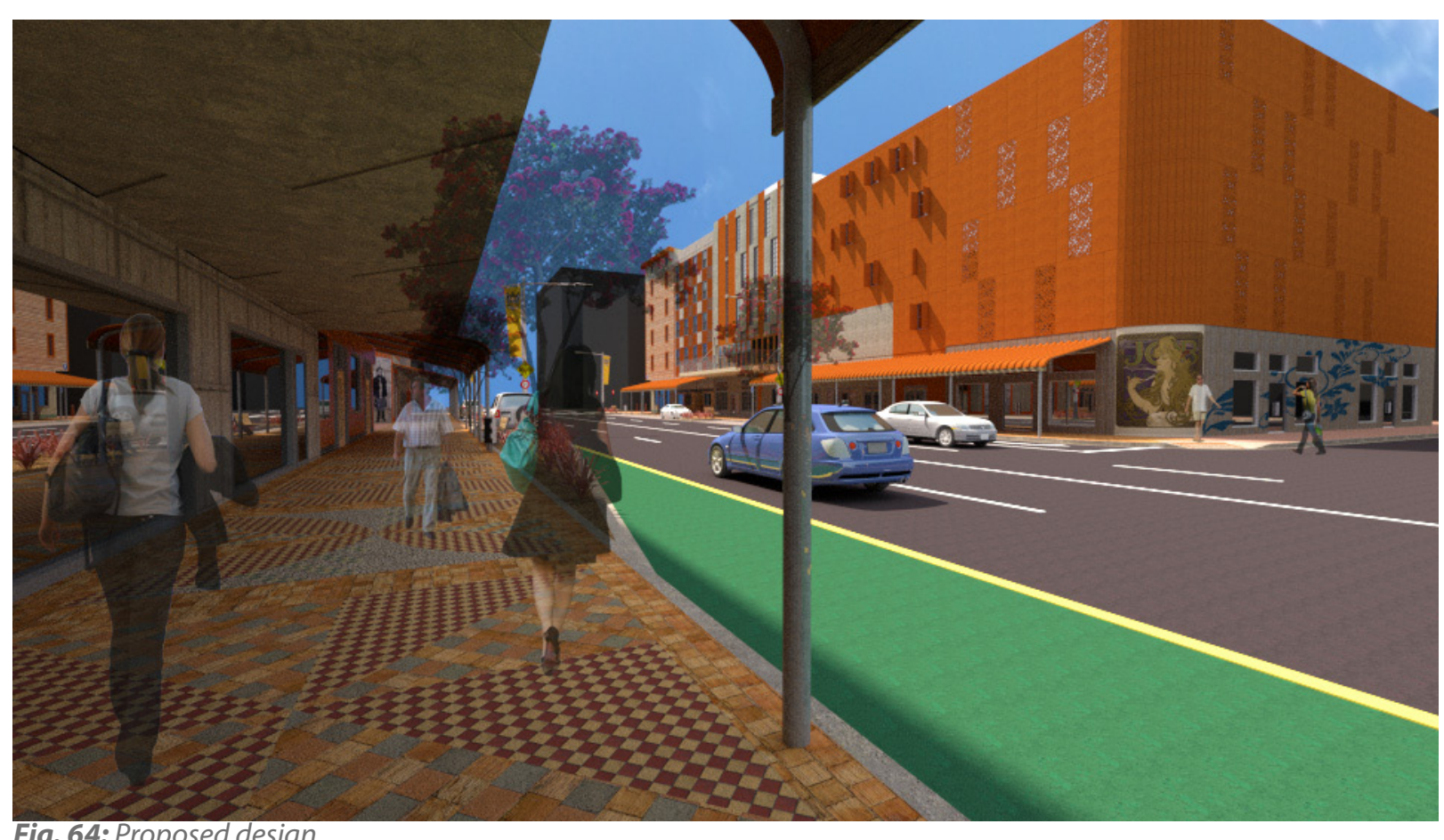

Fig. 64: Proposed design 


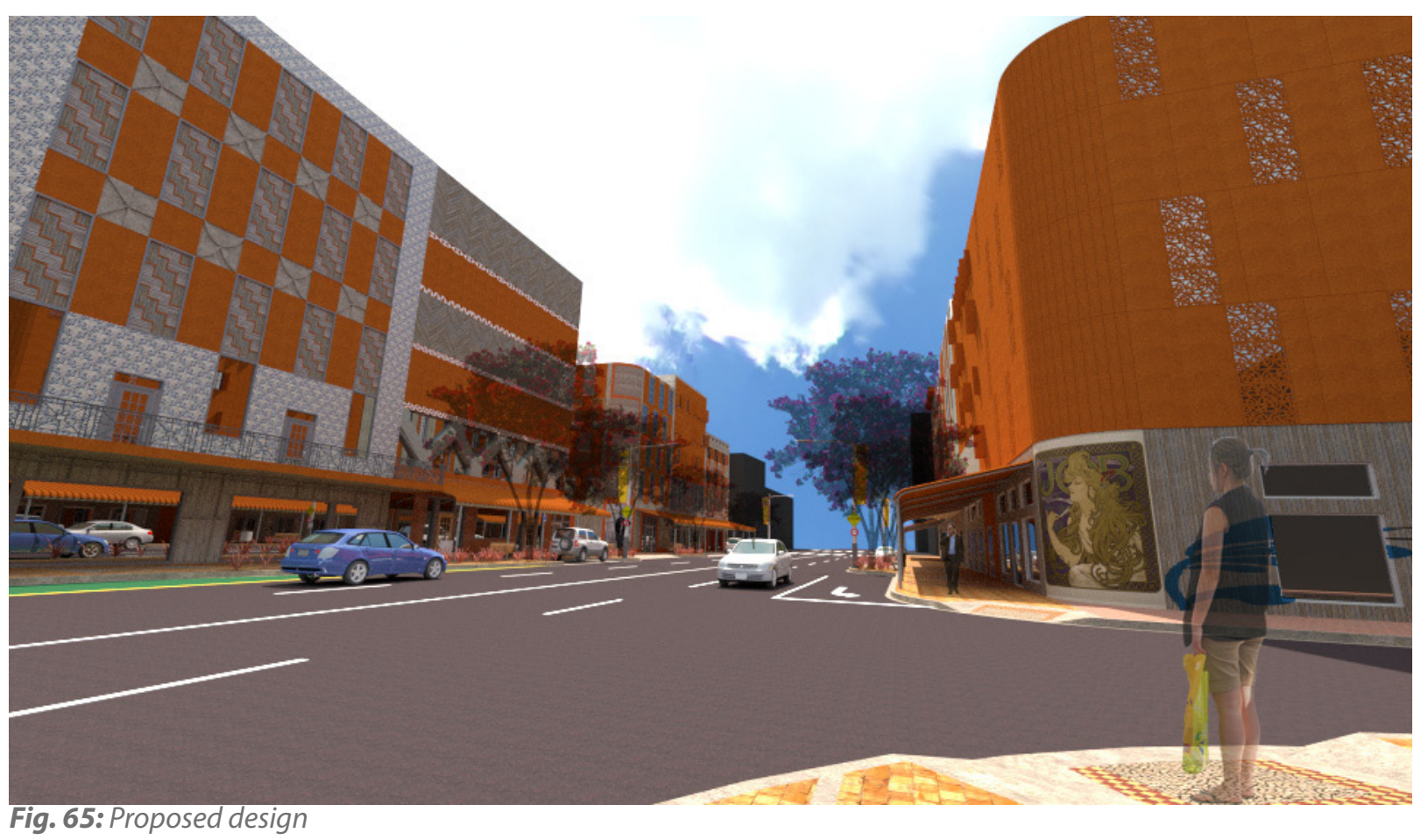




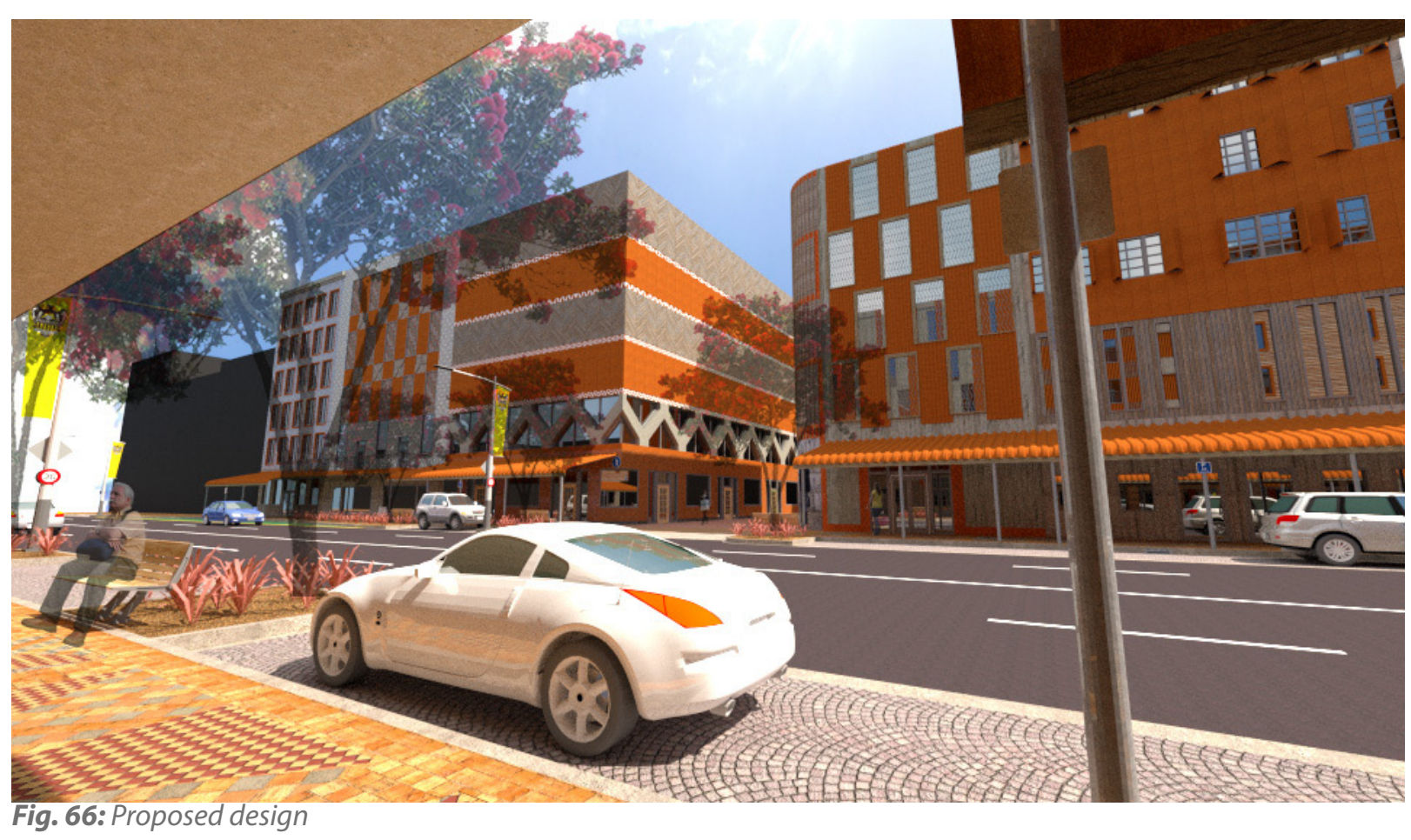




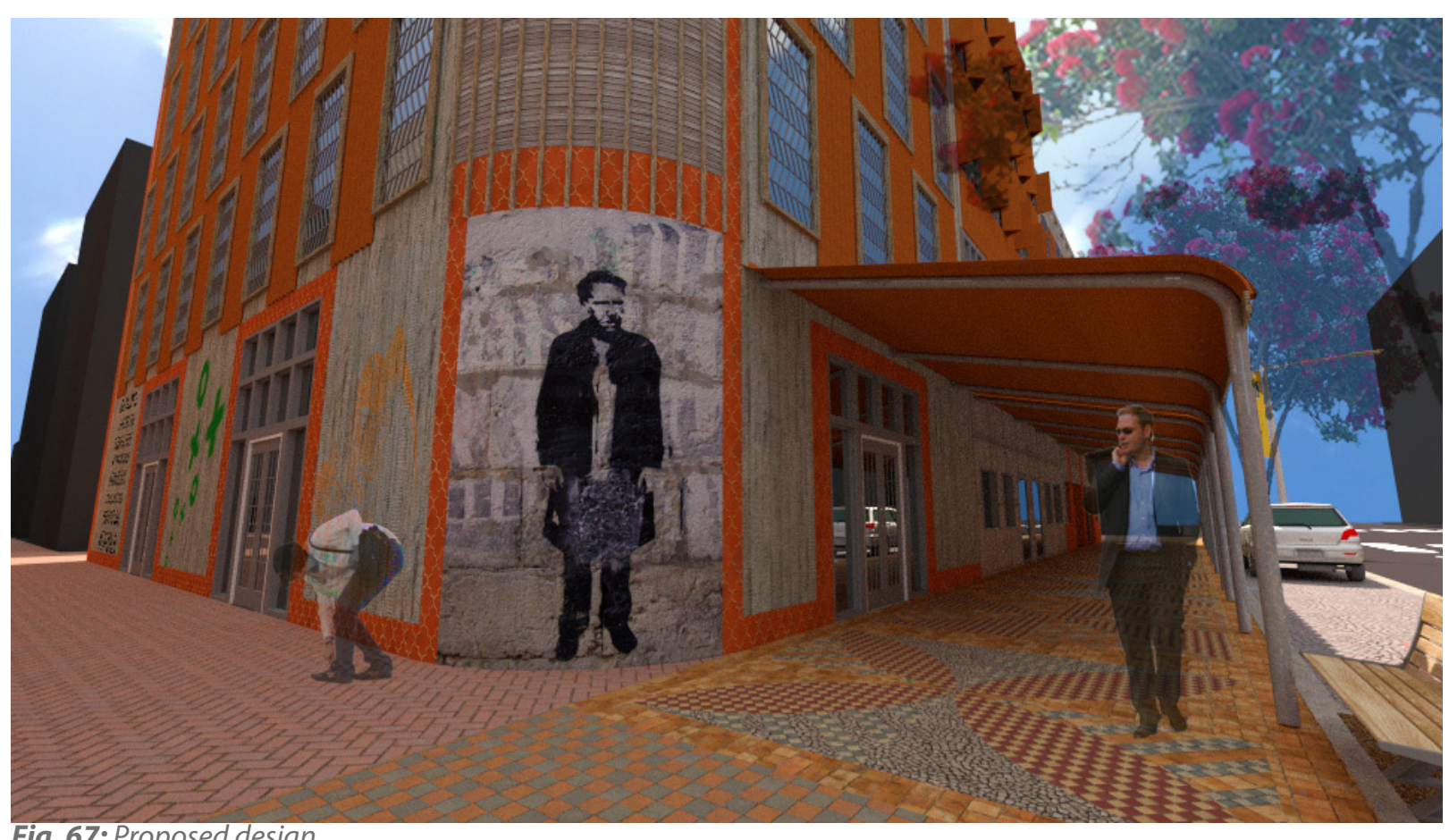

Fig. 67: Proposed design 


\subsection{DESIGN REFLECTION}

The purpose of this design was to explore the relationship between the extended definition of human scale and a considered interpretation of successful enclosure based on its physical formation and the sense of place, progression and safety. By closely following criteria developed from the research the design confirmed the supposition concluded from critical reading on both concepts; that there is indeed an inextricable connection between human scale and enclosure.

It quickly became apparent that it is difficult to design for human scale without considering enclosure because the two concepts are so intertwined. Human scale dictates the size of buildings and the width of streets and so therefore has an imminent effect on enclosure. Enclosure also has a direct effect on human perception, and is about scaling our surrounding appropriately so that space feels comfortable to pedestrians. This comfort is contributed to by those indirect relationships that simply help to foster a sense of place, progression and safety which are instrumental in determining the success of enclosure. Despite the direct relationships that appropriately configured enclosing masses, it is the addition of human scale aspects with indirect relationships to enclosure such as craftsmanship and texture that produced an interesting, responsive and safe environment that satisfied the criteria for successful enclosure.

The design process did, however, uncover unavoidable issues not apparent in the research, that warrant discussion here, and serve as eligible topics for future research. These issues were mainly the street as a vehicular corridor, and awnings. Both have an effect on the enclosure of the street. 
A street that is used frequently by vehicles means that the pedestrians are forced to the edges naturally. This has consequences in terms of visual, physical and social connections with the opposite side of the street, particularly if vehicular traffic is heavy and the street wide. Instead of both sides of the street feeling as part of one streetscape, they each become separate domains because of the divisive power of the vehicular traffic and distance from the opposite building line. Taranaki Street is also long and straight providing the 'tiring length perspective'. This could not be avoided without significant changes to the existing street pattern. Pohutukawa trees and awnings help to reduce visibility along any given length of the street for pedestrians, but in essence could be considered merely a superficial solution.

Awnings are, and have been a part of the New Zealand streetscape since the colonial era and are frequently found throughout central Wellington streets. Needed to shelter pedestrians from the often unpredictable weather, particularly in Wellington, they have their own enclosing effect on people. As enclosure is determined mainly by our vision, the sense of street enclosure dwindles because the awning, as an overhead surface close to our bodies, creates a tunnel effect shielding most of our vision of the surrounding streetscape. The awning also prevents social interaction with the upper floors - not just communication but also for those above being able to watch the comings-and-goings of the street below. In a sense the awnings create an intimate type of enclosure, and the size of them represents a human scale in the dimensional sense of the phrase, however at the same time, they also partially prevent the human from experience the broader applications of human scale - for instance on the urban level. It must be noted, however, that awnings do not completely impair ones senses of the broader streetscape, and in most cases, particularly if designed well, a sense of street enclosure can still be felt as a result. 
It is also understood that this is an ideal solution, and because of this there are several incompatibilities with current urban design and architectural practice. The design however was never intended to solve such problems, but rather highlight them. As the design has followed a thorough human scale brief, where it is at odds with regulations and standard time and cost constraints, it draws attention to the areas of current design processes that need to be re-evaluated. Although theoretical in this sense of being idyllic, it gives us good insight into the type and quality of design that could obtained if our knowledge and priorities shift. 
Chapter $8 \mid$ 
The objective for this thesis was to develop a better understanding of the role that human scale has to play in our urban environments by exploring the relationship between enclosure and human scale. As a result of a greater understanding of human scale, it was noted that overlaps occured with enclosure, a concept normally considered as a distinctly separate design objective. Believing that further investigation of the overlapping areas could advance the understanding of human scale, the development of a better insight into enclosure was ignited. Influenced by the orginal investigation into human scale it subsequently aided a more comprehensive appreciation of human scale by indicating not simply an 'overlap' but a deep relationship with enclosure. It is hoped that the repercussions of this research will encourage the identification of further inter-objective relationships as this would technically unify fragmented design theory under human scale and could change the process of design significantly.

Human scale was identified as becoming increasingly important due to recognising past mistakes in neglecting basic human needs. Human scale as a concept however is far from well understood, as is clearly demonstrated by the vast array of literature researched, and as such poses its own problem of how well such a poorly understood concept can be implemented.

Most commonly human scale is thought to refer to the comparison of sizes between the environment and the human body or anthropometry, however it is also used when referring to social patterns and physical movements among other comprehensive concepts, revealing both its ambiguity and complexity as well as identifying its inescapable connection with anthropology and the social sciences. The use of the word scale has been problematic, in that it has generally been defined too literally in relation to size - it appears to be more of an abstract and all encompassing notion relating to nearly any comparison between the human and his environment. The 
research therefore attempted to look at how human scale encompasses more than purely size, broadening and sophisticating the meaning of the term greatly.

Such a broad definition of human scale based on multiple opinions however, is largely interpretive, and therefore open to challenge. There is no one piece of literature which reveals that human scale is a concept covering a vast range of information, and in this sense this paper is valuable in highlighting this. However, although the research has not produced any conclusive evidence, an attempt has been made to better understand human scale by regarding the different existing opinions as equally viable arguments that collectively form the concept of human scale. This approach effectively redefined the term as a broader umbrella concept and produced findings which are the result of the collation and organisation of the currently scattered and seemingly different definitions. Such a redefinition allowed further research to be conducted in a new light where possible relationships were identified with enclosure; a design concept currently treated separately from human scale. By exploring this connection, the research sought to further the understanding and viability of such an inclusive definition of human scale, and its potential impact on the way we think and design for our environments.

Because human scale is about the tailoring of our urban areas to human comfort and perception, it is ultimately concerned with enclosure as it is also a concept which is dependent on our perception and comfort levels. Research indicates that relationships exist between these two concepts on direct and indirect levels, in which some human scale characteristics such as visual limits, walking distances and movement produce enclosed space and others like craftsmanship, texture and social activity simply affect the degree of enclosure by promoting a sense of place, progression and safety. Through the ambiguous consequences and limited nature of having multiple 
definitions, where human scale appears to be little more than another concept treated separately from other desirable urban design and architectural qualities, it is difficult to clearly see any relationship to enclosed space. Analysing human scale as a collective concept suggests that it is a fundamental aspect of architecture and urban design which has the potential to effect all areas of design, and is therefore not just a singular objective but an ethic and form of conduct. The connection between enclosure and human scale is clear and offers valuable information on the influential importance that human scale design has to the rest of the urban environment i.e. other urban design objectives.

Much of the problem however lays in the world we have developed. Some would say that since the $17^{\text {th }}$ century we have been gradually moving away from human scaleinducing practice, technologies and mentalities. As a result human scale has become increasingly absent in society and built environments and increasingly difficult to reinstate; particularly now that our world is dependant upon many extrahuman scale innovations. This is clearly seen in the design case study, in which human scale approaches often clash with the typically more contemporary cost and time efficient methods that dictate the choice of building materials, manufacturing techniques, regulations and incentives. The design helps us to realise the complexities involved in any transition back to a human scale mentality, and that it is unrealistic to expect it to be quick and thorough.

The consequences of human scale being neglected is understood, however there are also consequences if it is implemented incorrectly. To successfully implement such a concept, we need to have a consensus on its meaning, and its relationship to other urban design objectives such as enclosure must be common knowledge, particularly for design professionals. As the design, a procedural and multilevel 
(urban, architectural and detailed) implementation of human scale, resulted in the enclosure of a previously open space, it can be considered a demonstration of how closely intertwined human scale is with successful enclosure. The inability to avoid addressing enclosure out of consideration for human comfort, as well as it simply being affected by human scale choices, such as building heights and street widths clearly helped to emphasize the interconnection of the two concepts. Although some aspects of human scale arguably have stronger links than others, for example visual capabilities as opposed to social activity, and although no indisputable, unequivocal conclusions have been drawn, findings have resulted from equitable treatment of existing and fragmented definitions.

Due to the complexity and ambiguity of current discourse on human scale, the limitations to this thesis have been frequent. Locating adequate and direct definitions of human scale was difficult, with there being more information on some (such as anthropometry) than others and forced a methodological approach that relied heavily on interpretation of inference. This diminished the possibility of producing unequivocal findings. As a result of redefining human scale into a more inclusive concept, a selective strategy had to be formed in order to maintain focus on the relevant areas of the concept. However, as it was discovered, it is nearly impossible to isolate aspects of human scale as many of them are interdependent with one another and with 'exterior' concepts (such as enclosure). As a result many areas of human scale have not been addressed as fully as others and in several instances the research produced more questions than answers.

Human scale has been acknowledged in this thesis as being a concept which embodies multiple definitions. Treated as different aspects of human scale, they each represent limits imposed by human behaviour, perception and physical nature. Because of the 
relationship, these limits pass over into enclosure and are what help to determine what has been called successful enclosure. Yet it is accepted that the limits that once caused society to maintain a human scale have increasingly vanished with technological and social advancements. Either way, one can still conclude that consideration for man and the limits imposed by his perception, ability and frame influences design in a way that fundamentally forms enclosed space that fosters a sense of progression, place and security, and perhaps other design objectives. Enclosure as a consequence of human scale design therefore lends itself to a better understanding of human scale and its potential to form currently separate design objectives.

The implications that this research has on design are vast. The relationship of enclosure with human scale means that if designers have a thorough, and sophisticated understanding of human scale, not only will enclosed spaces become more successful but they will more likely form consequentially, without deliberate and separate treatment. Recognising the influential nature of human scale, simply means that designing environments that respond to humans in a positive way could ultimately address many current urban design objectives consequentially, although as enclosure has proven, not necessarily in total agreement with contemporary approaches.

Following research could explore how it is possible to utilise contemporary knowledge and technology in a way that promotes and refines human scale both theoretically and practically. This is because human scale should be fundamental to design and at the forefront of professional decisions. After all, architecture and urban design are professions first and foremost concerned with the comfort of people. 


\section{Bibliography}

(Prince ofWales), C. (1989). A vision of Britain: apersonalview of architecture (illustrated.). Doubleday.

Alexander, C. (2002). The phenomenon of life. Berkeley Calif.: Center for Environmental Structure.

Alexander, C., Ishikawa, S., \& Silverstein, M. (1977). Apattern language:towns, buildings, construction.

Oxford University Press.

Bentley, I. (1985). Responsive Environments. Elsevier Science.

Blumenfeld, H. (1953). Scale in Civic Design. The Town Planning Review, 24(1), 35-46.

Boffa Miskell, Wellington City Council, \& Randles Straatviet Architects. (2011).

Wellington Towards 2040: Smart Capital. Wellington City Council.

Canniffe, E. (2006). Urban ethic: design in the contemporary city. Taylor \& Francis.

Carmona, M. (2003). Public places, urban spaces: the dimensions of urban design. Architectural Press.

Clarke, D. M. (2005). Descartes's Theory of Mind. Oxford University Press.

Collier, J. (2006). The Art of Moral Imagination: Ethics in the Practice of Architecture.

Journal of Business Ethics, 66(2/3), 307-317.

Collins, G. R., Collins, C. C., \& Sitte, C. (2006). Camillo Sitte: The Birth of Modern City Planning: With a Translation of the 1889 Austrian Edition of His City Planning According to Artistic Principles. Dover.

Corbusier, L. (1986). Towards a new architecture. Dover Publications. 
Crowe, N. (1995). Nature and the idea of a man-made world : an investigation into the evolutionary roots of form and order in the built environment. Cambridge Mass.: MIT Press.

Cullen, G. (1995). The concise townscape. Architectural Press.

Davis, H. (2006). The Culture of Building. Oxford University Press.

Ewing, R. (2009). Pedestrian and Transit-Friendly Design: A Primer for Smart Growth. American Planning Association.

Ewing, R. (n.d.). Identifying and Measuring Urban Design Qualities Related to Walkability. Journal of Physical Activity and Health 2006, 3(Suppl 1), S223-S240.

Gehl, J. (2010). Cities for People. Island Press.

Gorus, G. (2010, March 24). Colombian top architect Simón Vélez calls for buildings on a human scale | MO*. Mondiaal Nieuws. Retrieved October 4, 2011, from http://www. mo.be/en/article/colombian-top-architect-simon-velez-calls-buildings-human-scale Hinton, A. L. (1999). Biocultural approaches to the emotions. Cambridge University Press. Jacobs, A. B. (1995). Great streets. MIT Press.

Kostof, S. (1999a). The city shaped: urban patterns and meanings through history. Thames \& Hudson. Kostof, S. (1999b). The city assembled: the elements of urban form through history. Little, Brown.

Krier, L. (1998). Architecture: choice or fate. Windsor Berks England: Andreas Papadakis. Lock, A., \& Peters, C. R. (1999). Handbook of human symbolic evolution. Wiley-Blackwell.

Maaløe, E. (1976). Towards a theory of natural architecture: effect and social importance of order, variation, texture and scale related to architecture. Arkitektens Forlag. 
Moughtin, C. (1999). Urban design: ornament and decoration (2nd ed.). Oxford ;BBoston Mass: Architectural Press.

Moughtin, C. (2003). Urban design: street and square (3rd ed.). Amsterdam „;Boston: Architectural Press.

Pearson, M. P., \& Richards, C. (2004). Architecture and Order: Approaches to Social Space. Routledge. Rogers, R. (1997). Cities for a small planet. London: Faber and Faber.

Salingaros, N. A., \& Mehaffy, M. W. (2006). A theory of architecture. UMBAU-VERLAG Harald Püschel.

Spreiregen, P., \& American Institute of Architects. (1981). Urban design, the architecture of towns and cities. Malabar Fla.: R.E. Krieger Pub. Co.

Talen, E. (2009). Design by the Rules: The Historical Underpinnings of Form-Based Codes. American Planning Association. Journal of the American Planning Association, 75(2), 144.

Thadani, D. A., Krier, L., \& Duany, A. (2010). The language oftowns \& cities: a visual dictionary. Rizzoli. Trask, L. (1997). Scare Quotes. Retrieved December 6, 2011, from http://www. informatics.sussex.ac.uk/department/docs/punctuation/node31.html

\section{Design Regulations}

Edinburgh Standards for Urban Design, retrieved from http://www.edinburgh.gov. uk/info/207/planning-policies/824/edinburgh_standards/4 
Los Angeles Downtown Design Guide, retrieved from http://urbandesignla.com/ downtown_guidelines.htm

Wellington City Central Design Guide, retrieved from http://www.wellington.govt.nz/ plans/district/volume2/vol2.html

BritishUrbanDesignCompendium, retrievedfromhttp://www.homesandcommunities.

co.uk/urban-design-compendium?page_id $=5542 \& \% 3 \mathrm{~B} \% 3 \mathrm{Bpage}=179$ 
Fig. 1: Narrow street, Venice, Italy (retrieved from http://www.scottshephard.com/wp-content/uploads/2009/06/Back-Street-Venice)

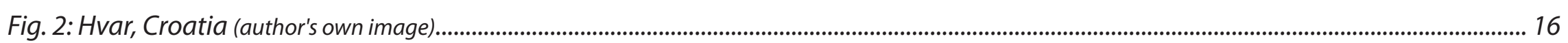

Fig. 3: Rothenburg-ob-der-Tauber, Germany (retreived from http://famouswonders.com/wp-content/uploads/2009/03/a-famous-street-in-rothenburg-

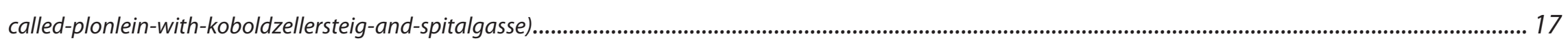

Fig. 4: Dinan, France (retreived from http://www.flickr.com/photos/paultomlin/3766886974/sizes/z/in/photostream/)................................................................ 17

Fig. 5: Blue streets of Chefchaouen, Morocco (retreived from http://goneawal.files.wordpress.com/2010/08/img/7828) .......................................................... 18

Fig. 6: Sightline, Siena, Italy (retreived from http://joshdoss.files.wordpress.com/2010/04/duomo/street-view) ............................................................................ 18

Fig. 7: Downtown Denver, CO, U.S.A. (retreived from http://www.downtowndenver.com/DNN/Portals/0/BID\%20at\%20Night) ............................................... 20

Fig. 8: Le Corbusier's orderly Plan Voisin (retreived from http://www.strabrecht.nl/sectie/ckv/09/Internationaal/CKV-f0020.htm) ............................................ 23

Fig. 9: Brasilia, Brazil, a city planned from above (retreived from http://brazilianstudies.wordpress.com/2010/04/15/brasilia-is-celebrating-its-50thanniversary/)...

Fig. 10: Common practice, scale modelling (retreived from http://www.sweetonioncreations.com/projects/photos-architecture-media) ............................... 24

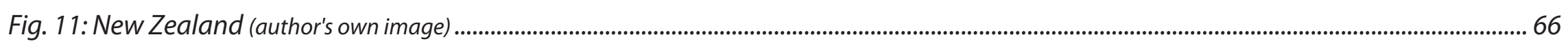

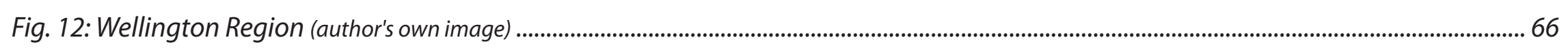

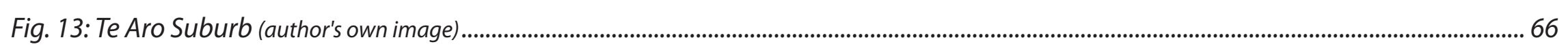

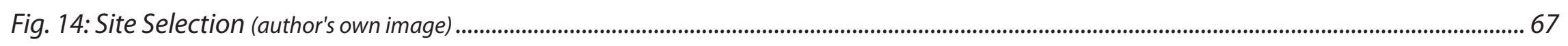

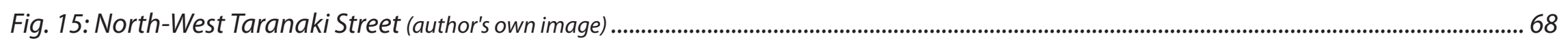

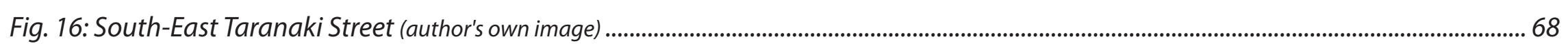

Fig. 17:Cuba St. maintains much of its character because of regulation (author's own image) ................................................................................... 69

Fig. 18: High vehicular traffic is a common site in central Wellington (author's own image)......................................................................................... 70

Fig. 19: Cohesion of the Taranaki streetscape is non-existant (author's own image) ................................................................................................ 70

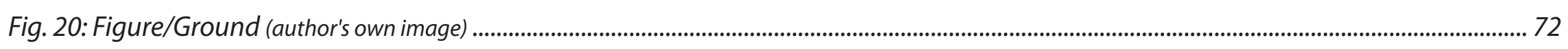

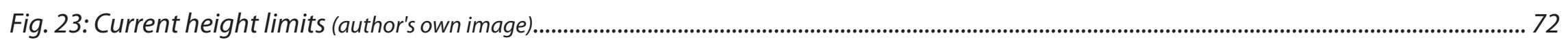


Fig. 21: Inverted Figure/Ground (author's own image)

Fig. 24: Protected heritage precincts (author's own image) ................................................................................................................................... 72

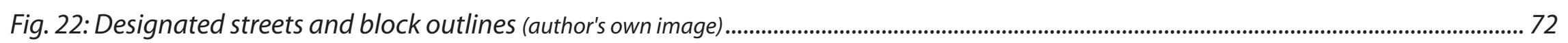

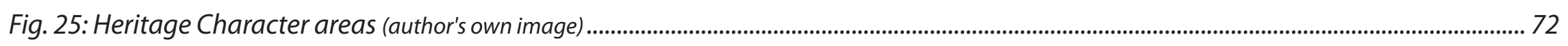

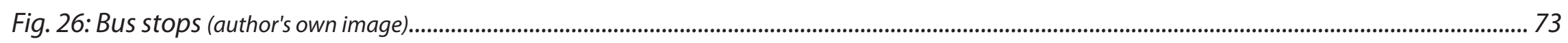

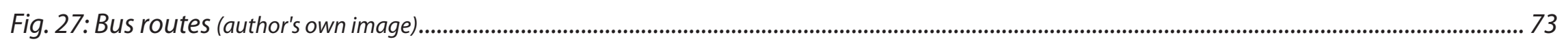

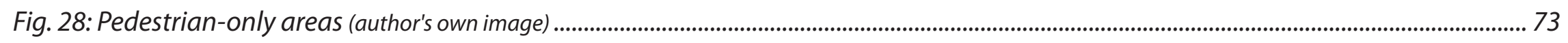

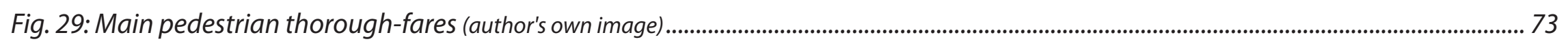

Fig. 30: Traffic generators (author's own image) .......................................................................................................................................................... 73

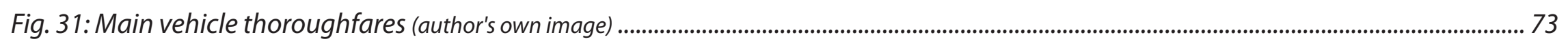

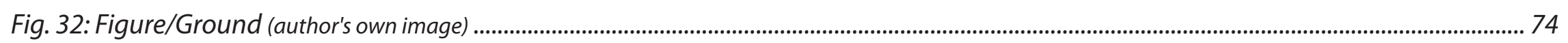

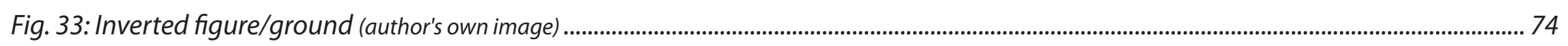

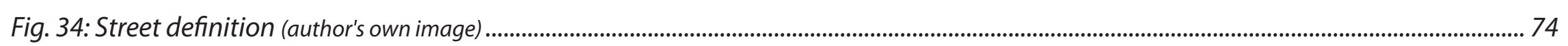

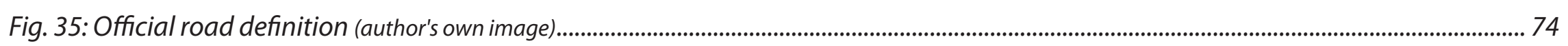

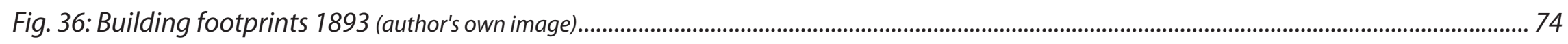

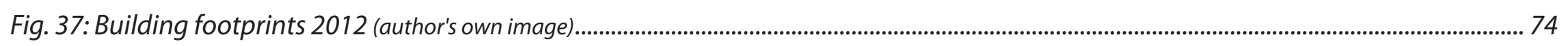

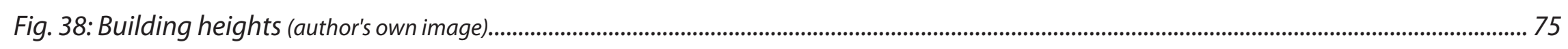

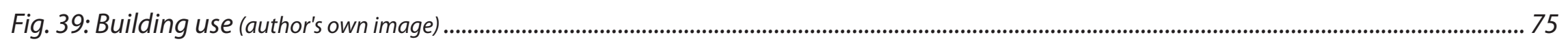

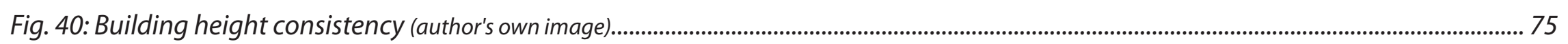

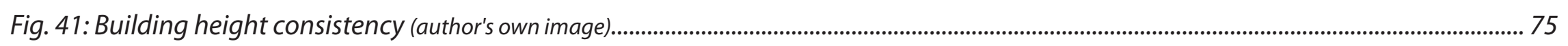

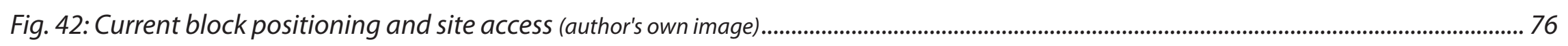

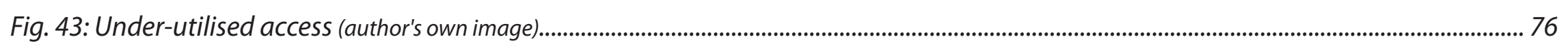

Fig. 44: Street width analysis (author's own image) ................................................................................................................................................... 77

Fig. 45: Current street width is on the verge of being too large (author's own image) ......................................................................................... 78

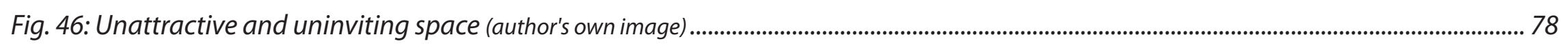

Fig. 47: Drastic changes in building height and roof line (author's own image) ......................................................................................................... 78

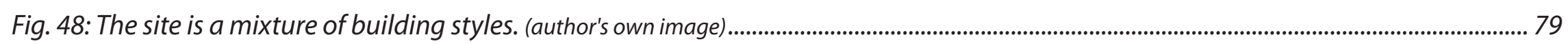


Fig. 49: No continuous building line, particularly on the North-west side. Variation of architectural styles apparent (author's own image)..... 79

Fig. 50: Very inhuman spaces with large, blank surfaces (author's own image)

Fig. 51: Flora is severely lacking, and the presence of concrete quite overpowering (author's own image) ................................................................ 80

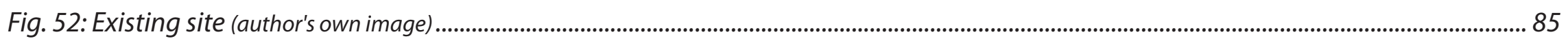

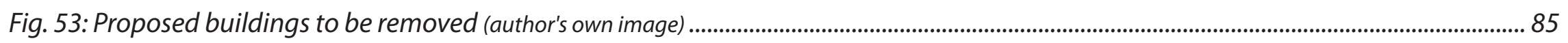

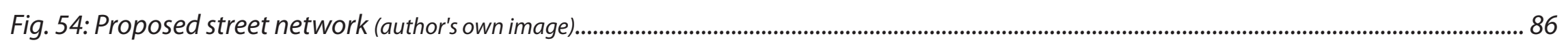

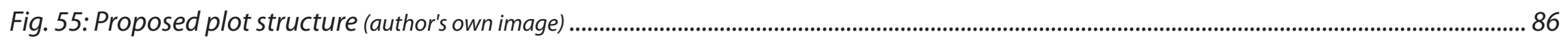

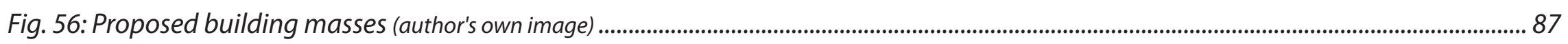

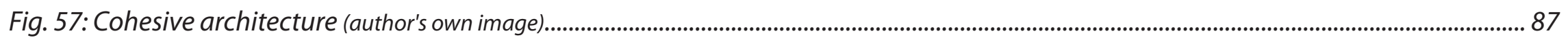

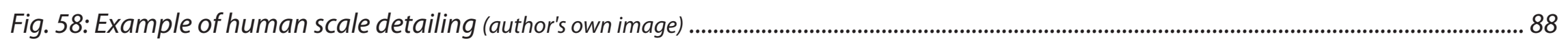

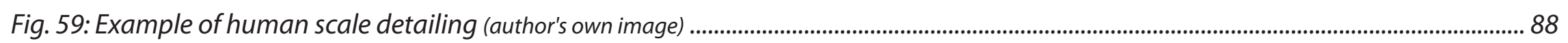

Fig. 60: Examples of craftsmanship that provide the texture and detail of a visually interesting environment (author's own image)................... 89

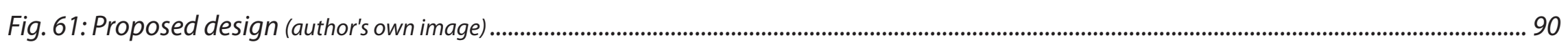

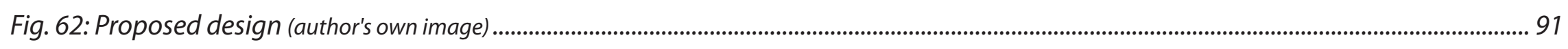

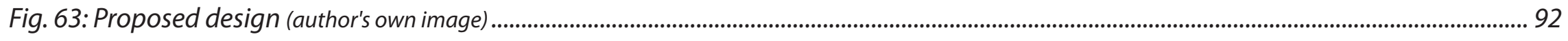

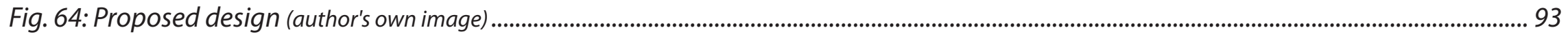

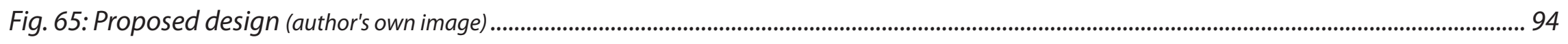

Fig. 66: Proposed design (author's own image) ........................................................................................................................................................... 95

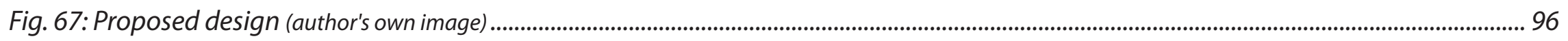




\section{Appendix}

\section{A1.1| TABLES}

\begin{tabular}{|c|c|c|c|c|c|c|}
\hline \multirow{2}{*}{\begin{tabular}{|l|} 
RATIO \\
$1: 1$ \\
\end{tabular}} & \multirow{2}{*}{$\begin{array}{l}\text { ANGLE } \\
45^{\circ}\end{array}$} & \multicolumn{2}{|c|}{$\begin{array}{l}\text { HEIGHT } \\
\text { (building) }\end{array}$} & \multicolumn{2}{|c|}{ WIDTH (street/ plaza) } & \multirow{2}{*}{\begin{tabular}{|l|}
$\begin{array}{l}\text { Maerten's comments or } \\
\text { angles }\end{array}$ \\
Best angle to perceive \\
the details in relation to \\
the whole
\end{tabular}} \\
\hline & & $70 \mathrm{ft}$ & $21 \mathrm{~m}$ & $70 \mathrm{ft}$ & $21 \mathrm{~m}$ & \\
\hline & intimate & $48 \mathrm{ft}$ & $14.6 \mathrm{~m}$ & $48 \mathrm{ft}$ & $14.6 \mathrm{~m}$ & \\
\hline \multirow[t]{2}{*}{$1: 2$} & $27^{\circ}$ & $35 \mathrm{ft}$ & $10.6 \mathrm{~m}$ & $70 \mathrm{ft}$ & $21 \mathrm{~m}$ & $\begin{array}{l}\text { Maximum angle to } \\
\text { perceive whole building }\end{array}$ \\
\hline & & $24 \mathrm{ft}$ & $7.3 \mathrm{~m}$ & $48 \mathrm{ft}$ & $14.6 \mathrm{~m}$ & \\
\hline \multirow[t]{2}{*}{$1: 3$} & $18^{\circ}$ & $23 \mathrm{ft}$ & $7 m$ & $70 \mathrm{ft}$ & $21 \mathrm{~m}$ & $\begin{array}{l}\text { Background can be } \\
\text { perceived }\end{array}$ \\
\hline & & $16 \mathrm{ft}$ & $4.8 \mathrm{~m}$ & $48 \mathrm{ft}$ & $14.6 \mathrm{~m}$ & \\
\hline \multirow[t]{2}{*}{$1: 4$} & $14^{\circ}$ & $17.5 \mathrm{ft}$ & $5.3 \mathrm{~m}$ & $70 \mathrm{ft}$ & $21 \mathrm{~m}$ & $\begin{array}{l}\text { Background becomes } \\
\text { equally as important }\end{array}$ \\
\hline & & $12 \mathrm{ft}$ & $3.6 \mathrm{~m}$ & $48 \mathrm{ft}$ & $14.6 \mathrm{~m}$ & \\
\hline
\end{tabular}


TABLE 1.2

\begin{tabular}{|c|c|c|c|c|c|c|c|c|c|c|}
\hline \multirow[b]{2}{*}{ Gehl } & \multicolumn{2}{|c|}{ Recognising human } & \multicolumn{2}{|c|}{$\begin{array}{c}\text { Discerning } \\
\text { action }\end{array}$} & \multicolumn{2}{|c|}{ Recognising face } & \multicolumn{2}{|c|}{$\begin{array}{c}\text { Facial } \\
\text { expression }\end{array}$} & \multicolumn{2}{|c|}{ conversation } \\
\hline & $\begin{array}{l}990 \mathrm{ft}- \\
1650 \mathrm{ft}\end{array}$ & $\begin{array}{l}300 \mathrm{~m}- \\
500 \mathrm{~m}\end{array}$ & $330 \mathrm{ft}$ & $100 m$ & $\begin{array}{l}165 \mathrm{ft}- \\
225 \mathrm{ft}\end{array}$ & $\begin{array}{l}50 \mathrm{~m}- \\
70 \mathrm{~m}\end{array}$ & $\begin{array}{l}72 \mathrm{ft}- \\
81 \mathrm{ft}\end{array}$ & $\begin{array}{l}22 \mathrm{~m}- \\
25 \mathrm{~m}\end{array}$ & $22.5 \mathrm{ft}<$ & $7 m$ \\
\hline Spreiregen & 4000ft & $1219 \mathrm{~m}$ & $450 \mathrm{ft}$ & $137 \mathrm{~m}$ & $80 \mathrm{ft}$ & $24 \mathrm{~m}$ & $40 \mathrm{ft}$ & $12 \mathrm{~m}$ & $10 \mathrm{ft}$ & $3 m$ \\
\hline $\begin{array}{l}\text { Maertens } \\
\text { Blumenfeld }\end{array}$ & 4000ft & $1219 m$ & $\mathrm{x}$ & $\mathrm{x}$ & $\begin{array}{l}70 \mathrm{ft}- \\
80 \mathrm{ft}\end{array}$ & $\begin{array}{l}21 \mathrm{~m}- \\
24 \mathrm{~m}\end{array}$ & $48 \mathrm{ft}$ & $14.6 \mathrm{~m}$ & $\mathrm{x}$ & $\mathrm{x}$ \\
\hline
\end{tabular}

TABLE 1.3

\begin{tabular}{|l|c|c|c|c|}
\hline & Above horizon & Below horizon & Normal tilt & Left and Right periphery \\
\hline Gehl & $50^{\circ}-55^{\circ}$ & $70-80^{\circ}$ & $-10^{\circ}$ & $\mathrm{x}$ \\
\hline Spreiregen & $+30^{\circ}$ & $-45^{\circ}$ & $\mathrm{x}$ & $65^{\circ}$ \\
\hline
\end{tabular}

TABLE 1.4

\begin{tabular}{|c|c|c|c|}
\hline $\begin{array}{c}\text { Ratio (height-to- } \\
\text { width) }\end{array}$ & Angle & $\begin{array}{c}\text { Relation to Spreiregen's upper } \\
\text { limit of vision (30 })\end{array}$ & Comment \\
\hline $1: 1$ & $45^{\circ}$ & $+15^{\circ}$ & full \\
\hline $1: 2$ & $30^{\circ}$ & $0^{\circ}$ & threshold \\
\hline $1: 3$ & $18^{\circ}$ & $-12^{\circ}$ & minimum \\
\hline $1: 4$ & $14^{\circ}$ & $-16^{\circ}$ & loss \\
\hline
\end{tabular}

\section{A1.2 $\mid$ REVIEW OF CONTEMPORARY DESIGN GUIDES}

A review of a selection of contemporary guidelines form around the word is hoped never say you 'hope' to do something to shed light on whether the complexity and ambiguity of human scale portrayed in the literature continues in our more practical documents. It seeks to: investigate how human scale is defined, and therefore is 
particularly concerned with locating uses of the specific term; locate properties of human scale as identified in interpretive definitions, this is because even if they are not associated with the term it is positive that these attributes are still being promoted in design; and highlight any connections made between human scale and enclosure. Awkward - needs more editing simple concept - design guides are the next logical place to investigate to see how they interpret and define the term, as ultimately these documents are the practical equivalent of the literature and are arguably more responsible for guiding our environments. In order to get the most indicative results within a reasonable scope, three city guides which cover a range of city types and ages, and one compendium are reviewed.

\section{City Urban Design Documents}

Understandably, there are different design guides for different areas of the city. Those chosen are relating to the central city area, in which density is expected to be higher, and the fabric older. The city design guides chosen are from:

Edinburgh, Scotland

Los Angeles, United States of America

Wellington, New Zealand

\section{British Urban Design Compendium}

The compendium, rather than being specific to a place, is a document which suggests best standard of practice and is not particularly sensitive to context. "the purpose is to help equip all those involved in the delivery of places with guidance on achieving and assessing the quality of urban design in developing and restoring urban areas." ("Urban Design Principles (UDC1) | Urban Design Compendium | Homes and Communities Agency (HCA)," n.d.) 
In Edinburgh's urban design principles, it very clearly states human scale as an important principle. It believes that raising densities to support vitality to the detriment of human scale buildings is not acceptable, and suggests that it already has numerous historic low-rise and high density precedents. It states that such precedents are successful because they have the following attributes: legibility (order and cohesion), security, private and communal gardens, and the lack of car dominance. It explicitly states that "These qualities create a human scale..." It also makes a link between human scale and enclosure by stating that "In order to create a satisfactory enclosure of space with human scale it is necessary to establish a suitable ratio between the width of the space and its enclosing buildings." It gives some examples of 'satisfactory' enclosure such as 1:1 which is common among mew houses in Britain, 1:3 as generally acceptable, and 1:6 as maximum. It also notes that enclosure can be redefined by trees, and recesses above certain heights can also help. However despite this, it is very unclear why these create human scale enclosure, giving not indication as to its horizontal importance. The last mention it gives in reference to human scale is the importance of "keeping blocks small..." so that "... a more human scale, 'walkable' and user friendly public realm is created." which indirectly links human scale with the permeability and connectivity of a city.

A1.2.2 | Los Angeles Downtown Design Guide

Notes the importance of maintaining a human scale base at street level in reference to tower buildings. It also says that the successful treatment of certain key features 
including: land use, building massing, material choice, walkability, footpath treatment, and the "particular attention to the details of a project in the first 30-40 vertical feet [9-12m], forms the basis for providing high quality development at a human scale."

This document is also extremely concerned with the street wall, which can be considered an aspect of enclosure, though the word is never mentioned. Instead of being advisory, in respect to the articulation of the street wall, the document becomes regulatory. It states five general rules which the design may have to follow including: the position of the street wall in relationship to the back of the footpath, $90 \%$ of the street wall must comply with specified minimum building heights, buildings may be required to step back above the minimum building height, breaks in the street wall should be limited, buildings must provide visual difference between bottom retail floor(s) and upper office or accommodation. Despite this document addressing both issues, there is no clear connection made between the two. The definition of human scale is broad and not particularly explicit as opposed to the detail given for street wall. However the concern is merely for the legibility that the street wall conveys and as such does not fully address the requirements for creating enclosed space.

\section{A1.2.3 Wellington City Central Design Guide}

Human scale first appears under one of four design issues that are highlighted as influencing the quality of the public environment. It defines scale as the first issue, saying that is is "the relative size of buildings and their constituent parts." and "... refers to a dimensional comparison. It only has meaning when both the subject and the object of comparison are explicit." Explaining that there are several common means of comparison referred to in the document, one of which is is when "A building's dimensions are compared with human stature. If a building contains features which 
are comparable in size with the human figure, the former may be said to have "human scale".' In providing guidelines for the context of the street, it states that "Up to the first height threshold 8 stories or $33.6 \mathrm{~m}$ under maximum floor to ceiling height of $4.2 \mathrm{~m}]$ it is important that a building's dimensions:

establish a clear relationship to human size

assist an observer's understanding of the overall size and dimensions of the building

There is no explanation given as to why eight stories is chosen as the first height threshold, which exceeds the perceptual limit of humans established in the research, which in most cases would render the second point somewhat contradictory. It further explains that,

"Legible building dimensions and "human" scale depend on a hierarchy of nested modules in which smaller elements are grouped, or otherwise composed, to form larger visual entities. In this way, the smallest elements (typically those which are commensurate with the human figure) "measure" the larger ones. In turn, these bigger units "project" intimate or human scale across the surface of still larger components of the building until the entire envelope has been dimensioned."

In this case, this design guide is emphasising the anthropometric aspect of human scale, unlike Edinburgh and LA which, although rather vague, suggested human scale was in fact created by numerous things not necessarily related to our bodily dimensions. Other aspects of human scale, as has been interpretively identified, are addressed however they are not explicitly associated with human scale. Enclosure is not addressed explicitly although aspects of it appear throughout the document. 
However because of this superficial treatment, enclosure is not clearly related to human scale, nor is evident as an important quality.

\section{A1.2.4 | British Urban Design Compendium}

The British Urban Design Compendium is covers more, and is perhaps more explicit than the above three guides, despite it not being specific to any one city. However the way in which it conveys human scale is somewhat inadequate. The first mention of the term it merely stats that the best tall building address human scale at their base, but does not provide any definition implying perhaps that the reader knows what human scale is - precisely a problem identified earlier in the literature. The second appearance of the term is in relation to small plot sizes, stating that this "encourages a 'human scale' and fine pedestrian grain". Again there is no indication as to what this human scale is, and in this context it surely means something different than when it is applied at the base of a tall building. Another problem with this sentence is the use of scare quotes. The quotes around the term human scale suggest that the writer is distancing him or herself from the concept due to its ambiguity or unreliability (Trask, 1997)s The use of scare quotes is common and has appeared in the other design guides as well as the literature. It only adds to the confusion around the concept. The few other places where the term is used provides no clear definition to the term, however it interestingly states that "Cladding systems tend to pose difficulties in evoking a human scale. If their use is unavoidable, then emphasise doors and windows and surface textures on the lower floors and in the immediate landscape." suggesting that it has something to do with textures and small, perhaps manageable materials. 
Enclosure is thoroughly covered, but again there is little to no apparent connection between it and human scale. It states good enclosure ratios, none of which building heights exceed street width, which seems to be at odds with the majority of 'great streets' that Allen B. Jacobs identifies. The importance of legibility and continuity of the building line is highlighted as well as the importance of enclosure as a principle which creates places for people.

\section{A1.2.5 Conclusion}

Although it is understood that even if some identified human scale properties are not clearly addressed as such, the designer would still be encouraged to use them with or without the knowledge that they are human scale properties. Human scale could in this case be 'accidentally' designed but the real problem is that there is not enough clarity on what human scale is for the term to be used without definition. It is clear that by analysing these three guides and the compendium that there are discrepancies between them concerning human scale and enclosure. They do however all share the same issues more or less. The complexity and ambiguity of human scale as identified in the literature appears to also occur in the planning documents, and as such raises further doubts over the certainty of the concept. 